\title{
Principles in practice? \\ Ownership in monitoring and evaluation in Vanuatu
}

\author{
Martha Geary Nichol
}

A thesis submitted to Victoria University of Wellington in partial fulfilment of requirements for the degree of Master of Development Studies

School of Geography, Environment and Earth Sciences

Victoria University of Wellington 2014 



\section{Contents}

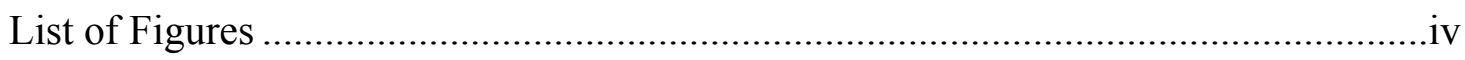

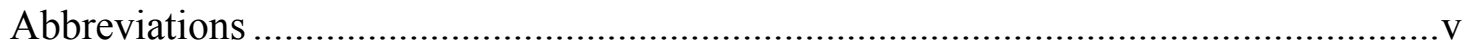

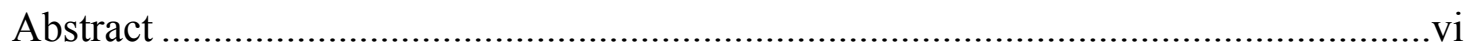

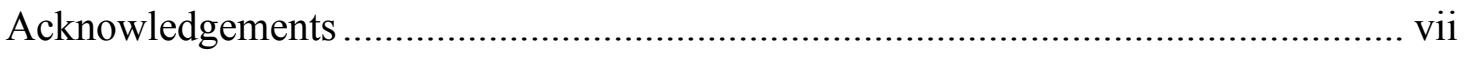

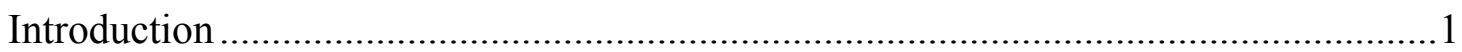

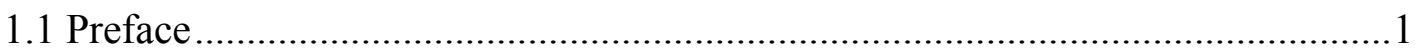

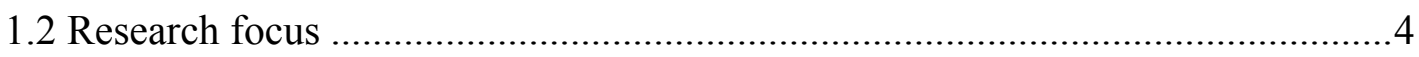

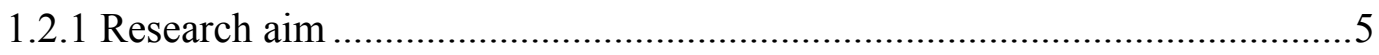

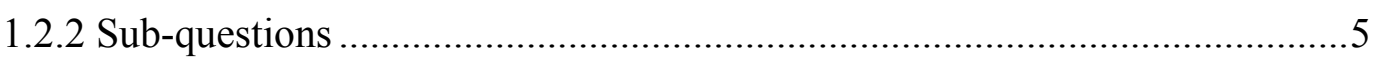

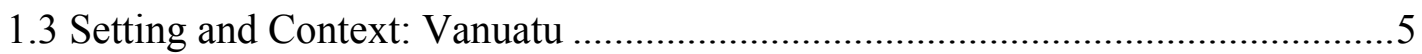

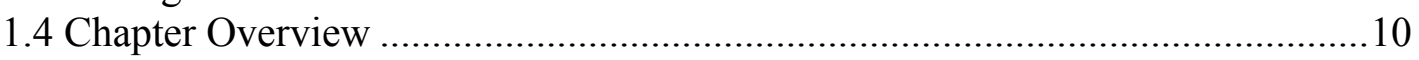

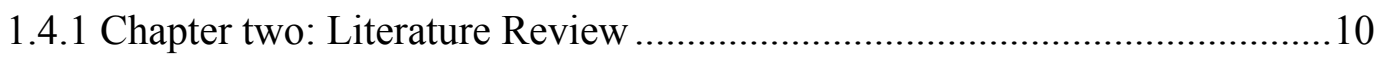

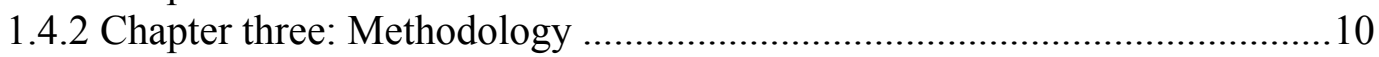

1.4.3 Chapter four: Looking In: Reflecting Internally ................................... 11

1.4.4 Chapter five: Looking Out: Reflecting Externally ................................... 11

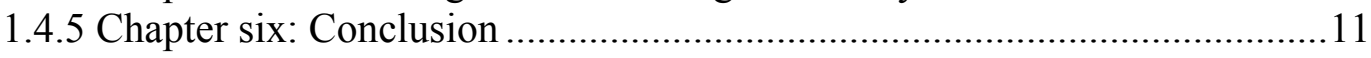

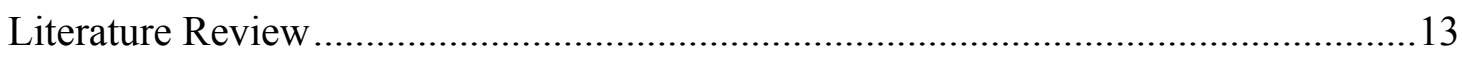

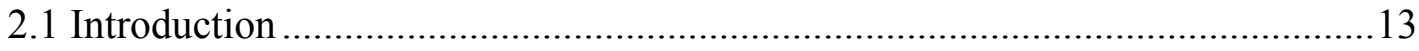

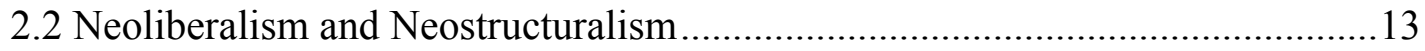

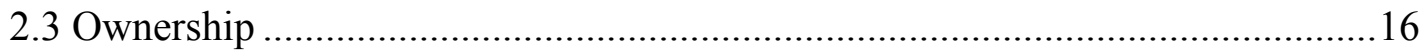

2.5 Change in Aid Modalities and Aid Management............................................ 18

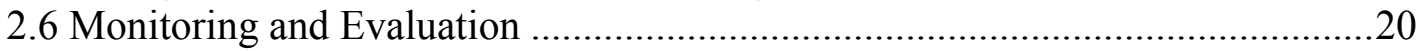

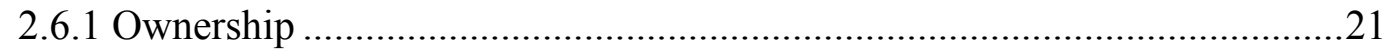

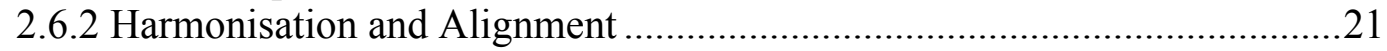

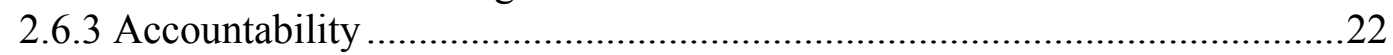

2.6.4 Results Management ...........................................................................2 23

2.6.5 Summary of Monitoring and Evaluation..................................................24

2.7 Vanuatu and the Pacific ..............................................................................24

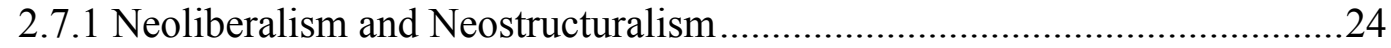

2.7.2 The Inverse Sovereignty Effect............................................................26

2.7.3 Vanuatu: Monitoring and Evaluation.......................................................26

2.7.4 Alignment and Harmonisation ..............................................................2

2.7.5 Vanuatu and the Pacific: Concluding Comments ....................................28

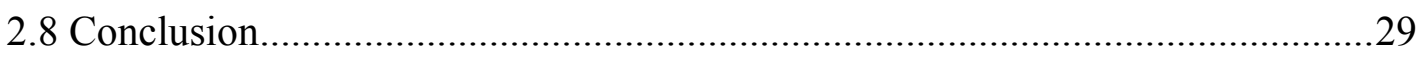

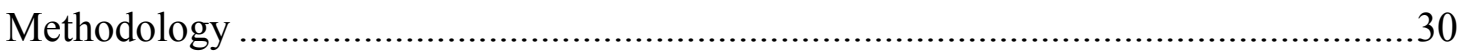

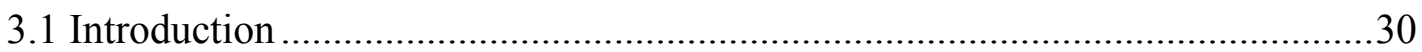

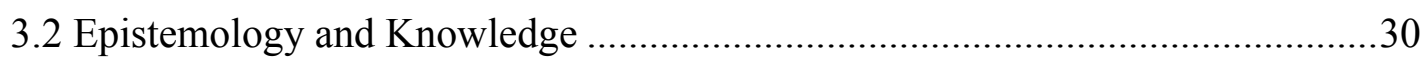

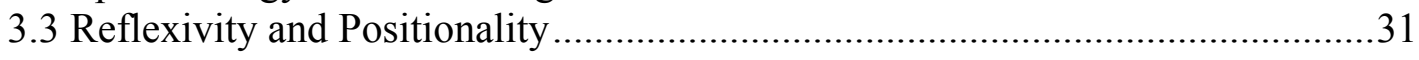

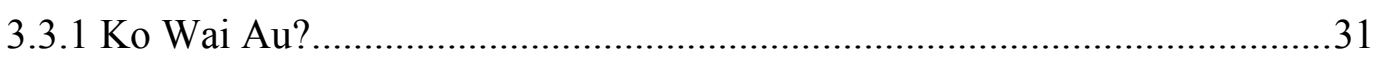

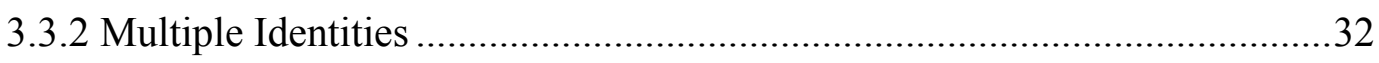

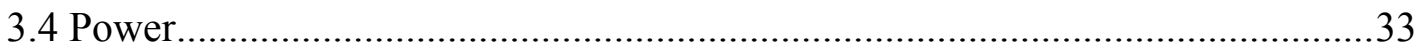

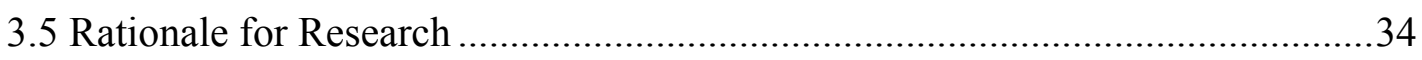




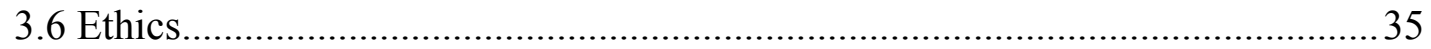

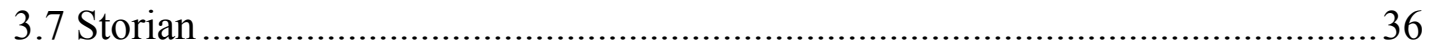

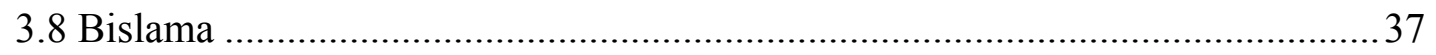

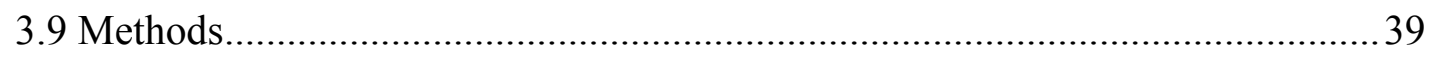

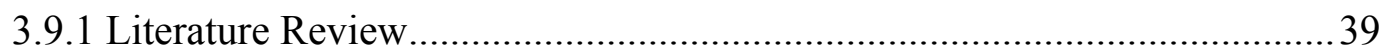

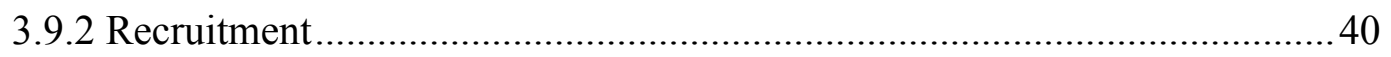

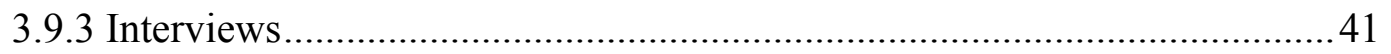

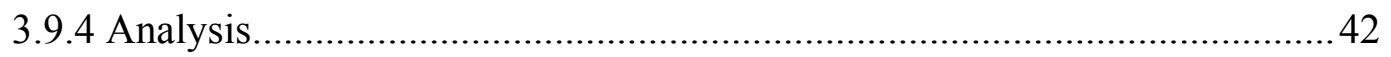

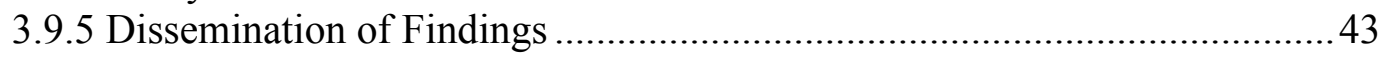

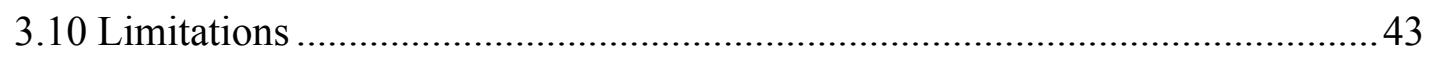

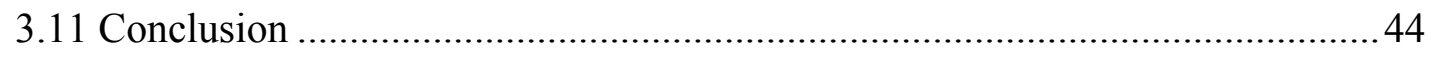

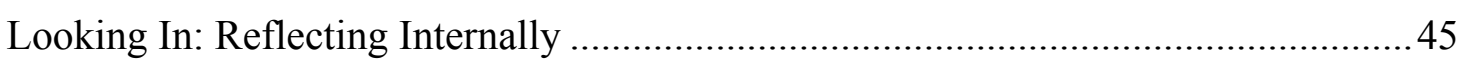

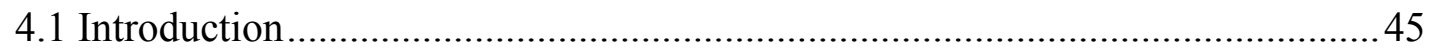

4.2 Understanding and Involvement in Monitoring and Evaluation.........................45

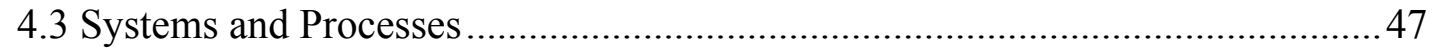

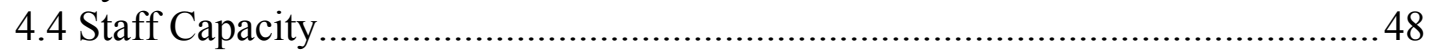

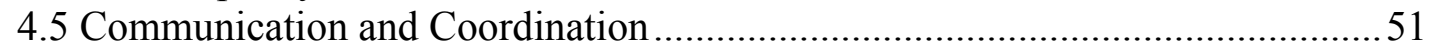

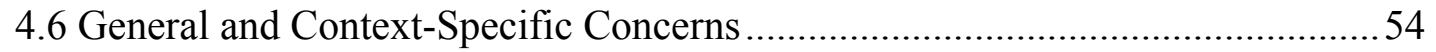

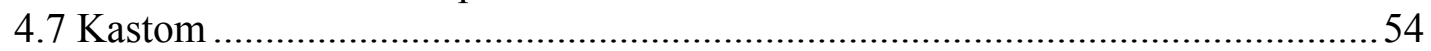

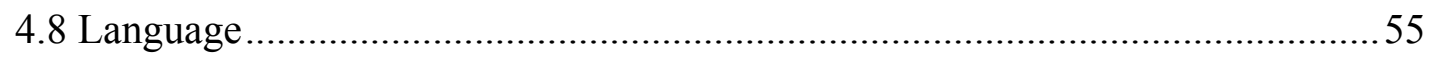

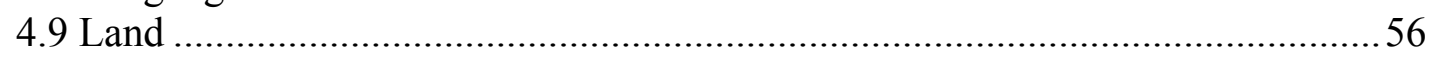

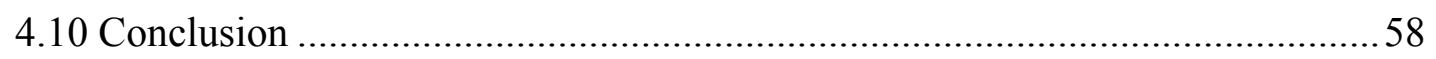

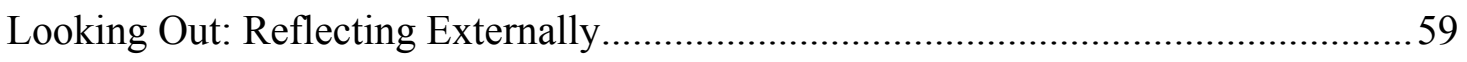

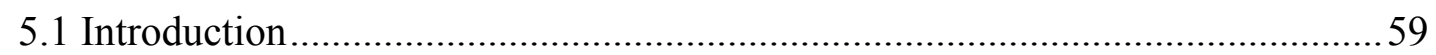

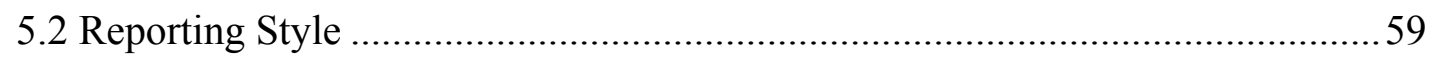

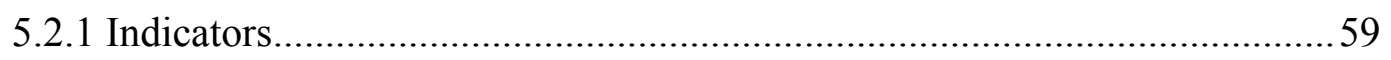

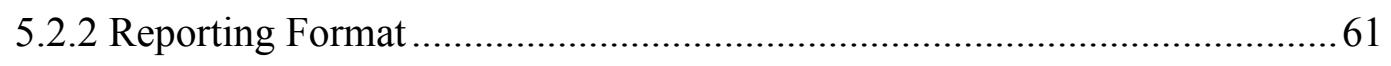

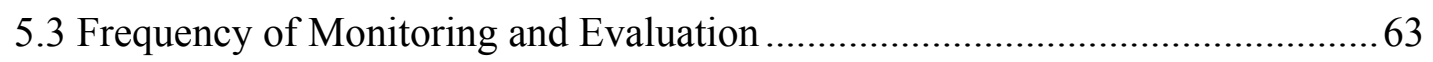

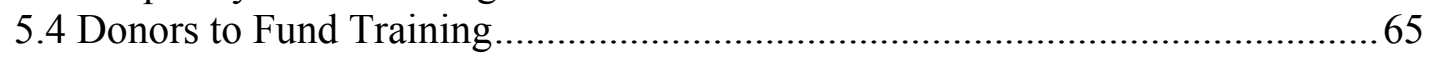

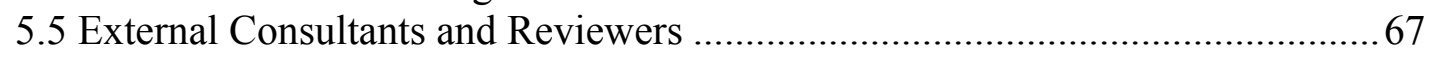

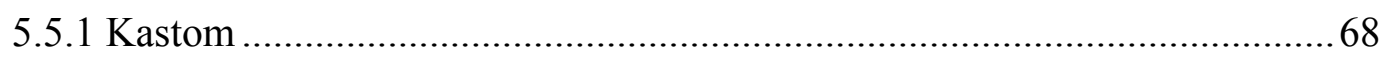

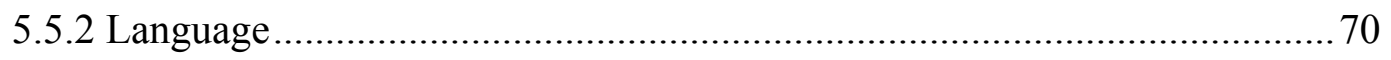

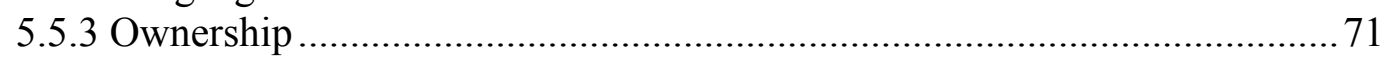

5.5.4 Increases in Ownership of Evaluations and Reviews ............................. 72

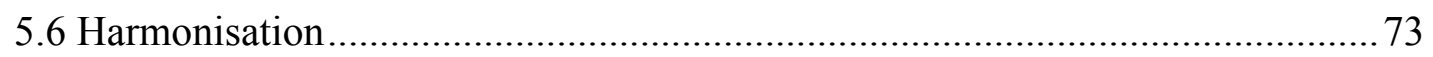

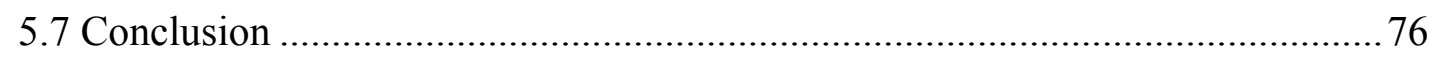

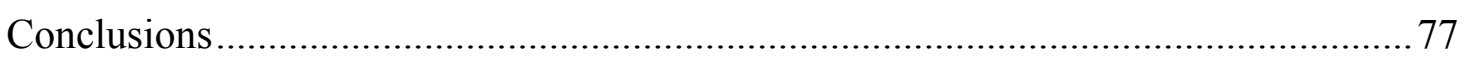

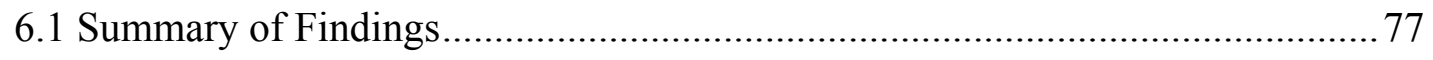

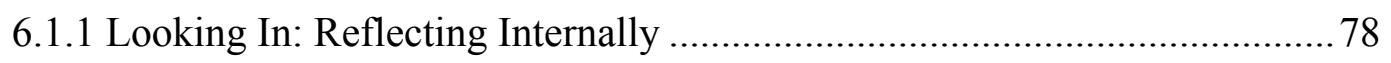

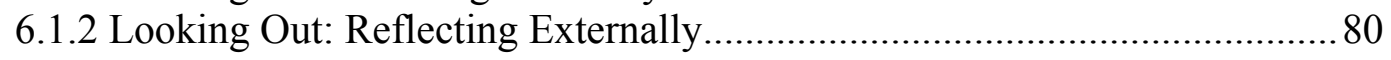

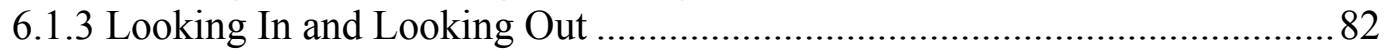

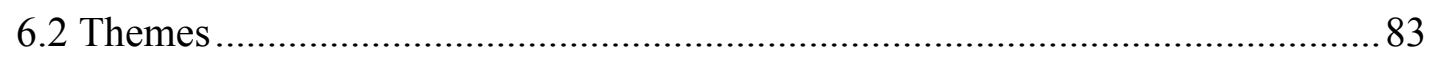

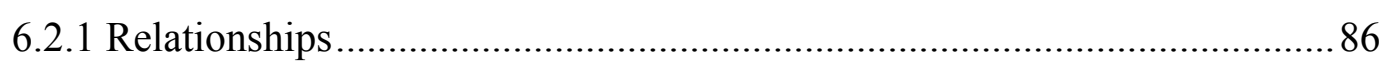

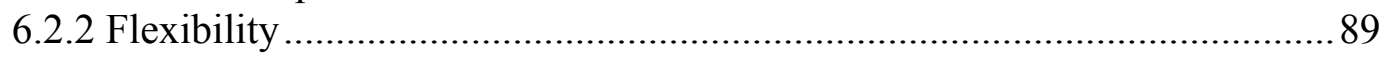




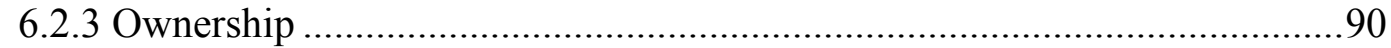

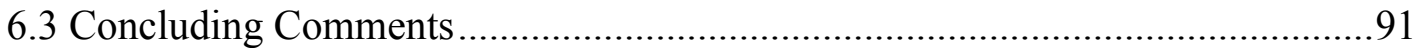

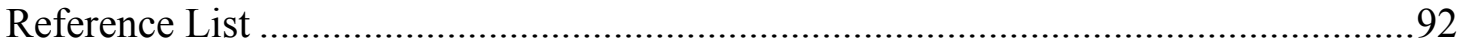

Appendix I: Consent to Participation in Research Form …....................................... 104

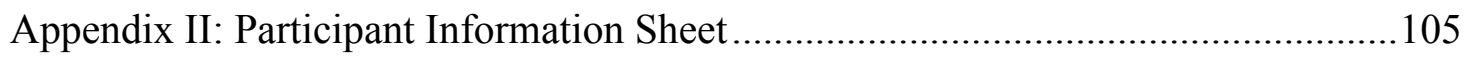

Appendix III: Sample Letter (Government Department) ............................................106

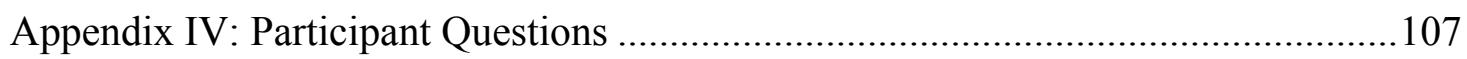




\section{List of Figures}

Figure 1: Increases in ownership of evaluations and reviews.................................73

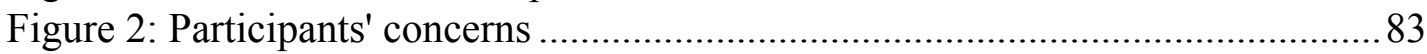

Figure 3: The role of local context and local lens in influencing themes of

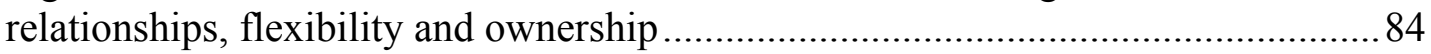

Figure 4: Increasing ownership of monitoring and evaluation .............................. 85 


\section{Abbreviations}

ADB Asian Development Bank

AusAID Australian Agency for International Development

CRP Comprehensive Reform Program

CSO Civil Society Organisation

DAC Development Assistance Committee

EU European Union

EURODAD European Network on Debt and Development

GBS General Budget Support

IMF International Monetary Fund

MDG Millennium Development Goal

M\&E Monitoring and Evaluation

MoU Memorandum of Understanding

NGO Non-Governmental Organisation

NZAID New Zealand Agency for International Development

OECD Organisation for Economic Co-operation and Development

OXFAM Oxford Committee for Famine Relief

PFM Public Financial Management

PIU Project Implementation Units

PRSP Poverty Reduction Strategy Papers

SAP Structural Adjustment Programme

SWAp Sector Wide Approach

UN United Nations

VANGO Vanuatu Association of Non-Government Organizations

VSA Volunteer Service Abroad 


\begin{abstract}
Presently, monitoring and evaluation is an aid practice that does not emphasise NiVanuatu ownership. Despite the current aid agenda's advocacy for ownership, principles of measuring for results and accountability are given preference in this practice. Eighteen participants working in monitoring and evaluation in NGOs and government departments in Luganville and Port Vila were interviewed for this study in April and May, 2013. Through semi-structured interviews they shared their experiences of the practice. They highlighted issues around capacity, kastom and donors, emphasising monitoring and evaluation's inability to account for the local context and promote ownership.

It was found that the current approach to monitoring and evaluation follows a universal model, disregarding country specific features of Vanuatu such as kastom, language and land. However, these features embody the identity of $\mathrm{Ni}$-Vanuatu and define Ni-Vanuatu ownership. They should therefore dictate how monitoring and evaluation is carried out. A move for stronger Ni-Vanuatu ownership of aid practices such as monitoring and evaluation will be complicated and messy. However, approaching monitoring and evaluation through a local lens while employing relationship building and flexibility can lead to increased $\mathrm{Ni}$-Vanuatu ownership of the practice.
\end{abstract}

Keywords: Vanuatu, Monitoring and Evaluation, Ownership, Neostructuralism, Aid Effectiveness, Aid Practices, Storian, Language, Kastom. 


\section{Acknowledgements}

Mi wantem talemaot tank yu fastaem long ol participants we oli bin tekem pat long risej ia. Tank yu tumas long yufala we yu bin akri blong mit wetem mi, we yu bin sarem ol tingting blong yu long saed blong monitoring mo evaluation mo tu we yu bin sidaon storian wetem mi long saed blong ol nara samting. Risej ia hemi blo yufala mo mi hope se hemi save kat yus blong mekem se ownership blong monitoring mo evaluation long Vanuatu I kam antap. Mi wantem talemaot tank yu tu long ol fren long Vanuatu. Yufala i bin reli helpem mi wetem risej ia mo yufala I bin mekem se mi harem se mi welkam long Vanuatu. Tank yu tumas long Leina we hemi bin helpem mi wetem ol translations long risej ia. Mi harem se mi laki tumas blong save mekem risej long Vanuatu wetem ol man ples, ale tank yu tumas.

E ai ki te whakataukī, ehara taku toa i te toa takitahi, engari he toa takitini. Ka nui te mihi aroha ki a Pete, Lynette koutou ko ōku hoakura. I ahau e rangahau ana, ka noho tata koutou ki te āwhina, ki te katakata, ki te tautoko hoki. Ki ngā kauhuahua: Jake koutou ko tōku whanau, ko te iwi hoki, kāore e ārikarika nga mihi ki a koutou. Nā koutou i hāpai, i amo, i tautoko tōku nei haerenga whai mātauranga. Ka huri aku mihi ki te Whare Wānanga o Wikitōria mō tōna tautoko moni i te korahipi Tu Horomata. Anō hoki ki te Manatū Aorere (Ministry of Foreign Affairs and Trade) mō te pūtea tautoko mō aku rangahau ki Vanuatu.

Finally, I'd like to thank my supervisor John Overton and Liz Medford from Student Learning Support Service for all of their support throughout this research. Thanks John for always being around to bounce ideas, clarify concepts and give me confidence in my writing. Thank you Liz for sharpening my sentences and always providing positive feedback. Ka nui te mihi rangatira ki a kōrua. 



\section{Introduction}

\subsection{Preface}

My motivations for conducting this research emerged from my year volunteering at a youth centre in Luganville, Vanuatu in 2011. The centre was attached to a sexual health clinic and was a very busy place. There were young people using the centre's resources, clients in the clinic, nurses, peer educators, tutors and a few volunteers frequenting the centre and clinic each day. I was well positioned to observe and encountered many examples of monitoring and reporting at the centre. However the experiences that stood out and made me most interested in this field were the evaluations and reviews. The clinic and centre had multiple funders and so it was common for overseas visitors to carry out evaluations, reviews or come in for meetings. Having studied development in university, I was looking forward to seeing how participatory development played out in practice. As it turned out the evaluations and reviews, while following the textbooks, were not quite as successful as I had anticipated.

It was always evident when someone from overseas came to visit. People would look at each other and ask who the waetman ${ }^{1}$ was on the premises. I was used to this as I had been that waetman for a long time but by the time the reviewers and evaluators came the centre was pretty used to me and I was no longer newsworthy. One particular group of waetman stood out for me. They were Australian, living in Port Vila and spoke strained Bislama. First they delivered their message, the reason for their review, to the group they wished to speak to (comprising staff and tutors of different ages and sexes from teenage boys to mamas over forty). Following this, they broke us into groups so that they could talk to us in smaller numbers. Groups consisted of different ages and sexes. However when the evaluators started talking to the groups the males stared at the ground and the mamas were silent apart from their clicking fingers which continued to crochet, not wanting to fall behind on their handcraft classes.

\footnotetext{
${ }^{1}$ European
} 
I was impressed that the reviewers were using as much Bislama as possible but with their thick Australian accents and the heavy reliance of English words within their Bislama they were not understood very well. They often reverted to English when they saw that no one understood them. However I'm not even sure that it was their poor command of Bislama that meant people were unwilling to talk to them. When no one volunteered responses one reviewer proceeded to go around the circle directing her questions to each person. There were a lot of "I don't know" answers and most people continued to stare at the ground. The reviewer was obviously frustrated by this, not seeming to understand that avoiding eye contact is very common in parts of Vanuatu in certain situations.

The reviewer went through her list of questions. One question asked how many youth from the previous year had returned to the centre that year. She then approached each person in the circle for a response. Seeing that she would have to answer, a mama turned to me and asked me in Bislama to explain the question. I said that the woman wanted to know how well we retain youth at the centre, how we make sure they want to come back again next year. The mama looked cross and explained to me that they weren't like white people, they moved around and people often went back to their home islands. Within the context, she couldn't understand why the question was being asked.

I often contrast that experience of an overseas review with another which was carried out in quite a different manner. An Australian man came together with a Ni-Vanuatu woman who was known to everyone as she worked for our Non-Governmental Organisation (NGO) in Port Vila. He arrived at the centre soaked in sweat and immediately sat and fanned himself in front of everyone exclaiming to the staff in a friendly manner, "I'm so hot!". This gesture succeeded in breaking the ice with the staff who laughed at this waetman fanning himself in his pressed shirt in the Vanuatu heat.

This reviewer sat and hung out with the staff while the Ni-Vanuatu woman arranged interviews through our boss. He made time to talk to every staff member, either individually or in groups as they preferred. While he did not speak any Bislama he conducted all interviews with the Ni-Vanuatu woman. He joked with the staff in English, and his comical manner meant he was understood across the language 
barrier. He stayed around to watch the hip-hop group after the interviews. They had wanted to show him some of their new moves and when they did not start on time he sat around under the trees happily waiting for them. He made people feel so comfortable that they actually wanted to have interviews and talk to him.

There was a significant difference between the two reviews. The first seemed to follow the rules for appropriate engagement. The review team members used Bislama, they introduced themselves in front of the group before breaking into smaller groups and they approached every member of the group to make sure all opinions were heard. The second method appeared random and disorganised. The man seemed almost unprofessional in his fanning and complaining about the heat. He stayed beyond his work hours to see a hip-hop group and appeared to be making friends with the staff. This hardly seemed an objective approach. Yet it was more in line with Ni-Vanuatu, with the way people work and relate to each other. $\mathrm{He}$ acknowledged each person by offering to meet them independently or in groups and despite the heat still dressed formally to indicate his respect for the occasion. $\mathrm{He}$ allowed people to feel relaxed, making fun of himself and making himself a lot less intimidating and scary.

It was these observations, together with the monitoring and reporting conducted at the centre, that started me thinking about monitoring and evaluation and how it is applied within the cultural context. It made me question the validity of a universal or 'one size fits all' methodology. The approaches of the first review could have been successful in certain New Zealand contexts but were clearly not working in the context of the youth centre. At university I had learnt about the Paris Declaration and the push for ownership. However at the youth centre in Luganville I couldn't see any real sense of ownership occurring at any stage during that first review. It was a donor-driven process that did not seem to reflect the everyday reality of what happened and what was achieved at the youth centre. The experience raised many questions for me in terms of development practice. Was there a "right" way to conduct monitoring and evaluation? What is more important: to follow the Western "objective" way of conducting aid practices, or to better represent the views and realities of local people? Why was a process being followed that clearly wasn't working? 
My personal view of development is based on the Māori proverb, "He aha te mea nui o te ao? He tangata! He tangata! He tangata!" "What is the most important thing? It is people! It is people! It is people!" People are central to development, ownership is central to development. So why then was monitoring and evaluation being carried out in a way that did not represent the people, that did not embody ownership? It seemed that people were working for the practice rather than the practice working for the people.

This was my personal motivation for the research: to try and understand how NiVanuatu felt about this practice. I wasn't as concerned with the technicalities of monitoring and evaluation but in what people thought of the processes involved. I wanted to see if they felt the same frustrations as I observed while working at the youth centre. Ownership and people need to be right at the centre for a process to be effective. So how could monitoring and evaluation better reflect the people it was supposed to serve?

\subsection{Research focus}

The current aid agenda prescribes a range of principles to improve overall aid effectiveness. Ownership is central to this agenda. The practice of monitoring and evaluation (M\&E), a fundamental element in aid management, is also emphasised by the aid sector's increased demand for accountability and push for results management. This research explores the notion of ownership within aid practice by examining monitoring and evaluation. It looks at the practice of monitoring and evaluation, as experienced by Ni-Vanuatu aid recipients, to see how ownership is being played out in reality.

Paramount to the research is people. As a consequence, the study centres first and foremost around Ni-Vanuatu and their experience and feelings about monitoring and evaluation. It seeks to approach the practice from a Ni-Vanuatu outlook, moving away from the universal donor viewpoint. By taking a wide lens the research looks at their experience of the overall practice, rather than focusing on the intricacies of the processes involved. It is therefore hoped that some of the findings can be applied to other aid practices. 
By examining the Ni-Vanuatu experience of monitoring and evaluation the research unravels the place of ownership within the practice. It uses the findings to suggest approaches for increasing ownership further. The research is divided into a two-part research aim and four sub-questions.

\subsubsection{Research aim}

The aim of this research is to analyse the place of ownership in monitoring and evaluation in Vanuatu in order to understand how it can increase.

\subsubsection{Sub-questions}

How do Ni-Vanuatu NGO and government employees experience monitoring and evaluation?

What are some of the obstacles to monitoring and evaluation in Vanuatu?

What is the role of donors with regard to monitoring and evaluation?

How could monitoring and evaluation work better in the Ni-Vanuatu context?

The study looks solely at NGO and government employees' thoughts and issues with the practice and does not attempt to provide a balanced view that includes donors. While donors' concerns are raised in the context of the literature and in participants' comments, unique donor concerns were not sought out.

Monitoring and evaluation and ownership are both key to aid effectiveness and consequently the research aims to contribute towards the literature on aid effectiveness. A Pacific Island was chosen for the research in order to contribute to this literature focussing on the Pacific (e.g. Murray and Overton (2011a); Ulu (2013); Wrighton and Overton (2012)). Researching in a small Pacific Island nation offers a unique take on the particular demands on ownership resulting from a nation's size (Murray \& Overton, 2011a). The research is based in Vanuatu as New Zealand is a primary bi-lateral donor to the country. Furthermore, as explained in the preface, it was here that I experienced first-hand limited local ownership of monitoring and evaluation.

\subsection{Setting and Context: Vanuatu}


To understand the context of the research a general overview will be given to introduce Vanuatu, with special attention to areas important to the research. The study is based in the Republic of Vanuatu, an archipelago nation of 83 mostly mountainous islands in Melanesia. Vanuatu has a population of approximately 234,000 (Vanuatu National Statistics Office, 2009a), 95.5\% of whom are NiVanuatu (Vanuatu National Statistics Office, 2009b). Almost a quarter of the population live in the urban centres of Port Vila and Luganville (Secretariat of the Pacific Community, 2013), the two towns in which the research was based.

Vanuatu's history has shaped the identity of the country of today. Melanesians were the first inhabitants of Vanuatu. They are believed to have migrated from southeastern Asia three thousand years ago in dugout canoes with their families and domestic animals, including pigs which still hold great importance in Ni-Vanuatu culture today (Miles, 1998). Vanuatu has an interesting colonial history. France and Britain jointly ruled the country, then called the New Hebrides, as a condominium. Governance was organized on the basis of equality of government and co-existence (Weisbrot, 1989), meaning separate education systems, medical services, police, currencies and languages. However joint systems existed in areas such as public works, public health, financial administration and land surveying. To confuse the matter further, the law was divided into French civil law, British common law, joint or condominium law, and indigenous customary law (Weisbrot, 1989). The system was inefficient and Ni-Vanuatu "were neither consulted in its establishment nor involved in its operation" (Molisa, Vurobaravu, \& Van Trease, 1982: 85; as cited in Weisbrot, 1989).

Following the trend of decolonization across the globe and Pacific, the New Hebrides gained independence on the 31st of July 1980 under Prime Minister Walter Lini (known as Father Lini) and was renamed Vanuatu. While the British supported this move, the French were reluctant. Vanuatu came to independence "with a sense of having had to fight for it, and of having defeated a more powerful adversary" (Campbell, 1989: 209). When independence was claimed, the French were said to have sabotaged their own office equipment to hinder the new administration (Fischer, 2013). The challenge for the Ni-Vanuatu government was to make sense of the mess left by the colonial powers (Weisbrot, 1989). 
Vanuatu today is a democratic country with provincial councils in its six provinces in addition to national government. It is classified by the United Nations and OECD as a Least Developed Country (LDC) ${ }^{2}$, and a Small Island Developing State (OECD, 2012; UN-OHRLLS, 2012). Vanuatu receives aid ${ }^{3}$ from both bilateral and multilateral donors. In 2012 Australia was its largest bi-lateral donor (Government of the Republic of Vanuatu, 2013), prioritising its aid around economic development, education, governance, health and general development support (Department of Foreign Affairs and Trade, 2013). New Zealand was the second largest bi-lateral donor (Government of the Republic of Vanuatu, 2013), prioritising private sector development, shipping and other infrastructure, education and governance (Government of New Zealand \& Government of the Republic of Vanuatu, 2011). The United Nations and the European Union (EU) are the major multi-lateral donors (Government of the Republic of Vanuatu, 2013).

Vanuatu national politics are plagued by instability, with regular motions of no confidence and reshuffling of political parties (Forsyth, 2009). This fragmentation also occurs at local level and the instability makes reform difficult with politicians hesitant to provide coherent policy (Forsyth, 2009). The instability and frequent changes of government also contribute to Vanuatu's recognised problem with corruption (Jowitt, 2005; Transparency International, 2011). ${ }^{4}$

Agriculture, forestry and fishing contribute approximately 15\% of Vanuatu's GDP (Government of the Republic of Vanuatu, 2011) and over half the population depends on subsistence agriculture for their livelihood (United Nations Conference on Trade and Development, 2012). Construction and tourism are the current drivers of Vanuatu's Gross Domestic Product. However its economy is exposed to natural disasters. Vanuatu ranks number one on the world risk index (Alliance Development Works, 2012). ${ }^{5}$ A further constraint on the economy is the country's geography: "a widely scattered and mountainous island geography, with the population scattered

\footnotetext{
${ }^{2}$ Based on per capita gross national income, human assets and economic vulnerability to external shocks.

${ }^{3}$ \$US23.5m in aid flows (grants) in 2012 (IMF, 2013).

${ }^{4}$ Vanuatu received a score of 3.5 on a scale where 0 is highly corrupt and 10 is clean in the Corruption Perceptions index 2011.

${ }^{5}$ Composing its exposure to natural hazards susceptibility, coping capacities, and adaptive capacities.
} 
across 83 islands, in association with poor transport infrastructure" (International Labour Organization, 2009).

The research focuses on both government and NGOs in Vanuatu. NGOs play a major role in providing services to the community. ${ }^{6}$ There are a large number of NGOs working in Vanuatu, approximately $120 .^{7}$ A Memorandum of Understanding (MoU) was signed between the Vanuatu Association of Non-Government Organisations (VANGO) and the Vanuatu government in 2004 putting VANGO in a greater partnership role with the government (World Bank, 2006). The MoU also highlights the need for the government to be accountable for public funds and NGOs to be accountable for funding provided through government programmes. Both parties are accountable for reporting to the public on joint initiatives (IFRC, 2011).

Although the research was only based in the towns of Port Vila and Luganville, it concerns a practice (monitoring and evolution) that is carried out across the country. Vanuatu is a very diverse country. This is illustrated by its geographical spread over many islands, the multitude of languages spoken and the different cultures and kastom unique to particular villages and islands. The extent of its diversity is highlighted in the words of one of its former presidents: "We are like 100 nations inside one country" (Culliwick, 2007; as cited in Forsyth, 2009: 19).

Culture is central to Ni-Vanuatu identity. Kastom is a concept that appears frequently in this research and in day-to-day conversation with Ni-Vanuatu. In this research, kastom is used to represent Vanuatu's customs, cultures and traditions. Though some literature has given it a stricter definition, such as Miles (1998) who likens it to morality in the West and describes it as signifying "the proper, or indigenously authentic, way of living, acting, and behaving in society, the proper and indigenous way of living and doing things" (Miles, 1998: 81), others, such as Bolton (2003) found that many people did not distinguish between custom, culture and tradition and kastom was used as an umbrella term representing all three. The lack of clarification around its meaning can lead to different interpretations (Tonkinson,

\footnotetext{
${ }^{6}$ For example, see the mention of NGOs in the Government of Vanuatu (2006) Priorities and Action Agenda 2006-2015.

${ }^{7}$ The Vanuatu Association of Non-Government Organisations (VANGO) has approximately 123 members (Vanuatu Daily Post, 2012) and most Ni-Vanuatu NGOs are associated with VANGO (World Bank, 2006) .
} 
1982). Therefore, the term will not be strictly defined. Keeping a broad definition of kastom aligns with the comment of former President of the Malvatumauri ${ }^{8}$, Chief Willie Bongmatur, who writes that only Melanesians can know for themselves the "meaning and significance of the terms culture, custom, and tradition and the importance of these concepts within national and village life" (Bongmatur, 1994: $85)$.

Ligo (1980: 58) points to language as a strong indicator of kastom being alive and practiced today, as kastom is heavily embedded in language: "Ol kastom blong Vanuatu ikat stamba blong olgeta hemi langwis". . Vanuatu has 106 indigenous languages with varying numbers of speakers (Lynch \& Crowley, 2001), and these languages are a symbol of identity within Vanuatu (Crowley, 2000). Bislama, a creole language, is the national language of Vanuatu and English and French are official languages.

There is furthermore a strong relationship between kastom and land. Land is central to Ni-Vanuatu identity (Leach, 2013; Regenvanu, 1980). Ni-Vanuatu's relationship with land can be best described in the words of former Minister for Lands Regenvanu (1980: 66):

Kraon olsem hemi wan pat blong laef blong ol man. Kraon long Ni-Vanuatu hemi sem mak olsem wan mama wetem pikinini blong hem. Wetem kraon nao hemi save talemaot hem mo wetem kraon hemi save holem taet ol kastom tambu paoa blong hem. ${ }^{10}$

Not surprisingly, land comprised a key factor in Vanuatu's strive for independence (Rousseau, 2011).

When discussing Ni-Vanuatu culture, it is also important to note that Vanuatu is a very religious country. $83 \%$ of Ni-Vanuatu identify as Christian (Miles, 1998) and the church plays a major role both in the community and on a national level. Despite

\footnotetext{
${ }^{8}$ Vanuatu National Council of Chiefs

${ }^{9}$ This is translated in the text as, "It can be said that language is one of the bases of custom in Vanuatu."

${ }^{10}$ This is translated in the text as, "Land is an intrinsic part of themselves and their whole being. Land to Ni-

Vanuatu is what a mother is to a baby. It is with land that he defines his identity and it is with land that he maintains his spiritual strength.”
} 
the unique syncretism of "native and imported religion" (Miles, 1998: 117), of kastom and Christianity, most Christians see kastom as compatible with Christianity (Miles, 1998: 102).

Naturally, kastom is constantly influencing and shaping new practices in Vanuatu. This is seen in the ongoing negotiation of the kastom system and the court system (Forsyth, 2009). Likewise kastom will play a role in defining ownership of monitoring and evaluation practices.

The Ni-Vanuatu context serves not only as a backdrop but plays a central role in this research. The research aims to understand the place of ownership in monitoring and evaluation in Vanuatu and how ownership can increase through looking at the experiences of Ni-Vanuatu. The Ni-Vanuatu context, including kastom and language, is important as it is ever-present in the participants' worldviews and how they experience monitoring and evaluation.

The research will be unfolded over six chapters, including this introduction which concludes with a chapter overview providing a brief summary of the remainder of the thesis:

\subsection{Chapter Overview}

\subsubsection{Chapter two: Literature Review}

An overview of the global literature around current aid paradigms, aid effectiveness, ownership and monitoring and evaluation is offered. These areas are explored with specific reference to ownership and the part ownership plays. The context is then grounded in the literature by the presentation of regional-specific writing on the Pacific and Vanuatu.

\subsubsection{Chapter three: Methodology}

This chapter explores my approach to the research. It introduces my epistemological stance, examines and critiques reflexivity and positionality, as well as the concept of multiple identities. The chapter then looks at the rationale for the research and ethical issues. Methodologies are discussed, including storian and the use of Bislama. Methods used in the research are presented and are broken into the steps 
followed in conducting the research: the literature review, field research, analysis and presentation of findings. Finally, limitations of the methodology are put forward.

\subsubsection{Chapter four: Looking In: Reflecting Internally}

The research findings are broken into two chapters. The first chapter, "Looking In: Reflecting Internally", explores the participants' reflections on themselves with regard to the monitoring and evaluation practice. The participants put forward two groups of tensions or difficulties with monitoring and evaluation. The first group consists of generic concerns, common in the development literature, around capacity: systems and processes, staff, and communication and coordination. The second group of tensions presented are not barriers but represent the contextual features of Vanuatu which clash with monitoring and evaluation. These are kastom, language and land. They form a critique of monitoring and evaluation's ability to meet the local context.

\subsubsection{Chapter five: Looking Out: Reflecting Externally}

The second chapter of findings presents the participants' views 'looking out'. This explores the participants' views on external factors, namely donor behaviour and practices. Monitoring and evaluation is seen largely as an externally driven practice, and therefore many of the processes do not align with Ni-Vanuatu kastom. Participants offered critiques of the style and frequency of reporting. A significant amount of the conversation also focused on external evaluations and how NiVanuatu can gain greater ownership of this practice. The limited harmonisation and alignment of donors are also examined. The chapter includes suggestions from the participants for the improvement of donor systems and practices in order to increase ownership. These suggestions inform the themes discussed in the concluding chapter.

\subsubsection{Chapter six: Conclusion}

The final chapter presents an overview of the research and explores the key concerns of each of the findings chapters. Both of these show that the monitoring and evaluation practice, as it currently stands, is not tailored for Vanuatu and does not promote Ni-Vanuatu ownership. The findings lead to three key themes that are then 
explored through an underlying local lens: flexibility, relationships and ownership.

Through these themes, the chapter makes recommendations for increasing local ownership of monitoring and evaluation. 


\section{Literature Review}

\subsection{Introduction}

This chapter will explore monitoring and evaluation and ownership within the aid literature. These two concepts have roots in the neoliberal and neostructural paradigms. Failings of the neoliberal agenda together with the influence of neostructuralism and its emphasis on the state have led to a strong focus on ownership. At the same time, a need for aid efficiency and results management has seen a strong push for monitoring and evaluation. This has resulted in ownership being encouraged while at the same time Western systems of accountability and transparency, including monitoring and evaluation, being enforced. The literature explores this interplay and at the same time critiques the universal approach to aid whereby practices are not tailored by local contexts. This global literature provides a backdrop in which the geographical literature focusing on the Pacific, and moreover Vanuatu, is then situated.

\subsection{Neoliberalism and Neostructuralism}

Neoliberalism, an economic, political and cultural paradigm, dominated aid policy in the 1980s and early 1990s. It held that state intervention causes inefficiency and a deregulated market allows investment and trade, notably comparative advantage, that maximizes total global welfare (Murray, 2009). While poverty was not an immediate concern, it would be addressed by the trickle-down effect (Murray \& Overton, 2011a). In reality, the reduced size and capacity of the state meant that NGOs were left to deliver vital services (Murray \& Overton, 2011b).

Neoliberal policies spread throughout developing countries, mainly through Structural Adjustment Programmes (SAPs). SAPs were imposed on developing countries by organisations such as the World Bank and International Monetary Fund (IMF) through conditionalities of aid (reform measures linked to aid). SAPs used neoliberal approaches to policy reform to integrate developing countries' economies instantaneously into the global market, the same market for which industrialised countries had had decades to prepare their own economies (Murray, 2009). By 1990 all Latin American and almost all African countries had adopted neoliberal policies 
and most had also adopted SAPs, resulting in the West holding significant control over developing countries' economic sovereignty (Murray, 2009).

However, SAPs were widely criticised and found to be ineffective (Craig \& Porter, 2006; Hermes \& Lensink, 2001; Killick, 1996, 1997). Policies failed to be 'country owned' (Koeberle, 2005; Leandro, Schafer, \& Frontini, 1999) and even willing countries often lacked the capacity to carry out reforms (Morrissey 1999). Implementing institutions such as the IMF were sometimes seen as setting national agenda by bypassing a country's national decision making process (IMF, 2005) and thereby infringing on a country's sovereignty. Reforms also failed to recognise the need for tailored approaches to countries with unique political, social and cultural environments (Sippel \& Neuhoff, 2009; Wood \& Lockwood, 1999). Other critiques of the SAPs include the reform measures' ex ante nature (Koeberle, 2005) and the lack of penalties for non-compliance (Killick, 1997).

Neoliberalism did not result in the economic growth it had promised. Its harsh austerity measures led to increases in poverty and inequalities, widening the gap between rich and poor (Dwivedi, Khator, \& Nef, 2007; Kay \& Gwynne, 2000; Murray, 2009). The Asian Crash of 1997 saw strong economic downturn, especially in Latin America, and resistance movements towards neoliberalism grew (Murray, 2009).

Consequently, the Economic Commission for Latin America and the Caribbean (ECLAC) began searching for alternatives to neoliberalism. Their findings recommended a place for the state but, like neoliberalism before it, neostructuralism still has a market focus. Neostructuralism promotes the use of participatory and democratic society to build a successful economy. This has been described as a neostructural means to meet a neoliberal end (Murray \& Overton, 2011b: 317). Reforms advocating the inclusion of the state became known as the 'PostWashington Consensus', the policy embodiment of neostructuralism (Murray \& Overton, 2011a).

Neostructuralism spread as South American governments appealed to voters through social policies. Without the pressure of the cold war, the West did not resist these changes. Furthermore, concerned with terrorism post 9/11, the West encouraged 
stable states as they were less likely to harbour terrorists (Murray \& Overton, 2011b). Neostructuralism has brought with it a strong focus on poverty and draws from participatory theory. Buzzwords such as participation, partnership and community have again become popular, although these are sometimes described as simply an attempt at making liberal approaches more inclusive (Craig \& Porter, 2003).

Neostructuralism and its acceptance of the state aligned with the concept of 'good governance' (Murray \& Overton, 2011b), emphasising human rights, transparency, accountability and democracy (Craig \& Porter, 2006; Murray \& Overton, 2011b). Its stress on accountability and transparency in particular (triggered by James Wolfensohn, President of the World Bank's speech in 1996 on corruption) saw the aid community push for changes in management systems and the strengthening of audit institutions, public procurement and independent anti-corruption measures (Murray \& Overton, 2011b; Pomerantz, 2011).

Neostructuralism's focus on poverty is demonstrated through the establishment of the Millennium Development Goals (MDGs) in 2000. These are a set of eight timebound and quantified goals for reducing poverty by 2015 endorsed by 189 states at the United Nations. They provide targets by which performance of aid can be measured. The Millennium Declaration demonstrated the shared ambitions of the global community for new global social policy of greater equity, social justice, and human rights (Poku \& Whitman, 2011). The MDGs were also influential in increasing aid budgets.

Under neoliberalism aid was cut in real terms. Its delivery was centred on project funding through civil society organisations such as NGOs (Murray \& Overton, 2011a). Aid increased under neostructuralism and donors (pressured by constituencies wanting to see aid spent appropriately) became concerned with effective aid delivery. The Paris Declaration of 2005 (OECD, 2005) marked a major change in the way aid was to be delivered and administrated and represented a consensus amongst the aid community (Overton, Prinsen, Murray, \& Wrighton, 2012). The declaration established core principles of recipient ownership of development, donor alignment with recipient countries, donor harmonisation, accountability and managing for results. It reinforced the neostructural agenda in its 
emphasis on the state as the leading actor in a country's development rather than the market or civil society (Overton et al., 2012). Principles of ownership and alignment also hinted at a change in power relations (Murray \& Overton, 2011b).

\subsection{Ownership}

It is widely acknowledged that ownership is crucial to successful development (IMF, 2001; Killick, 2003; Leandro et al., 1999; World Bank, 1998). Ownership is now woven into documentation, policy, and international agreements. The Paris Declaration symbolises the new aid agenda's commitment to ownership in which ownership stands as its first principle. It is echoed throughout the document, filtering into and advising the declaration's commitments including the call for donors to harmonise and align with recipient processes (OECD, 2005). The focus on ownership can also be seen in the new aid modalities which aim to give greater recipient management of aid.

Ownership can be applied at multiple levels (EURODAD, 2001: 3). It most often refers to the relationship between governments and donors, but it can also refer to those within a country, for example, between internal stakeholders such as Civil Society Organisations (CSOs), unions, private sector groups and the government (EURODAD, 2001). The place of internal stakeholders such as CSOs, local governments and the private sector is playing an increasingly important part in the ownership definition (OECD, 2008: 2), recognising the importance of their role for successful development (Smith, 2005).

While ownership has been accepted as central to good development, its definition is often blurry and differs significantly between organisations. The 'owner' in 'ownership' is often vague, it is difficult to know who represents a country when referring to 'country ownership' of development (Buiter, 2007). Is it still fair to say that development is 'country owned' if the country is run by a corrupt government which was not elected democratically (Buiter, 2007)? NGOs were largely excluded from the Paris Declaration (despite the declaration's commitment to local strategies already being implemented by NGOs (Warning \& Post, 2007)). However they gained increased recognition in the Accra Agenda for Action (OECD, 2008: 1) as complementing the government and private sector as independent development 
actors. The change in definition of ownership to "democratic ownership" in the Fourth High Level Forum on Aid Effectiveness in Busan (OECD, 2011b: 5) saw the role of NGOs further highlighted, recognising that ownership of development includes broader national stakeholders, further increasing the role for CSOs in development (Council for International Development, 2012).

Ownership, as a current buzzword, is subject to overuse. In practice, it is difficult to define and its application can often be tokenistic. It can mean anything from a country having designed and drafted its own programmes, to a country being informed of programmes drawn up by another party (Buiter, 2007). Donors often intend a particular definition, but then water this down, revealing that in practice they are not willing to cede control (de Renzio, Whitfield, \& Bergamaschi, 2008). This vagueness around ownership's definition means donors can be seen to uphold ownership while not substantially changing aspects of their aid relationship with recipients (Cramer, Stein, \& Weeks, 2006).

The different actors involved in aid relationships means that ownership carefully navigates and adapts to the intricate power relationships involved. For ownership to develop partnerships need to evolve and power imbalances need to be addressed:

The form ownership takes and the problems of achieving it change over time. Whatever the form, ownership dynamics imply the renegotiation of partnerships to make them less unequal in bargaining power, more tolerant of differences in views, and based upon the recipient government and national stakeholders driving the development process (Cramer et al., 2006: 422).

Hence, the concept of ownership is broad and ever evolving and differs according to parties involved, time and space. Therefore ownership can be viewed as both broad and relative:

The concept of 'ownership' is a relative one. It really only makes sense when seen in the context of what happened before, and thus ownership can be seen 
as moving away from the imposition of the content and process... ${ }^{11}$ by outsiders (EURODAD, 2001: 3).

Since ownership is difficult to define, it is necessarily difficult to measure.

Separating what governments and donors have initiated and control is complicated given the development of aid relationships over a long time within changing aid systems (de Renzio et al., 2008).

\subsection{Change in Aid Modalities and Aid Management}

Under neostructuralism aid modalities have changed dramatically. A new focus on ownership and the acceptance of the state has meant that general budget support (GBS) (unearmarked aid to the government budget) has become the ultimate goal of aid. Various stages lead up to this pinnacle exist, such as Sector Wide Approaches (SWAps). Progress to GBS is analysed and evaluated by donors and external agencies and follows a Poverty Reduction Strategy (PRSP) - a development plan moulded to a donor approved template. The template PRSP path to GBS requires recipient countries to follow steps on a continuum which adopts Western systems of management and administration. However, the PRSP framework has the opportunity cost of different, perhaps more tailored approaches to development, as governments are forced to focus on best practice and its integration (Craig \& Porter, 2003).

PRSPs represent the Paris Declaration's (OECD, 2005) primary measurement of ownership. Ironically, this is measured by donors rather than recipient countries (Venter, 2008) and consequently does not promote ownership (Zimmermann, 2008). Adopting a PRSP may only indicate that a developing country is following a donorpaved path (Zimmermann, 2008). Moreover PRSPs could be accused of decreasing ownership by replacing national processes (Oxfam International, 2004).

The new modalities are government administered. This not only reflects neostructuralism's focus on the state but allows for a single point of contact for donors. The increase in ownership through means such as GBS demands a higher degree of consultation, dialogue and decision making with donors (Smith, 2005).

\footnotetext{
11 "of structural adjustment programmes" was removed from the original so that the definition could be applicable to further situations.
} 
However governments often do not have the capacity to deal with these bigger demands (Brown, Foster, Norton, \& Naschold, 2001). Administration and public service, reduced under neoliberalism, has had to expand and be built up again. The expertise needed to meet donor expectations often calls for the use of technical assistants or expatriate staff. This has been described as a new kind of colonial occupation that undermines ownership (Overton et al., 2012).

The new aid modality has affected NGOs differently. Neostructuralism's focus on channelling aid through government has seen a decrease in focus on aid delivery by NGOs. Despite this the period 2001-2009 saw total Development Assistance Committee (DAC) aid channelled to and through NGOs increase significantly. ${ }^{12}$ Interestingly, only earmarked aid increased ${ }^{13}$ and core support remained constant (DAC/OECD, 2011). This supports the view that donors use NGOs to reach a specific development objective (DAC/OECD, 2011: 14). ${ }^{14}$ Neostructuralism has seen an increased focus on core support (GBS) for government but, with the state seen as the primary actor, this has not extended to NGOs.

Both NGOs and government have been affected by the increased focus on managing for results and accountability which has in turn pushed for standardised aid practices. Aid relationships have begun to focus on standardised operating procedures and practices for accountability, results management and harmonisation (Bornstein, 2006; Wallace, Bornstein, \& Chapman, 2006). This includes a focus on pre-fixed results, reported through set formats and templates for project-management. Meeting global targets is important and increasingly funding is tied to the MDGs.

A Wallace et al. (2006) study into the aid chain between donors and NGOs in the United Kingdom and recipients and field offices in Uganda and South Africa claims that the new approach shows a bias towards valuing systems and approaches

\footnotetext{
${ }^{12}$ From \$US4.7 billion (in constant 2008 dollars) to \$US9 billion (DAC/OECD, 2011: 20).

${ }^{13}$ Aid increased from \$US2 to \$US6.3 billion. These are only DAC estimates and only account for a portion of aid (they exclude aid from significant countries such as China and also transfers from metropolitan governments to territories and dependencies (Overton, Prinsen al. 2012).

${ }^{14} 20$ out of 25 donors hold that a "very important" or "important" objective for working with NGOs is "To reach a specific development objective (implement aid programmes) linked to service delivery" (DAC/OECD, 2011: $14)$.
} 
developed in the West. Tools and guidelines have such a strong influence that reporting for aid is often based on templates rather than analysing the challenges seen in development and reporting on the learning. Such inflexible systems can be difficult to follow and of no value for local use. They do not recognise local knowledge or views, and fail to capture complex relationships, cultural subtleties and context specificities. Local knowledge of staff, which is often verbally communicated, cannot be captured in the documentation-intensive system. The rigid processes mean that even if donors want to hear about success directly from the field, this is not normally possible.

The study furthermore found that recipients in developing countries are often conflicted by trying to meet the demands of donors who control the funding stream, while also trying to find locally appropriate ways to address poverty. Significant time is spent for upward accountability and consultation despite the rhetoric of participation. However, these conditions, policies and procedures are often difficult to change but many NGOs comply with them as a global norm, while others disagree but follow them to access funding.

The study's example of the impact of the results management approach to aid administration highlights some of the ownership issues recipient countries are struggling with. Upward accountability and bureaucratic conditionalities may be impeding ownership. Murray and Overton (2011a) argue that the new aid agenda, with its focus on increased ownership and participation, has increased demands on recipient countries by setting new conditions to adhere to. Conditionality used in SAPs under neoliberalism was criticised as coercive, forcing governments to choose between protecting the welfare of its citizens by accepting aid and the conditions attached to it, or protecting its sovereignty (Kilby, 1999). The new conditions imposed could be criticised similarly.

\subsection{Monitoring and Evaluation}

The changes in aid direction and aid modalities, together with the influence of the Paris Declaration, have pushed for an increase and improvement of monitoring and evaluation systems. The PRSPs, with their focus on transparency and accountability (Craig \& Porter, 2003) carrying heavy expectations of monitoring and evaluation, 
have been a catalyst for its improvement (Holvoet \& Renard, 2007). Strong recipient-led monitoring and evaluation is required to improve ownership, to encourage donor alignment, to increase accountability and to allow for results management. However, as seen in sub-Saharan Africa, monitoring and evaluation may be one of the weaker adopted practices of the new aid paradigm (Holvoet \& Renard, 2007).

\subsubsection{Ownership}

Recipient-led monitoring and evaluation systems support the Paris Declaration (Feinstein, 2009; Holvoet, Gildemyn, \& Inberg, 2012) including the ownership principle which stipulates that recipient countries need to lead the coordination of their aid (OECD, 2005). Recipient-led systems allow locally identified data to be collected which may differ from that chosen by donors. Accordingly, this data is most likely to be data that meets local evaluation needs (Lundgren \& Kennedy, 2009). Furthermore, local leadership of the process allows for sustainability of evaluation systems (Lundgren \& Kennedy, 2009) and gives the recipient country a tool for evaluating the new aid modality (Feinstein, 2009).

Although ownership of monitoring and evaluation requires recipient initiation and agenda setting (Lundgren \& Kennedy, 2009), in practice, it has been suggested that this may need to be encouraged by donors as current adoption of the practice is slow (Feinstein, 2009). The Accra Agenda for Action specifies this area for development, requesting donors to support the strengthening of national information systems (OECD, 2008). It has been suggested that capacity can be built through training, technical and financial support, and joint-evaluations (Lundgren \& Kennedy, 2009). However, such training may impede the development of unique monitoring and evaluation systems and simply replicate donor practices. It is imperative that evaluation systems are locally tailored in order to be sustainable (Lundgren \& Kennedy, 2009) and support ownership.

\subsubsection{Harmonisation and Alignment}

The Paris Declaration principle of harmonisation urges donors to coordinate thereby simplifying procedures and sharing information (DAC/OECD, 2011). Harmonisation 
avoids duplication which, in terms of monitoring and evaluation, translates to fewer overall reporting requirements from multiple donors and a reduction in transaction costs for recipient countries (Holvoet et al., 2012). Donors, however, have been found to be slow to harmonise for monitoring and evaluation procedures (Holvoet et al., 2012).

Alignment calls for donors to reduce parallel systems and align with recipients' systems (OECD, 2005). Alignment, like harmonisation, can reduce high transaction costs resulting from a multitude of donors carrying out the same processes (Feinstein, 2009).

In practice it has been shown that donors are reluctant to commit to recipients' monitoring and evaluation systems (OECD, 2011a as cited in Holvoet et al., 2012: 750). Holvoet and Renard (2007) describe donors' situation as a chicken and egg scenario. One the one hand, donors will resist alignment if recipient countries do not hold a minimum institutional capacity for monitoring and evaluation (Holvoet \& Renard, 2007). On the other hand, the downsizing and alignment of donors' systems is crucial in the strengthening of recipient institutional capacity (Holvoet et al., 2012; Holvoet \& Renard, 2007). However evidence has shown that donors are slow to use country systems as they prefer to practice "risk avoidance" rather than "risk management" (OECD, 2011a: 52) and donors vary as to how much risk they will take. By the same token, there is little evidence proving that donors are more likely to use country systems if they are of sound quality (OECD, 2011a: 41).

\subsubsection{Accountability}

The increase in focus on good governance and the change in aid modalities to broader funding such as GBS, have resulted in an increased demand for transparency and accountability (Kusek \& Rist, 2004), including downward accountability (Holvoet \& Renard, 2007; Holvoet \& Rombouts, 2008). The Paris Declaration highlights this concern in its increased focus on accountability (Holvoet et al., 2012). Constituents and donors are concerned that aid is used effectively and is not absorbed by corruption. Good monitoring and evaluation is a fundamental tool in increasing accountability and reducing corruption which in turn reduces transaction costs, allowing for greater aid effectiveness (Adrien \& Jobin, 2009). However, the 
increase in donor demands under the new aid agenda could have a negative effect on accountability. An exploratory study into NGOs' accountability in Uganda (Burger $\&$ Owens, 2010) investigating inaccuracies in reported financial transparency and participation found that unrealistic donor demands could stand as an obstacle to transparency. Therefore, an increased focus on accountability and transparency through increased demands could simultaneously undermine this same focus.

\subsubsection{Results Management}

The Paris Declaration principle of measuring for results focuses on "managing and implementing aid in a way that focuses on the desired results and uses information to improve decision-making" (OECD, 2005: 7). Good monitoring and evaluation systems are essential for results-based budgeting and management.

This strong focus on results management stemmed from a branch of New Public Management. This "emphasises the importance of defining expected results with the involvement of key stakeholders" (Hatton \& Schroeder, 2007: 427) and involves a strong monitoring and evaluation component which includes "monitoring programmes designed to achieve these results through the use of appropriate indicators, reporting on performance in achieving results, and acting on performance information" (Hatton \& Schroeder, 2007: 427). Results-based management has been adopted widely by donors, multilateral agencies and NGOs (Hatton \& Schroeder, 2007). However this focus on results and linking policy measures to specific outcomes raised concerns around the web of factors that contribute to outcomes. For example, outcomes are affected by access to reliable and timely data, the ability to develop meaningful indicators, exogenous shocks and the lag effect of changes in economic, environmental and social changes (Koeberle, 2005). Furthermore, as Koeberle (2005) points out with reference to policy-based lending, it is difficult to ascertain what would have happened if a programme or project were not carried out.

EURODAD (2008) has found that the European Commission's move to focus on results has led to increased monitoring and evaluation challenges including insufficient funding, data and disclosure of data. Despite the push for recipient-led systems, indicators are often selected by donors (e.g. MDGs, Paris Declaration and indicators for SWAps and GBS (EURODAD, 2008; Smith, 2005; Venter, 2008)). 
They are mainly quantitative (EURODAD, 2008; Smith, 2005) and can be insufficient in their representation of the full picture (EURODAD, 2008). Easy to access data, which is often used, is not always suitable for local priorities (Smith, 2005). Moreover, the change to results-based approach has often seen an overall increase in the extent of monitoring and the number of indicators (EURODAD, 2008).

\subsubsection{Summary of Monitoring and Evaluation}

The new aid agenda calls for better monitoring and evaluation. Improvements are needed in order to meet higher demands for accountability, allow for use of the new results-management framework, encourage donor alignment and give recipient countries a new tool for ownership. Unfortunately, in practice, the heavy requirements of the limited monitoring and evaluation systems of recipient countries contradict the agenda's own rhetoric around increased ownership.

\subsection{Vanuatu and the Pacific}

\subsubsection{Neoliberalism and Neostructuralism}

The Pacific experienced global aid trends, although later than the rest of the world. The SAPs of the 1980s and early 1990s were enforced in the Pacific in the mid1990s (Murray \& Overton, 2011a). Between 1995-1998 the Asian Development Bank (ADB) moved from supporting sector and project lending to macroeconomic stabilisation and structural adjustment in the Pacific (Knapman \& Saldanha, 1999). For example the Cook Islands was forced to cut the size of its civil service by $57 \%$ (Knapman \& Saldanha, 1999) after a significant cut in its budgetary support was imposed (Murray \& Overton, 2011a). The neoliberal practice of trade liberalisation was enforced when Pacific Island countries were no longer granted preferential trading for their key industries (Murray \& Overton, 2011a). The good governance agenda was present, through public sector reform and a focus on accountability and corruption (Larmour, 2005).

Vanuatu, in seeking outside support, accepted an SAP in 1997 in the form of a Comprehensive Reform Program (CRP) with the ADB. The policies included represent a neoliberal agenda, emphasising privatisation, corporatisation, and 
economic liberalisation (Gay, 2014). The public service decreased by $10 \%$ from 4,250 to 3,825 (Knapman \& Saldanha, 1999). Identical packages were rolled out in other Pacific Island countries such as Samoa and the Solomon Islands (Gay, 2014). The reform includes a focus on good governance in order to make the public sector more modern and accountable (Gay, 2004). Good governance has been highlighted as a key priority area for Vanuatu as outlined in the Priorities and Action Agenda $2006-2015$ (Government of the Republic of Vanuatu, 2006).

Vanuatu's CRP has been criticised as "poorly focused" (Pacific Institute of Public Policy, 2009: 4) as few resources were identified to finance the objectives listed. The CRP resulted in a worsening fiscal situation (Gay, 2004) and Gay (2014) found that despite the ADB's assessment of continuous consultation and media coverage (ADB, 1999) many people felt they were not properly consulted on the reforms.

Furthermore, the CRP failed to take into account the local context, especially features unique to Vanuatu such as kastom, the use of money and land ownership (Gay, 2014).

Neoliberal land reform was also promoted by donors in the Pacific, undermining the relationships that local people have with their land (Murray \& Overton, 2011a). A land registration scheme introduced in Vanuatu has been created "for Vanuatu to develop economically and be attractive to investors", to further Vanuatu's economy rather than benefit Ni-Vanuatu (Daley, 2010: 35). Land is central to Ni-Vanuatu identity (Leach, 2013) and the current land model, driven by foreign investors, threatens Ni-Vanuatu control of their land and development futures (Daley, 2010).

The neostructural agenda experienced on the global stage also began to have a presence in the Pacific. Rebuilding the state became central to security concerns around deemed 'unstable states' (Dobell, 2007) in Australia's 'arc of instability' extending from East Timor through Papua New Guinea, the Solomon Islands and Vanuatu to New Caledonia and Fiji (Dobell, 2007; Murray \& Overton, 2011a). Furthermore, the poverty agenda became particularly evident when it was adopted by Australia and New Zealand, major aid donors to the Pacific, in the late 1990s (Murray \& Overton, 2011a). Neostructuralism and the poverty agenda can be seen in Pacific Islands' focus on the MDGs (Murray \& Overton, 2011a) and actions such as the establishment of the Pacific Aid Effectiveness Principles in Koror, Palau in 
2007. These reflect the principles of the Paris Declaration but add some regional elements such as the role of technical assistance (Pacific Islands Forum Secretariat, 2007). Off-track in meeting the MDGs, the Pacific Islands Forum met in Cairns to discuss the Pacific Plan and signed the Cairns Compact (Pacific Islands Forum Secretariat, 2009), an agreement that reinforced the Paris Declaration, the Accra Agenda for Action and commitment to the MDGs.

This adoption of the neostructuralist poverty agenda together with the presence of neoliberal trade reforms and CRPs demonstrates a neostructuralist façade in the Pacific with underlying neoliberal tones (Murray \& Overton, 2011a).

\subsubsection{The Inverse Sovereignty Effect}

The new aid modalities and aid management has increased administration requirements such as policy frameworks and financial and auditing systems for limited Pacific Island bureaucracies (Murray \& Overton, 2011a). Murray and Overton (2011a) suggest neostructuralism's push for ownership, while simultaneously imposing heavy demands, creates an "inverse sovereignty effect" whereby an aid paradigm which advocates ownership is actually undermining recipient sovereignty. This effect is particularly experienced in the Pacific where the limited size of bureaucracies may struggle to meet such demands.

\subsubsection{Vanuatu: Monitoring and Evaluation}

Vanuatu's government has limited monitoring and evaluation capacity. This presents a challenge in monitoring the development outcomes of newly implemented policies (Prime Minister's Office, 2010b). Vanuatu received a $\mathrm{C}^{15}$ for its result-orientated framework (indicator 11 of the Paris Declaration (OECD, 2011c)), held back by the poor quality of development information and the incomprehensive coverage of indicators for its national development strategy. Challenges around up-skilling for data collection and computation were also highlighted. Moreover, stakeholder access to information was seen as poor, with few materials in Bislama and it was suggested

\footnotetext{
${ }^{15}$ The World Bank accesses this score from evidence provided by the government, with A being the highest score and $\mathrm{E}$ the lowest.
} 
that information contained in monitoring and evaluation reports was not being used to its full advantage.

However, the Government of Vanuatu has sought to improve its monitoring and evaluation. In recognising the need for accountability and transparency for good governance and the need to move towards evidence-based policy making (Prime Minister's Office, 2010b) the government has established a Monitoring and Evaluation Unit together with a government Monitoring and Evaluation Policy (Prime Minister's Office, 2010b). The unit collates data collected by individual line ministries and is responsible for the planning, monitoring and evaluation of the economic and development agenda of the Government (Pacific Institute of Public Policy, 2009). The goal is to, "improve efficiency and effectiveness of service delivery" (Prime Minister's Office, 2010b: 5) through the promotion of accountability, learning, feedback and sharing knowledge around results. The forming of the Monitoring and Evaluation Unit together with the Monitoring and Evaluation Policy has the potential is an important step forward for Vanuatu in increasing ownership of its development.

\subsubsection{Alignment and Harmonisation}

The literature has shown that alignment is critical to increasing ownership. While Vanuatu's monitoring and evaluation capacity is limited, Vanuatu's budget and Public Financial Management (PFM) systems are sophisticated and seen as best practice in the region (Pacific Institute of Public Policy, 2009). The OECD (2011c) survey on Vanuatu, Aid Effectiveness 2011: Progress in Implementing the Paris Declaration found that Vanuatu met its 2010 MDG target for reliability of country PFM systems. ${ }^{16}$ In 2010, 31\% of aid to the government sector used country PFM systems (OECD, 2011c). Donors noted the weak capacity of line ministries in budget execution, financial reporting and auditing as reasons for not channelling more aid within the systems. Despite the assessment of Vanuatu's PFM systems, in 2010 there were nine parallel project implementation units (PIUs) set up avowedly due to weak

\footnotetext{
${ }^{16}$ Vanuatu received a score of 4 for the quality of its Public Financial Management systems (with 1 being very weak and 6 being very strong).
} 
capacity environments that cannot ensure implementation efficiency nor guarantee the correct and transparent use of funds (OECD, 2011c). Vanuatu did not participate in the same survey in 2006 and 2008; therefore it is difficult to ascertain whether alignment in these areas is improving.

Lack of harmonisation has also been highlighted as an obstacle to development. Demands around meeting multiple donors' requests or consultations place a heavy burden on recipient countries' resources (OECD, 2011a), especially in small Pacific Island Nations (Murray \& Overton, 2011a; Wrighton, 2010; Wrighton \& Overton, 2012). Harmonisation, therefore, is central to aid effectiveness, as ratified by the Paris Declaration (OECD, 2005). In Vanuatu, donors performed poorly in their ability to conduct joint missions, whereby only $23 \%$ of the 59 donor missions in 2010 were jointly conducted (OECD, 2011c). Individual donors' interests, language issues and internal procedures have been put forward as barriers to joint missions (OECD, 2011c). Despite the poor performance in joint missions, donors were closer to their target in joint analytical work (Indicator 10b). This includes country studies, evaluations and discussion papers. Donors coordinated $60 \%$ of analytical work in 2010, just short of their 66\% target (OECD, 2011c).

\subsubsection{Vanuatu and the Pacific: Concluding Comments}

Vanuatu and the Pacific have been subject to global aid trends. Neoliberalism's presence is seen most clearly through the CRPs accepted by many Pacific nations including Vanuatu. However, Vanuatu's CRP has been criticised due to the lack of consultation in its development and its inability to account for the local context (Gay, 2014). Similar to the global experience with SAPs, these criticisms highlight the lack of ownership in Vanuatu's CRP. The neostructural agenda is seen in the Pacific through the poverty focus and adoption of the MDGs. The recognition of the need for aid effectiveness has seen Vanuatu move towards evidence based policy making by establishing a Monitoring and Evaluation Unit. It is difficult to ascertain the degree to which donors are supporting Vanuatu's country systems as there is limited information available on alignment for comparisons over time (OECD, 2011c). However, donors appear to be harmonising on joint analytical work which, in theory, would benefit Vanuatu by reducing the amount of duplicate reporting. The limited research available on Vanuatu leaves room for further research around the 
extent to which the neostructural agenda's focus on ownership is being played out in the practice of monitoring and evaluation.

\subsection{Conclusion}

In summary, two major aid paradigms, neoliberalism and neostructuralism have contributed to current aid practices. While neostructuralism has pushed for a greater focus on poverty and the state, neoliberal undertones still exist. Ownership has been highlighted under the new aid agenda. However monitoring and evaluation obligations imposed on recipient countries mean that the current delivery of aid undermines the very principles the agenda seeks to uphold. Current monitoring and evaluation practices reflect poor recipient ownership and donors are furthermore reluctant to align with recipient systems. The Pacific and Vanuatu have experienced the global aid trends of neoliberalism and neostructuralism. The results management agenda has been adopted and Vanuatu is seeking to improve its monitoring and evaluation practices. However, the extent to which ownership is exercised in these practices leaves a gap within the literature to be explored. 


\section{Methodology}

\section{$\underline{3.1 \text { Introduction }}$}

In conducting research in Vanuatu, an appropriate methodology is imperative. This chapter begins by explaining my epistemological stance which shapes the research's approaches, analysis, interpretation and dissemination (Chilisa, 2012). It then goes on to explore reflexivity and the impact of my positionality on the research. Ethics procedures are highlighted and ethical concerns are woven throughout the chapter, recognising that ethics is not an isolated process but present throughout the study (Smith, 2006). Storian, a methodology anchored in Vanuatu, is then explored before methods used are expanded. Finally, the chapter concludes with consideration of the limitations of the methodology.

\subsection{Epistemology and Knowledge}

The research's epistemological stance is based on social constructivism (see Berger and Luckmann (1967); Lincoln and Guba (1985)). Social constructivism holds that individuals seek understandings through the world around them and develop varied and multiple subjective meanings of their experience (Creswell, 2009: 8). These meanings "are not simply imprinted on individuals but are formed through interaction with others (hence social constructivism) and through historical and cultural norms that operate in individuals' lives" (Creswell, 2009: 8).

Feminist and indigenous paradigms add to this epistemology. In particular, the work of feminists on positionality and reflexivity (Gilbert, 1994; Kobayashi, 1994; Madge, 1993; McDowell, 1992a, 1992b; McLafferty, 1995; Rose, 1997) and indigenous authors on indigenous paradigms (Chilisa, 2012: 13; Farrelly \& NaboboBaba, 2012; Gegeo \& Watson-Gegeo, 2002; Smith, 1999) who recognise a completely different way of knowing and therefore the need for different research processes. In acknowledging indigenous paradigms I reject modernisation theory, that countries should follow a linear development path modelled on the West. Despite this, I recognise that the research focuses on a Western tool of development: 
the aid practice of monitoring and evaluation. However, it tries to present this research from an indigenous perspective through the voices of the participants.

My epistemological stance contributes to the employment of reflexivity, the adoption of an appropriate methodology and the use of qualitative methods.

\subsection{Reflexivity and Positionality}

Reflexivity was recognised as an ongoing process and therefore was continually practiced throughout the research. I was constantly reflecting on and attempting to better understand my positionality: how my actions, my history and my identity affected the research. Contrary to positivist assumptions of neutrality, social constructivism recognises that research cannot help but be biased and value laden (Chilisa, 2012; Creswell, 2009); positionality shapes how we look at the world and therefore how we carry out research. Therefore, it is important to understand one's positionality and to learn from it (Schoenberger, 1992). Moreover, being aware of positionality and reflexivity is needed to address power imbalances (Chacko, 2004). However, Rose (1997) reminds us that we cannot assume to be so self-aware as to know the full impact of our positionality on our research. There are many questions that reflexivity seeks to answer but "the answers are so massive, the questions are so presumptuous about the reflective, analytical power of the researcher, that I want to say that they should be simply unanswerable: we should not imagine we can answer them" (Rose, 1997: 311).

\subsubsection{Ko Wai Au?}

Before I explore the impact of my positionality, I will briefly introduce myself, so that the reader is aware of who is conducting this research. Such practice is important in a Māori context, answering ko wai au? Who am I? This translates beyond my name to where I come from, which determines who I am.

Ko Taranaki te maunga

Ko Matanehunehu te awa

Ko Taranaki te iwi

Ko Ngā Mahanga te hapū

Ko Puniho, ko Oakura ngā marae 
I am of British and Māori decent. My parents are Chris Nichol and Shona Geary who are both from Dunedin. I am the youngest of three girls, brought up in Christchurch and Wellington. I have spent time living overseas in Italy and Vanuatu and these countries have become second homes to me, with the people there becoming family. Although this introduction is brief, it is important in illustrating who I am, shaped by my history, family and those before me (Webber, 2006).

\subsubsection{Multiple Identities}

My history, family and those before me have framed my multiple identities. The concept of multiple identities has been raised frequently, particularly in feminist literature (Chacko, 2004; Haraway, 1991; Madge, 1993; Reinharz, 1997; Rose, 1997). My multiple identities had different impacts on the research.

My education, and perhaps the colour of my skin, meant that I had relatively easy access to information and people in Vanuatu. Sidaway (1992) notes that in the field, researchers often move to a different hierarchy in society. I realised it was possible for me to walk into a government department, without contacts, and ask for a meeting. However when considering this, Wrighton (2010: 15) always rang in my ears:

The ease of access to officials is one reason why they are so busy seeing people who call in. It is possible to knock on the door of the Secretary to Government, ask if he is free for a few moments and then take up his time on matters of note to you. I doubt that any senior official in any of the donor countries is able to be accessed quite so simply.

If I could not do this in my own country, why would it then be acceptable to do this in Vanuatu? I was constantly reflecting on this point in Port Vila, where I did not feel comfortable approaching a department without prior contact or on the basis of a recommendation. While I undoubtedly missed out on interviews as a result, I did not want to recruit participants in this way.

In the street and around town, the colour of my skin was a clear indicator of the fact that I was an outsider. I was aware of some of the local perceptions of white people, based on the expatriate community, the tourists, the aid workers, the resort owners 
and the condominium administration. I got used to being referred to as 'misis', a colonial term loosely meaning "female expatriate and/or employer" (Rodman, 2007: 1). Being called 'misis' and the association of the colour of my skin always made me feel a little uneasy and overly eager to disprove negative stereotypes. I sought to do this by speaking Bislama, demonstrating my basic understandings of kastom and how things work in Vanuatu picked up from my time living there.

The participants did not make me feel the burden of the 'misis' label. They were used to working with foreigners in their offices. I felt that the participants respected that I had spent time living in Vanuatu. Having been a Volunteer Service Abroad (VSA) volunteer distinguished me in Luganville where almost every NGO and government department has had a VSA volunteer working either with them or nearby. Furthermore, having worked in an NGO in Vanuatu made me feel like more of an 'insider'. NGO participants spoke as if I knew their work, as became evident in our conversations and the use of "you know" throughout the interviews.

\subsection{Power}

Recent literature on power draws attention to the higher status, the education and the luxuries of the researcher compared to her participants (Gilbert, 1994; Kobayashi, 1994). However, in the case of this research, I was interviewing skilled professionals. The participants generally had undertaken more educattion than me and all were more experienced in their work.

I felt that being a young researcher also freed me from some of the power imbalances and the weight of the 'misis' label. Similar to Jones' field research experience in Fiji (Jones, 2012: 13), researching in a culture which emphasizes respect for elders meant that being young was somewhat liberating. I was initially worried that being younger made me less credible as I clearly would not have the same experience as an older researcher and therefore may not have seemed worthy of participants' time. However, the participants never made me feel like this. On the contrary, they were really supportive and interested in the research. Many interviews ended with conversations about the participant's study (usually abroad) and with participants giving me advice as to the next step in my career. I recognise, however, 
that the participants were not representative of the population, and outside of the interviews I often felt uncomfortable about different statuses.

Despite the status of my participants, I still sought to even power relations with regard to how the research was carried out. Interviews were conducted on participants' terms: they set the time and place. I also asked the participants initially recruited what they would like to get out of this research, to help me better focus the study for their needs. Participants were always given the option to pull out should they have felt uncomfortable with any of the processes or information shared.

\subsection{Rationale for Research}

I have discussed my personal reasons for wanting to conduct the research in the preface to this thesis. However, feminist and indigenous writers (e.g. Chacko (2004); Chilisa (2012); Hutchings (2010); Smith (1999)) had me constantly reflecting on whether I was the right person for the study and whether I was conducting the work in the right way. While I do believe the research was more than just 'new academic tourism'(Mowforth \& Munt, 1998), I cannot deny that some of the drivers of the research were personal interests and career advancement (Chacko, 2004: 59). This became particularly evident when I realised that the undertaking was consistently referred to as "my research", language implying ownership despite my recognition that the data belongs to the participants and the study aims to be for their use.

The research gave participants the opportunity to express their opinion, and have it documented as something that could inform the general literature and contribute to informing monitoring and evaluation practice. The two part aim of the research, to reflect on current practice (the place of ownership) and to make recommendations (how ownership can increase) sought to be useful to participants both reflecting and looking forward. However, the recommendations discussed in the conclusions do not intend to "label, name, condemn, describe, or prescribe solutions or challenges..." (Chilisa, 2012: 7). They are, rather, broad recommendations drawn out from the participants' comments and leave space for the reader to interpret them for their own context. 
I recognised that the research added to the many demands of each participant's work day. In researching a practice that has already been flagged as a burden to NiVanuatu government employees (Prime Minister's Office, 2010a), I saw that this work could also be viewed in the same way. However participants had the right to decline participation (which many did) and others found they could not commit to the interviews as they had other engagements. I was relieved to note that the participants who did take part showed a strong interest in the topic and in taking part. They all commented on the importance of monitoring and evaluation and requested a summary of the findings.

I constantly questioned whether I should ethically be researching in the context of Vanuatu. However I found that focusing on the work of NGOs and government departments meant that I was not a complete 'outsider' to the context. Murray and Overton (2003) discuss the 'foreignness' of a researcher to her participants' context as on a continuum "influenced by cultural, life-cycle, gender and geographical factors" (Murray \& Overton, 2003: 18). Having had experience working in the NGO sector in Vanuatu, I was relatively familiar with the area of research and the work of the participants. Furthermore I had contacts in Vanuatu working in this field. I would not have had the same experience (or linguistic ability as later explained) to research other aspects of Vanuatu and could not have justified researching a topic that was further 'foreign' to me.

\subsection{Ethics}

The Vanuatu Cultural Council's guiding principles helped steer the overall research ethically, particularly the methods ${ }^{17}$. A formal university ethics process was also followed, as required, which allowed me to reflect on ethical issues ensuring the research always respected the participants. Ethics approval was sought through the Victoria University of Wellington Human Ethics Committee which reviewed the research questions and processes before granting approval on the 20th of March, 2013. However following Smith's (2006) explanation of ethics in Kaupapa Māori, I recognised that ethical behaviour extends beyond the formal university process of

\footnotetext{
${ }^{17}$ I was not official bound to these principles as the research topic fell outside of the scope of the Vanuatu Cultural Council's "cultural research" definition (Vanuatu National Cultural Council, 2009: 36).
} 
obtaining ethics approval for a set of questions. One is forever bound to ethical behaviour around the research (Smith, 2006).

Free, prior and informed consent is imperative when working with indigenous communities. On top of this, consent is always an ongoing negotiation and can change (Mead, 2006). An information sheet along with a consent form was written up $^{18}$ to be signed by participants. The forms were written in English which I thought was appropriate given that all participants interviewed worked with English documents. However, in hindsight I should have provided the document in both English and Bislama. Participants were always verbally informed of the research, the process involved and the research's use. Verbal consent was always sought to take part in the research, but the consent form was not always used, especially when interviews were unplanned. Participants did not always feel comfortable signing the consent form and therefore some did not sign. Despite its necessity for university ethics approval, I found that it wasn't the most suitable approach for the Vanuatu context.

Participants' name, position and organisation remained anonymous in the research in order for them to feel comfortable to express their opinions. They are represented in the research by the type of organisation they work for and a letter of the alphabet e.g. NGO Employee A or Government Employee A. While expressing each participant's position and workplace would be helpful for the reader, in a country with such a small population this extra information would take away anonymity (King \& Horrocks, 2010) and so, in the interest of respecting the participant first, this information was withheld.

\subsection{Storian}

Talanoa has recently gained significant attention in academic literature (Farrelly \& Nabobo-Baba, 2012; Halapua, 2000; Robinson \& Robinson, 2005; Vaioleti, 2006) and is now perhaps the most prominent methodology used in the Pacific (Farrelly \& Nabobo-Baba, 2012: 2). Storian is Vanuatu's form of talanoa (Warrick, 2009) and was adopted as a methodology for this research. Like talanoa, storian involves and translates to swapping stories, talking and yarning (Crowley, 1995: 235; as cited in

\footnotetext{
${ }^{18}$ See Appendix I for the consent form.
} 
Warrick, 2009: 83). Storian lends to less formal qualitative methods: "Storian is an umbrella term indicating semi-structured interview, informal interview, and opportunistic discussion as part of observation" (Warrick, 2009: 83). An advantage of a storian methodology is that it "allows people's perspectives to be more adequately reflected as they talk around the topic in their own way" (Warrick, 2009: 84). However, like talanoa, storian is more than just "informal open-ended interviews" (Farrelly \& Nabobo-Baba, 2012: 1). Central to storian is relationships: "Irrespective of specific method, the central feature of storian is building rapport with participants" (Warrick, 2009: 83). Therefore the two methodologies, storian and talanoa, have a strong emphasis on being physically present (Halapua, 2000).

Other indigenous methodologies hold similar emphases. Kanohi kitea in kaupapa Māori stresses the importance of face-to-face communication for participants to be able to assess the subject of the research using all senses (Cram \& Pipi, 2000 as cited in Cram, 2009:314). Furthermore, kanohi kitea promotes relationship building and being physically seen around the community (Cram, 2009). In following a storian methodology and exercising indigenous values such as kanohi kitea, it was important for me to conduct interviews face-to-face, for participants to be able to meet me and fully assess whether they wanted to be part of the research. Furthermore, the methodologies served as a reminder of the importance of building relationships and the value of yarning, chatting and getting to know each other before tackling the issues of the research. By the end of each interview, I had gotten to know many of the participants quite well and some interviews extended significantly past the formal questions while we chatted about our lives.

\subsection{Bislama}

Bislama is used almost everywhere in Vanuatu as lingua franca (Crowley, 2000). Being fluent in the language (in terms of speaking it effortlessly and with continuous performance (Byrnes, 2012: 509)) enabled me to engage more deeply than speaking English alone would have allowed. It enabled me to chat, to be less formal and to talk around the topic while the participant directed what part of the topic they wanted to focus on (Warrick, 2009: 84-85). In other words, Bislama enabled me to storian. As the majority of words in Bislama are based on English (Crowley, 2004) and many new terms with regards to organisational processes are expressed in English, my 
topic was relatively easy to discuss. However, had the research focused on another topic, for example land, I would have struggled to discuss the research with fluency. Linguistically speaking (disregarding the inappropriateness of my researching land) I would not have had the lexicon (land concepts in Bislama would not have borrowed so heavily from English) nor the 'conceptual competence' (the ability to use and understand abstract concepts and figurative language (Andreou \& Galantomos, 2009)) to research land issues. Despite my confidence in my ability to storian about monitoring and evaluation, I do recognise the potential to have missed nuanced meaning by conducting many of the interviews in a language other than my mother tongue (Rossman \& Rallis, 2003).

Mooko comments that the use of European languages reflects the colonial experience and rulers (Mooko, 2009). Conducting interviews in Bislama was one strategy for avoiding this. However I quickly found that most government and NGO workers could speak English very well and other (non Ni-Vanuatu) participants spoke English better than Bislama. In fact, some interviewees preferred to be interviewed in English. As a result I considered each interview individually before deciding which language to use. Approximately half of the interviews were carried out in Bislama and half in English, although most involved a mix of the two languages. I believe that my understanding of Bislama still allowed me to use English in a way that enabled the storian approach inherent in Bislama.

While speaking Bislama had obvious professional benefits, it had personal benefits too (Leslie \& Storey, 2003). It helped me get by day to day and to meet people. For example, I was able to chat with the manager of my accommodation and discuss news with the women working in the nearby store. The ability to speak the local language significantly decreased any sense of isolation.

I recognise that writing the thesis in English reinforces the colonial experience. As has been highlighted by Gegeo and Watson-Gegeo (2002) in the Kwara'ae culture, simple translations of some indigenous concepts into dominant languages do not allow for the same idea and feelings to be transferred. Therefore Ni-Vanuatu concepts that do not translate well into English, such as kastom, have remained in the text in Bislama as opposed to 'colonising' them into English. This is the reason for 
the absence of a glossary in this thesis: a simple translation would not allow for NiVanuatu concepts' full meaning to be understood.

I did not employ a translator for the fieldwork as I did not believe it to be necessary given the research topic, my command of Bislama and the participants' strong command of English. When being interviewed in Bislama, participants were always very patient with me and expanded or explained ideas if something was not completely clear. Many also encouraged me to email them if I needed anything clarified again later. Translators have also been described as having a role as a 'cultural broker' (Temple \& Young, 2004). However, I did not find this necessary. I was familiar with the workplaces of the participants and the topic we were discussing. Furthermore, participants and the workplaces I entered were used to working with researchers.

While I did not use a translator during my fieldwork, I did ask a Ni-Vanuatu translator in Wellington to examine the translations used within the thesis. While this could be criticised as I had, at that point, already selected quotes from the participants, I did feel that I had understood all the conversations clearly. Quotes were entered into the thesis verbatim and many involve a mix of English and Bislama. In order to emphasise the participants' voices quotes in Bislama are left in Bislama throughout the thesis, with footnotes used for translations.

\subsection{Methods}

My epistemological stance, methodology and the nature of the research questions led me to employ qualitative methods. Such methods allow the research to display the complexity of a situation while focusing on individual meanings (Creswell, 2007). Qualitative methods allow the participants, as opposed to the researcher, a greater role in directing the focus of the topic (Creswell, 2009). Research was undertaken through a literature review and raw data was collected through semi-structured interviews. The findings were then analysed and presented.

\subsubsection{Literature Review}

The literature review played an important part in analysing the current writing in the field, recognising areas for further research, and areas of contention. However, it 
must be acknowledged that much of the literature on developing countries has been developed by outsiders frequently through methods that gave no voice to the 'researched' in how they were represented, often creating unfavourable 'knowledge' to those researched (Chilisa, 2012). Wide readings of the literature and extending the review beyond solely academic articles allowed for alternative understandings of issues. Consequently I actively reflected on the way that I used literature and wrote it up, determined not to compound this 'knowledge' unfavourably.

\subsubsection{Recruitment}

Initially recruitment was conducted by emailing a letter to potential participants outlining the research. ${ }^{19}$ I gained these participants' email addresses through contacts in Vanuatu as well as NGO and government websites. I generally addressed my emails to the head of the department or organisation, but often sent it to a few people within the organisation in order to get a response. I hoped to interview anyone involved in any aspect of monitoring and evaluation.

I received a few responses back from emails and confirmed a small number of interviews before I arrived in Vanuatu. Once in country, I gained the names of others working in monitoring and evaluation in NGO or government departments through personal networks and called or emailed to arrange interviews. In some cases in Luganville I would visit offices and arrange an interview or even be granted one on the spot. I felt comfortable doing so, having lived in Luganville and having been sent to each organisation on the advice of others in the sector.

Many planned interviews fell through or I would turn up at the arranged time and find no one there. In most instances when this happened another staff member would volunteer to be interviewed or the absent participant would be contacted and another interview time would be set up. I did not find this experience overly frustrating as I knew the heavy demands placed on participants and granting an interview was done out of their own goodwill. Prior to the research I accepted that I would not be able to undertake all the interviews I had planned.

\footnotetext{
${ }^{19}$ For an example letter see Appendix III.
} 
In Port Vila, most of the recruitment was through email. Again, I mainly emailed potential participants whose addresses I had gained through personal networks. Most of the originally planned interviews fell through in Port Vila and it was difficult to get hold of participants via email or phone. As earlier indicated, I knew I could have walked into a government department and asked for an interview. But without the connections that I had in Luganville I felt very uncomfortable doing this and chose to approach government departments in Port Vila more formally. In retrospect, I could have approached the departments in person to leave a letter.

I had intended to interview local people working in NGOs and government departments, but after arriving in Vanuatu I was struck by the question of what local actually meant. Did it mean the person had to be Ni-Vanuatu? Many people of other ethnicities have been in Vanuatu for generations. Furthermore, if people of other ethnicities had been appointed to monitoring and evaluation roles by $\mathrm{Ni}$-Vanuatu, could they not then represent the local? One of the defining features that came through from the interviews was how the person described their organisation. Did they use "we" and include themselves as a local, or did they use "they"? However I did not conclude on a definite term for local. Most of the participants were NiVanuatu but I did interview some expatriates working for local organisations. These were not consultants and I believed that these participants could offer insights into experiences of monitoring and evaluation.

\subsubsection{Interviews}

Eighteen semi-structured interviews were conducted. This format was chosen as it allows respondents to talk about what is important to them and lets the conversation flow to places where it may not otherwise have gone if more structured questions had been used (Hesse-Biber \& Leavy, 2010; Ritchie \& Lewis, 2003). A set of 24 questions ${ }^{20}$ developed from the findings of the literature review guided the interview. However, it quickly became clear that there was not enough time to ask all the questions and the area they covered was too broad. The questions asked were therefore tailored to themes emerging after the initial interviews and follow-on questions expanded on issues that each participant brought up.

\footnotetext{
${ }^{20}$ See Appendix IV for a list of the questions.
} 
One highly successful interview technique was simply asking "Yu kat eni narafala tingting blong yu?" or, "Do you have any other thoughts?" at the conclusion of each interview. A lawyer friend had suggested I do this as it was a helpful technique for making sure nothing was missed. I found that it was very effective and participants would use this question to share comments that hadn't come up in the interview, usually an issue they were quite passionate about. Despite my attempt to make the environment of the interviews one where participants felt comfortable to storian, sometimes the semi-structured interview format was too structured and participants felt too restricted by the set questions. This final question allowed participants to express their opinion on anything and frequently, the follow-on storian emerging from this question led to the most interesting data in the research.

Interviews were mostly recorded and this significantly increased the quality of my interviewing. When recording, I could make interviews more of a conversation. I could be responsive and ask follow up questions more easily as I wasn't constantly writing. In most cases, participants were comfortable with the recorder. Permission to use it was indicated on the consent form but I also always asked for verbal consent. The recorder was not used when I felt it was inappropriate, when a participant did not wish for it to be used, or when I conducted an unplanned interview and a recorder would have interrupted and overly formalised the conversation. Interviews were significantly more difficult without the recorder. In recording by hand, I had to make quick judgments on what information was important. However, when later listening to the recordings I would often discover other issues of importance that I hadn't identified during the interview. Unfortunately this additional data may have been lost in the interviews written up by hand.

\subsubsection{Analysis}

While transcription was time-consuming, especially for interviews conducted in Bislama, it allowed me to become very familiar with the data (Langdridge, 2004). Transcribing interviews was considerably easier when done immediately after or close to the conclusion of the interview. It was easier to recall topics and the silences in the transcripts that had been filled with hand gestures. It meant that I did not lose too much of the contextual features (King \& Horrocks, 2010). Transcribing was 
done verbatim, I included side commentary (which explained the conversation) when necessary. However, despite this, the transcription cannot ever be complete and capture the same feeling of the original conversation (Devault, 1990). I made the decision to paraphrase conversations about other areas of work when transcribing the recordings, listening first to them several times to make sure nothing was missed. I kept the original audio files to listen back to throughout the write-up process.

The data was coded and interpreted by hand, rather than using software. This allowed me to get to know the research better and get closer to it. The coded data was then grouped into themes. From these themes, I could start to understand the direction of the thesis and what needed to be discussed. The research findings were presented over two chapters, a significant portion of which through quotes. The quotes ensured the participants' voices came through and that they were at the forefront of the research. Unfortunately, I was unable to use direct quotes from participants whose interviews were not recorded. The findings of the study led to recommendations. As earlier discussed, these are not concrete solutions. The intention of the recommendations is to inform, rather than prescribe.

\subsubsection{Dissemination of Findings}

All participants in the research were interested in a summary of the findings. This will be emailed to them in both Bislama and English. Participants will also be able to request a full copy of the thesis which will be sent in PDF form via email.

\subsection{Limitations}

While the research produced rich and diverse data it was limited by time and scope. Data collection was subject to time and finance constraints meaning interviews offered after my departure date could not be undertaken. Additional time would have enabled me to build stronger relationships with the participants and perhaps produce richer data. The scope of a Master's project also limited the research. This meant that there were only resources available to look at a single issue and to a certain extent. For example, other service providers, such as the Church in Vanuatu, were beyond the research scope. However, I believe the interviews were largely representative of the aid recipients involved in monitoring and evaluation. While it is acknowledged 
that the number of participants restricted the research, the congruence of responses indicates that the number was suitable.

\subsection{Conclusion}

This chapter has summarised the choices and challenges faced in researching within a cross-cultural context. It has illustrated the careful negotiation of epistemologies, worldviews, methodologies and methods necessary to conduct research. It has shown the synchronisation of social constructivist, feminist and indigenous epistemologies to create an appropriate methodology for the participants, the researcher and the research context. Furthermore, this chapter has stressed the importance of reflexivity and positionality, illustrating that the researcher cannot be removed from the research. 


\section{Looking In: Reflecting Internally}

\section{$\underline{4.1 \text { Introduction }}$}

This first chapter of findings presents the participants' considerations 'looking in', or reflecting on their own place within the monitoring and evaluation practice. Firstly, the chapter will look at local understandings of monitoring and evaluation. The participants' comments on areas of tension with the practice will then be presented. These are divided into two groups. The first group represents general concerns: systems, staff, communication and coordination. The second group constitutes factors unique to Vanuatu: kastom, language and land. Rather than obstacles to overcome, these context-specific features form a critique of monitoring and evaluation, arising from its inability to account for the local context and subsequently promote ownership.

\subsection{Understanding and Involvement in Monitoring and Evaluation}

$M \& E$ bifo I no bin wan subject matter we yumi consider se hemi wan important something. ${ }^{21}$ - Government Employee A

Monitoring and evaluation is a new practice to Vanuatu. While it is gaining importance, the participants recognised that it is still relatively weak and faces many challenges in the Vanuatu context. In most cases, with the exception of senior-level government employees, monitoring and evaluation was discussed primarily in terms of reporting. Reporting, the provision of information at periodic intervals (United Nations Development Programme, 2009), was the part of the monitoring and evaluation practice in which local NGOs and government employees were principally involved. While reporting is an important part of monitoring and evaluation, it does not represent the whole process.

For most participants reporting involved processes such as writing up activities, inputting numbers and completing reports to give context to projects and programmes, explaining challenges and highlights. Presenting a "most significant

\footnotetext{
21 "Monitoring and Evaluation wasn't something that we previously considered as important."
} 
story $^{22 "}$ was also important for some of the participants. While some of the reporting was done in place of monitoring, it was unclear how much monitoring was done systematically and regularly and used "to provide current advice for implementation and adapt design as needed" (Boardman, 2012). However, monitoring was viewed as a practice that needed to be done more frequently. Most participants saw a greater need for it despite its limited adoption. One participant noted,

Lo ples ia hemi wan samting we mifala I reli wik lo hem. Sam I save mekem reporting be monitoring blong hem nao hemi. Nobody seems to be monitoring. ${ }^{23}$ - NGO Employee A

Another participant referenced the decay of government buildings as an obvious example of the need for further emphasis on monitoring. This need was also seen in a recent public seminar on infrastructure maintenance in Port Vila, which stressed the need for increased maintenance, rather than new infrastructure (Dornan \& Newton Cain, 2013).

Evaluation was largely described as a donor practice. Often local employees would help facilitate evaluation but it was usually externally led. The major exception to this is the Monitoring and Evaluation Unit, which plays a larger part in Vanuatu's adoption of monitoring and evaluation. As evaluation was so strongly viewed as a donor practice, local feelings around evaluation will be elaborated on in the next chapter that explores participants' reflections 'looking out' at donors and donor processes.

Despite the fact that most participants were not involved in all monitoring and evaluation processes, the participants did have an understanding or thoughts about the overall practice. Not surprisingly, given the participants' consent to partake in the research, all participants showed a genuine interest in monitoring and evaluation and how the tool could be better used. The participants recognised and often

\footnotetext{
${ }^{22}$ The most significant story, or most significant change (MSC) is a form of participatory monitoring and evaluation whereby the stories of significant change are collected and the most significant are chosen throughout the project cycle (Davies and Dart). In speaking with participants, it often meant simply reporting a significant story from their workplace at reporting time.

23 "It is something that we are really weak in here. Some know how to report but the monitoring of it. Nobody seems to be monitoring."
} 
advocated in the interview for the need to strengthen the practice. While participants discussed its importance as a tool for the sustainability of development and longterm effectiveness of projects, financial reasons such as accounting and transparency for funding came across as the main driver for conducting monitoring and evaluation. This is confirmed by the Pacific Institute of Public Policy (2009: 18) who found that, "Monitoring and evaluation generally does not take place until and unless tied with external aid". This use of monitoring and evaluation primarily as a tool for funding is evident throughout the findings and is further commented on in the research's conclusions.

The participants faced many challenges and difficulties with monitoring and evaluation. General concerns around systems and processes, capacity, communication and coordination will be presented first.

\subsection{Systems and Processes}

The absence of robust systems and processes poses a barrier to good monitoring and evaluation practice. Given the novelty of the practice, systems and processes may not yet be prioritised or properly implemented. Their absence can be seen, for example, in irregular data collection as described in this participant's words:

It's easy enough to do but we haven't really managed to make it become a routine thing which is something I think we need to look into. We need to make sure that it's part of the daily, you know, work that we do continually and do that. We really have not got any to the monitoring and evaluation system in place that is routine. It's when we need something we go out and look for it which is not very good. Currently it's the way we do things. NGO Employee B

The lack of proper systems also meant that information would often be collected in different ways by different people, creating duplicate systems:

I was asking to see some of these documentation from the supervisory visit and he's like "Oh I don't really have any" or hasn't really kept any records and I ask him what form he's using and he pulled out 4 or 5 different ones and he's like, "I didn't like this one so I kind of created my own and it's sort 
of like". I showed him the new one that I thought had been rolled out and everyone was using and he's like "Oh, no I've never seen it" - NGO Employee $H$

A further consequence of poor systems and processes was the considerable stress at reporting time. Many participants recounted the panic of scrambling for last-minute data. Even recorded information could be inaccessible for simple reasons such as being deleted from the computer, or lost in the locked computer account of an absent staff member. For these easily avoidable reasons data would sometimes need to be collected, or recollected, close to the reporting deadline:

Yes and you're ringing people and saying this and that! It shouldn't happen because by the time you're sitting down to do your report you should have all the information and you concentrate on your report. In saying that because we have databases that the nurses use, the [other staff] have a database as well so when it's reporting time I just go into the database and collect all the. But then there are things missing so I have to chase up on this and that. NGO Employee B

\subsection{Staff Capacity}

Improved staff capacity was raised regularly as a necessity for improving monitoring and evaluation in Vanuatu. Discussions of capacity are found throughout the development literature, including the literature on monitoring and evaluation (e.g. Feinstein, 2009; Holvoet et al., 2012; Holvoet \& Renard, 2007; Lundgren \& Kennedy, 2009; Mackay, 2009). The Pacific Institute of Public Policy (2009) identified the lack of well-qualified staff, in particular with regard to monitoring and evaluation, as one of the major problems facing Vanuatu's public service. In this Vanuatu is similar to many small island countries.

While many of the participants had undertaken tertiary education abroad or had worked for many years in their roles, they recognised the need for monitoring and evaluation to be understood and used at all levels within the organisation or department, not just those in senior positions like themselves. ${ }^{24}$ However in reality,

\footnotetext{
${ }^{24}$ Most participants were at some level of management if in a larger NGO or government department.
} 
the people collecting data were often not familiar with monitoring and evaluation. This is highlighted in the following example:

Blong statem off ating hemi no bin isi. Because yumi use blong mekem wok I ko yumi no stap kaontem ol namba ia. Namba hemi no bisnis blong yumi mi wantem luk se wok I ko ahead. Hemi talem from laek yu mekem wan rod, afta public works bambae I wantem save se long saed blong M\&E I wantem se be $y u$, maintenance man lo public works, hamas distance nao yu kaveramap long wan wik blong save maintainen for instance the ring road? Hamas kilometers? Maintenace man hemi lusman ia. Even site manager blong hemi bambae I se, no mi mi silim nomo I ko. Afta while I stap silim rod I kat wan man I stap lo ples ia I mekem narawan lo ples ia, I silim I ko. But gradually mifala I stap blong developem oli kasem nao. ${ }^{25}$ - Government Employee A

This example also emphasises the common feeling that monitoring and evaluation requires is as an extra burden. This view has also been recognised by the Government (Prime Minister's Office, 2010a: 5).

Another participant shared a similar story. When collecting information for reporting from other ministries, they found that employees could be offended that questions were being asked of them:

So in terms of capacity, we find in, because you know most of the ministries are finding this as a new thing to them. You know sometimes some of them were so frustrated that you know, because we were installed in 2012? Something will take this as, "Why are you trying to ask us this question? We are doing our job!'”- Government Employee C

\footnotetext{
25 “In the beginning it wasn't easy because we were used to doing work and not counting all the numbers. Numbers weren't our business; we wanted to make sure work was being done. They would say “you make a road" but then after the public works would want to know for monitoring and evaluation, it would want to say, "You, maintenance man of the public works, how much distance have you covered in one week to be able to maintain, for instance, the ring road? How many kilometres?" The maintenance man then doesn't turn up for work. Even his site manager would say, "no, I just seal the roads". There are also men sealing roads here and another one here. But gradually we are developing their knowledge in this area. “
} 
Naturally, given the limited understanding of monitoring and evaluation overall by employees throughout an organisation or department, the participants saw upskilling and training across the board as important,

For M\&E yumi nid blong yu trainem, and yu no trainen olgeta long level antap nomo, because information flows hemi stap daon ia. Yu nid blong channeling training iko kasem olgeta long daon. Wanem nao ol basic training requirements blong yu lo ples ia? Needs blong yu blong mekem? After yu ko mekem midel reporting, after antap. Then bambae everything I klia. ${ }^{26}$ - Government Employee A

Basic training is fundamental and vital for increasing basic competence in monitoring and evaluation. This has also been highlighted by the Pacific Institute of Public Policy (2009) who found that statistics officers in the Ministry of Health did not receive reports from the provinces due to insufficient staff, training and incentives to check and enter data into the system. Reports could be delayed or not completed due to a lack of basic skills such as using the Microsoft programme properly and knowing functions such as changing the layout for printing.

Specific capacity, in terms of being able to report to a donor's preferred style was also mentioned. Employees could be good at their jobs but it was increasingly important to know how to write reports for donors:

To me I think we need, especially organisations, we need more skilled people on how to write good reports and to better monitoring with capacity building trainings so we develop to what the donors expected through the trainings that we have, we can do it. As long as you know the steps on how to do it. NGO Employee $C$

\footnotetext{
26 "For M\&E, we need to train and not just train those at the top because information flows and is located at the lower levels. You need to channel training so that it goes to everyone further down. What are the basic training requirements for you here? What are you needs to do the job? After, you focus on the middle reporting, then on top. Then everything will be clear."
} 
Many participants brought up the need for a dedicated monitoring and evaluation officer(s) to save time and relieve the workload. Dedicated monitoring and evaluation staff would have the necessary skills and also be able to be impartial:

$M \& E$ needs to be something we really need to think about because we do a whole lot of things are happening and each individual section does their own monitoring but it might be good to look at how that can be consolidated into an overall [Name of $N G O] M \& E$ framework and then educate a group of people who just does that. You know they go out. Because sometimes it's difficult for someone within the programme to be critical or to be objective about what is happening and what the challenges are? So it's good, it would be good if that happens, but we're an NGO, we don't have the luxury of people sitting around with no job, nothing to do. Nobody is lying around. NGO Employee B

However, one concern raised about up-skilling staff is that once trained they wouldn't stay within the organisation, or even within Vanuatu. One participant discussed the brain-drain which sees trained Ni-Vanuatu emigrating and leaving a capacity gap in their previous roles:

And also another thing in the capacities you can't, you know, in Vanuatu we are very limited skills people you know people who actually tend to policy analyst or monitoring and evaluation there is very few so. So if you tell everybody there for three years and then it moves on and then you lose the person. Actually some of us in PNG because now we have the Melanesian trade so now some people are going to work in Fiji so that is one of the challenges we face we get people moving on. - Government Employee C

The preceding examples have illustrated that capacity was a central concern for participants. However, they saw it as an area that could be improved through donorfunded training, especially as the monitoring and evaluation practice itself is donor induced. The role of donors in funding training will be elaborated on in the next chapter.

\section{$\underline{4.5 \text { Communication and Coordination }}$}


Coordination and communication, or lack thereof, was regularly brought up as restricting monitoring and evaluation. It was common that within an organisation or department reporting would be passed up to management and thereafter never seen again. Lack of feedback meant that it was often unclear what was done with the reporting and its place within a wider monitoring and evaluation framework. Even at management level, where reporting was given to donors directly, donors often failed to provide feedback. A common feeling about reporting is illustrated in this participant's comment:

I don't have a clear understanding of how this informations are used and people who use it. - Government Employee B

This same participant emphasised the importance of communicating feedback:

Now I'm finding that it's not just lack of reporting, it's lack of responding. It needs two ways; I mean if this is a new practice it needs the two traffic you know? You have to communicate. - Government Employee B

While poor communication and coordination was raised as an issue by some participants, others did not identify it as a concern and subsequently may not see it as a major obstacle. Moreover two government department employees illustrated strong internal coordination and communication in that that they saw their reporting and used it to compare outputs and outcomes across other provinces.

Discussion around communication extended to include the communication between NGOs and government, in particular the absence of information sharing. While this is something that has been flagged for improvement, participants did not feel significant progress has been made. It seemed that while there is an intention to share information, there is no-one able and available to take on the necessary coordination role. The Pacific Institute of Public Policy (2009) also noted the limited effectiveness to date of this focus on centralising and sharing data. Hence, NGOs and government departments produce documentation but the absence of a central collection point means that it is not available to be accessed or utilised by other parties: 
Yeah, there's a lot of information that is being collected and has been collected also in different ways, but there is no central place where you can. [Name of person] was supposed to look into setting up a central place where all, any research that is conducted in Vanuatu, all the reports go there and someone is supposed to collate it and if questions are asked they can direct them to this place. Forget it! Too difficult, it's too difficult! Too big of a job! - NGO Employee B

Government employees also identified the limited communication received from NGOs resulting in confusion around the location and work of the numerous NGOs in Vanuatu. Participants commented that it is sometimes very unclear which organisations are working within a single community:

One problem that we face here is that we also want to know what the NGOs are actually doing, because the government we actually monitoring the budget and we want to see, for example, we report to the government, what the supply department is actually doing, but we don't even know what the $N G O s$ are doing because some changes are actually installed in the water supply and we don't know! We don't have the information in that and if someone in the same area submit a project to us we won't even know! We just approve it! And even if there's a water tank install or drill, we don't even have that information. So this is the kind of situation we are facing. Government Employee C

This somewhat strained relationship between government departments and NGOs has been identified in the literature (Pacific Institute of Public Policy, 2009). The Pacific Institute of Public Policy (2009: 11) found that institutional volatility, illdefined roles and responsibilities as well as weak coordination between provincial and national levels contributes to poor coordination and harmonisation. The exception to this trend, where close coordination was mentioned in the interviews, was between some government departments, the Statistics Department and the Monitoring and Evaluation Unit. Despite the difficulties, participants were overall eager to strengthen relationships between government and NGOs. They saw it as essential for good development: 
Wan narafala samting bifo yumi ko, ating I mask at ol jejis in ol tingting mo attitude even between NGO and government. NGO and government tufala should be complementing in their activities. ${ }^{27}$ - Government Employee A

The participant continued,

Good blong coordinate ol information I kam antap. I gud tumas. ${ }^{28}$ Government Employee A

\subsection{General and Context-Specific Concerns}

Systems and processes, staff, and communication and coordination were highlighted as general challenges to monitoring and evaluation in Vanuatu. These same challenges are frequent in the literature and are experienced globally. The participants felt strongly about improving these factors.

The second group of concerns (kastom, language and land) are unique to Vanuatu. They were noted as internal aspects that collide with monitoring and evaluation. These factors constitute the Ni-Vanuatu context and highlight the inability of monitoring and evaluation to address the local setting. They will be introduced in this chapter, as they are internal factors, and will inform the critique of monitoring and evaluation in the next chapter where the participants reflect on external factors by 'looking out'.

\subsection{Kastom}

As described in the introduction ${ }^{29}$, in this research the term kastom is used as an umbrella term to represent Vanuatu's customs, cultures and traditions. Given the importance of the traditional and indigenous in kastom, it naturally collides with newly introduced foreign processes such as monitoring and evaluation. Many participants commented on this collision. Monitoring and evaluation is currently inflexible in relation to kastom:

\footnotetext{
27 "One other thing before we go, maybe there should be changes in all the thoughts and attitudes even between NGOs and government. NGOs and government should both be complementing in their activities."

28 "[It's] good to coordinate all the information so it improves. Really good."

${ }^{29}$ See section 1.3 Setting and Context: Vanuatu.
} 
And I think that's why we fail, not fail but we lack. The expectations for us to do M\&E, it's like out of the blue. The offices are landed with this sheet of paper that you have to do. It's new culture, totally. It's new practice, $\mathrm{Ni}$ Vanuatu I mean to local offices they're like, one is this an extra task for us to do? Why are we doing this? Because AusAID wants it? Oh no, I don't know where the informations are? So it's like we jump from $A B C$ and we landed on Z. - Government Employee B

The integration of new practices with kastom is not straightforward. Vanuatu is a very diverse country and kastom is unique to different communities. Participants explained how monitoring and evaluation needs to be flexible to work with different kastom in different areas:

O even for $M \& E$ from we Vanuatu hemi kat wan diverse culture, yu no save apply wan standard o wan size fits all I stap long Torres kasem. Mo aelen tu oli difren. Wanem mi tokabaot long Santo, sem message ia we yu komunicate long santo yu no tink se bambae I kam gud blong talem yu mas changem language blong yu blong sutem man we I andastand we I tekem. ${ }^{30}$ Government Employee A

Monitoring and evaluation's inability to work with kastom represents a significant shortcoming of the practice. This will constitute a main critique of donors as explored in the next chapter.

\section{$\underline{4.8 \text { Language }}$}

Notwithstanding the fact that Vanuatu's lingua franca is Bislama, most reporting and evaluations are conducted in English. While a mastery of English in Vanuatu is described by linguist Charpentier (2006) as rare, the participants proved that there are many people at senior levels with strong English language skills. However, Bislama is the only language with increasing use in Vanuatu (Charpentier, 2006).

\footnotetext{
30 "Or even for monitoring and evaluation, because Vanuatu has a diverse culture, you cannot apply one standard or one-size-fits-all from the Torres down. All the islands are different too. What I was talking about in Santo, this same message that you communicate in Santo you don't think that it can be told like that, you need to change the language to suit the person you are speaking to so he understands."
} 
The conflict between what is required for reporting and the linguistic reality is captured in this participant's comment:

We have to get every report in English. Most of the time they're in Bislama though. - NGO Employee E

It would be difficult for Ni-Vanuatu to play a strong role in the higher-level monitoring and evaluation processes without a strong command of English. Similarly, Kulwaum (undated) argues that the use of English in bureaucracies in Papua New Guinea prevents the participation of those who are not confident in using English in its written form. Writing in English could be difficult even for NiVanuatu staff that speaks English well, especially when, as participants explained, donors expect a particular type of language for reporting. To make matters more complex, French is also used for administration. One francophone participant commented on the frustrations of reporting in French only to have Anglophone readers misinterpret the information.

While Bislama was not used for reporting to donors, in some organisations Bislama could be used for reporting at lower levels within the organisation. However, it is still challenging for some to convey information, even in Bislama, in written form. $\mathrm{Ni}$-Vanuatu come from a strong oral culture where knowledge is traditionally communicated orally (Vanuatu Kaljoral Senta, 2013) and storian is very strong. NiVanuatu have a remarkable oral history and ability to recall. As a result, collecting information and recording it in written text is not always current practice:

People are still, the verbal communication in Vanuatu is still very strong. Amazing people remember the things they've done the last 12 months very well so they verbally communicate it. The keeping records written, it's getting there slowly. - Government Employee B

Accordingly, one participant found that they had significantly greater success in compiling reports through voice recordings, rather than written reports.

\subsection{Land}


The vast archipelago of rugged terrain that constitutes Vanuatu, together with poor road infrastructure, inevitably leads to major issues of accessibility. This land barrier has been identified as a challenge to other sectors such as the economy (International Labour Organization, 2009) and the court system (Forsyth, 2009). While some good roads have been built on Efate and Espiritu Santo, it is difficult to access villages off the sealed routes. Many communities are difficult to reach and access on dirt roads is extremely difficult following the frequent heavy rains. Consequently, it is very expensive to access remote areas. This results in a high cost to conduct routine monitoring and providing verification as demonstrated in this participant's example:

If I get the report from the Public Works Department and they will tell me that in the report they will say ok, in last 6 month, we actually fixed the road from this point, this point, this point, this point in South Santo. But how can I prove it? And I can't even go there because there is no money to fund my trip there and there's no money to pay for transport! So it's very costly also. You have to verify this. - Government Employee C

One participant spoke of data that needed to come into town from rural villages. Information is usually collated in Port Vila and Luganville or occasionally in provincial centres. However, without the additional funding for those living rurally, the significant distance and difficulty of travel meant that reports did not arrive or needed to wait for someone else from the rural area to be travelling to town.

The remoteness and difficulty of access also poses problems for harmonisation amongst government and NGOs. Participants commented that it is often difficult to know what projects and programmes are taking place between the plethora of NGOs and government working in remote areas. One province is currently running a project to try and map the activity of different groups working within the province to allow for better coordination.

A Pacific Institute of Public Policy (2009) report suggests that improvement and increased adoption of information communication technologies, such as mobile phones, radio, internet and television, can play a large part in lowering the disadvantages of inaccessibility. Communication, though substantially improved in 
the last five years due to a significant increase in mobile phone subscriptions (International Telecommunication Union, 2013), is still fragile.

Other suggestions for improved participation of rural areas in monitoring and evaluation include training. This can help alleviate the costs of having staff from Port Vila and Luganville travel to rural areas:

It's a challenge. So but if we have capacity in the provinces like, you know provincial government they have the office but if they have a $M \& E$ expertise there they could assist us, go there and verify information. -Government Employee C

The significance of land to $\mathrm{Ni}-\mathrm{Vanuatu}$ means it is not something that can be ignored by conducting all monitoring and evaluation in Port Vila and Luganville. To allow for people in rural areas to be counted and be able to take part in monitoring and evaluation while living in their villages, the issue of land needs to be taken into account in the monitoring and evaluation practice.

\section{$\underline{4.10 \text { Conclusion }}$}

The internal factors pertaining to monitoring and evaluation expressed in the participants' interviews can be divided into two groups: general and specific to Vanuatu. The context specific factors (kastom, language and land) offer a critique of monitoring and evaluation's ability to work within the local context. Kastom, language and land not only represent the $\mathrm{Ni}$-Vanuatu context but are anchored in $\mathrm{Ni}$ Vanuatu identity. Their inclusion is therefore critical in promoting ownership which in turn is key to successful monitoring and evaluation systems (Morra-Imas \& Rist, 2009). While the new aid agenda's focus on results management has been picked up, its rhetoric of ownership, through the inclusion of the Ni-Vanuatu context, is yet to become a reality. 


\section{Looking Out: Reflecting Externally}

\subsection{Introduction}

“Looking Out: Reflecting Externally" explores the participants' views on donor behaviour and practices associated with monitoring and evaluation. Participants discussed and critiqued the reporting formats and the frequency of reporting. They furthermore highlighted funding for capacity building, ownership issues in external evaluators, and discussed harmonisation and alignment. The preceding chapter's context-specific factors inform the critique of the donor processes in this chapter, particularly with regard to monitoring and evaluation's poor tailoring to the $\mathrm{Ni}$ Vanuatu context. Suggestions from the participants for the improvement of donor systems and practices are woven throughout the discussion and inform the themes drawn in the concluding chapter.

\subsection{Reporting Style}

\subsubsection{Indicators}

Donors are particular in how they want participants to report. In line with the aid agenda's focus on results management, participants noted donors' demand for quantitative indicators. However, many participants also had the opportunity to explain and add context to any numbers they had to submit. Indicators and targets reported on would usually link to the original proposal or agreement with donors. Deviations from the targets outlined in the proposal needed to be explained. Such rigid reporting, however, led to problems of representation where the reality of a project or programme could not be expressed through pre-established indicators. This same finding was expressed in the literature review (e.g. EURODAD, 2008). For example, a project could be highly successful but this success may be difficult to capture in quantitative indicators. One participant explains a situation where the quality of a project failed to be captured quantitatively:

So many volunteers' assignments the outcomes are not really measurable in numbers and I feel really bad that there are some volunteers that when they get to that graph you just see them deflate saying "Oh, I haven't done anything”. So I have to explain that this is just a way that [name of NGO] 
needs to be reporting, but it's all just so, I find there's just huge areas for inaccuracies in that, you know, what is a training programme? I'll have some volunteers who developed perhaps a course in food safety or something and they've done that for half a day or the equivalent by the time there's breaks etc and yet I've got a volunteer who's on Ambae who's running a training in a joinery course and the number of training completed, he hasn't finished it yet and it's a six month training course and the students will get a certificate at the end of it. And I know we include the number of days that's included but it's really difficult to actually be accurate in representing what quality of trainings and so all a bit waffly. - NGO Employee D

Indicators are often unrepresentative as they are not tailored to the Ni-Vanuatu context. Donors often put forward universal indicators that reflect global aid trends, ignoring the local context. For example, one participant commented on a gender ratio their NGO was required to submit. However, in seeking to represent the place of women in farming groups the gender ratio ignored kastom and the way that $\mathrm{Ni}$ Vanuatu live and work. It does not necessarily provide the best representation:

I think sometimes as it becomes a little bit theoretical because if one of your monitoring objectives is to identify the gender ratio for example, how would I know how many females might be part of a farmer group when in Vanuatu ownership of resources and management of resources is very much a male thing, it doesn't necessarily mean to say that the female is not involved but how do I monitor that? And therefore how do I then say which members are then part of the savings scheme when again it might be the male for the household that takes the name on the savings or loan co-op agreement. NGO Employee F

Similarly, the following government employee explains how an indicator failed to recognise that monitoring and recording information is not yet routine throughout Vanuatu, so records should not be depended on in all circumstances:

So, initially, one of the indicators was to see an improvement in the immunisation rate vaccination, you know they vaccinate kids. And they want to see the number increases. If not all Vanuatu but at least the reports are 
coming it's increasing the doctors and nurses are actually going out into the provinces. But then there is a problem with the indicator that, you know, this has not been increasing, but it's not the case because some nurses have been doing the vaccination but they have not been recording. And then it was, we thought, you know, and then we thought that ok, maybe this indicators is not good. We cannot see yeah, so we have actually changed that indicator to the rate or budget allocated to fund medical supplies. And the rate of medical supplies distribution, the distribution to the provinces, if you want to see it increasing, if we should have increasing that means that the supplies are actually going out to the provinces. - Government Employee C

However, there is a significant difference between the two previous examples. While NGOs tend to accept unrepresentative indicators, the participants working in senior government positions are able to influence the indicators. This is demonstrated by the change in indicator in the preceding quote and further reinforced by another government employee:

Samtaem ol donors oli kivim wanem ol perceived to be good indicators. But then as they come then we lukluk long graon and se ok be indicator I kud be samtaem hemi broad tumas. Maybe yumi stap addressem hemia but the grounds of the issue stap lo ples ia, then yumi mas review, save revisitem. ${ }^{31}$ Government Employee A

\subsubsection{Reporting Format}

Although some participants supported the simplicity of a formatted template, it often failed to account for complex activities and contexts. This has been noted elsewhere in the literature (e.g. Wallace et al., 2006: 118). Consequently, bound by the template and operating within an NGO with limited power to dictate the terms of reporting, one participant explained the necessity of creativity:

\footnotetext{
31 "Sometimes the donors give what are perceived to be good indicators, but then as they come we look on the ground level and say, "Ok, the indicator is good but sometimes it's too broad. Maybe we are addressing this here but the grounds of the issue are over here". Then we must review and then revisit."
} 
As someone at [name of NGO] said "Throw the logframe out and then you'll be alright", we sort of say that quietly. We're running a market project and sometimes our market projects don't fit really well to the logframe so we have to be a little bit creative and that's really the answer I would give in that within your objective of your activity within the logframe you have to actually be a bit creative about the way you answer the questions. - NGO Employee $F$

Similarly, attribution proves difficult within the reporting framework. This critique was highlighted in the global literature, whereby a web of factors, not necessarily just one project, contributes to an outcome (Koeberle, 2005). One participant discussed how NGOs feel pressured to claim the sole cause of a change. The pressure to claim attribution discourages cooperation on an informal level as NGOs need to claim outcomes for their own reporting:

I get excited about that because I think that's a really good way to do development is that we're all working together but there can be sort of a territorial thing when it comes to reporting as to who can claim it. Whereas I'm thinking you know surely you can say it's a collaborative thing but the message I get back is that [name of NGO] has to say, the pressure is on them to say what is done. - NGO Employee D

As discussed in the previous chapter, language, especially donor language, poses a challenge to reporting. Donors expect reporting to be carried out in English despite many Ni-Vanuatu not feeling confident in the language. Consequently in some cases, as seen in the following example, only a few people within the organisation (in this example, an expatriate) are able to write reports,

In cases like this that we would get people like [Name of person] come in who are, you know, understands Bislama and English and then we'll be able to put it in the language that is correct for [donors]. - NGO Employee E

One participant seeks to overcome this obstacle by encouraging staff to report through numbers, thus overcoming the writing component of reporting. 
Overall, the rigid style of reporting, employing universal indicators, fixed templates and demanding the use of English is clearly not designed for Ni-Vanuatu. Adding to this, the poor level of feedback from donors reaffirms the belief that monitoring and evaluation is a tool for donor funding, rather than as a tool from which to learn, to share successes and improve development practice in Vanuatu. The following participant summarises this feeling:

It's just going into the system to tick the box to get the money. So I do question that I mean I think some of the real output is not actually utilized properly so if you do something that's exceptional within the project, they don't have a system to cope with that. So do you expect kind of you know they talk about cut and paste logframe output, is that really all they want from their money? Or do they want something that's actually going to stand outside of the box and give people the opportunity to stand outside of the box. - NGO Employee F

\section{$\underline{5.3 \text { Frequency of Monitoring and Evaluation }}$}

Many participants critiqued the frequency of monitoring and evaluation. Problems around timings of monitoring and evaluation relate back to the original proposal made with the donor. The significant lag between submitting a proposal and beginning a project means that intentions for monitoring and evaluation can be cast into the background:

Yeah, we have the problems that we get funding for directly and we manage that's sort of ok because the proposals should have originated from us so we're supposed to know what we said we'd check up on, but again you write the proposal and sometime the time between when you write the proposal and you get the money is sometimes a bit ridiculous. So by the time you've got the money you've got no idea what you said you were going to do and the circumstances have changed - NGO Employee B

When reporting is often used as a vehicle for monitoring, it needs to be more frequent so that timely changes can be made to a project. For at least one participant 
it appears that this is the case and changes to a project need to be signalled through reports and then approved by the donor:

Not only that be taem yu mekem changes after wan year samtaem hemi kam too late blong mekem changes. Yu should have made the change maybe six months ago, be naoia yu leko I kam kasem one yia I stap kam too late now. ${ }^{32}$ - NGO Employee A

On the other hand, some participants found donors had unrealistically high expectations about what could be achieved and reported back within a defined period. For example, when results lag participants find it particularly difficult to report required outcomes from one phase in order to receive funding for the next:

They're like they give their funds in phases, like phase one, phase two, and maybe funding the phase one you will see that in phase two there's some results from phase one that has been overlooked or something. Sometime you have a report for one year and it's hard to get the most significant changes straight away. - NGO Employee E

Local NGOs mentioned this same concern in the Wallace et al. (2006) study in Uganda and South Africa: it was difficult to report on change within a period that was not long enough for change to have occurred. Accordingly, the following participant thought the timings of evaluations need to match the expectations of the impacts. For example, if a programme aimed to change attitudes, indicators to measure this change would not be evident or available immediately.

And some sections, [government department name] for instance you know, often a lot of donors funding has phase 1, has phase 2, 10, 5 years the project ends. For me to evaluate [sector of work] when you want to change people's approach to [sector of work] attitude behaviour, that's silly! You can't do that in five months phase project! You know? So to me in a way we're not, if that's an expectation, that's not realistic. Maybe give it, I don't know, they

\footnotetext{
32 "Not only that but when you make changes after one year, sometimes it comes too late to make changes. You should have made the change maybe six months ago, but now you've left it one year, it's too late now."
} 
have to find ways to come back twenty years later. - Government Employee $B$

The scheduling of evaluations and reviews was also important to the participants, as it required a large amount of their time. One participant felt that their NGO was targeted for reviews as a result of the good work they were doing and therefore donors would continuously review and evaluate their work to demonstrate effective aid spending to taxpayers. Consequently, staff at this NGO was disproportionately engaged in evaluations and reviews compared to other NGOs:

If an evaluation happens every two to three years that's ok. I think that shouldn't be too bad if it's a manageable thing and it makes sense to do an evaluation because it's the only way you can find out information that you can then use to build your programme, but it's not very productive to do it too often and if an evaluation is going to be done for the clinic, that one evaluation should be enough for everybody to, you know, get their information from. I don't think it's fair on the organisation or on the people for different groups and different donors to be wanting, you know this one is ok but we want this kind of information. It's very, it can be very painful. NGO Employee B

The participant continued,

In the last five years, probably five or more. And so we get reviewed quite a lot. I don't know why but I guess it's because we do the work and so it's one way for the donors to show their money is being, we've done. -NGO Employee B

\subsection{Donors to Fund Training}

Training was seen as an important way that donors can support participants in overcoming challenges in monitoring and evaluation. Training would allow more people locally to be involved in the process, rather than outsiders coming in to complete the work, and therefore increase local ownership: 
That's why, coming back to your question about donors, how they're providing assistance I think the basic, for now is proper training local staff. I mean the stretch of the government is pretty good, I've never been in the government but if you're in the government you are a public servant, serve here, you staff in the system, that's good, train that person. The advisors who come and go that nothing personal evolves. Train, the more training the better. I know M\&E is new, as I say, new culture, so don't jump to you know, "Do this, do this", just provide training first you know? Have people on the right track. - Government Employee B

The participant stressed the need for skills to be passed on to local staff, rather than consultants who may carry out the work without sharing any knowledge with others. The participant also emphasised the need for basic training, as identified in the previous chapter:

That's a lot of training I mean AusAID is doing, I've attended a couple but specifically more on analytic reporting which is fantastic but I can access say you're going too advanced reporting but how do we collect that information at the start? - Government Employee B

Financially, participants saw monitoring and evaluation training as the donor's responsibility:

Hemia nao olsem ${ }^{33}$, for donors to fund the project then they have to look at whoever but have some money for capacity building the staff.- NGO Employee E

Another participant agreed:

Yeah, if they're serious about, if they want it to happen then they should fund it. But they say well you haven't put it in the budget? You gave us a thing and we don't want [we'd rather put our money] into the activities than checking up for what you want to know, you should pay for that! - NGO Employee B

\footnotetext{
33 "That's it, like"
} 
Wallace et al. (2006) found that there was limited financial support for monitoring and evaluation, yet donors were increasing their demands for monitoring and evaluation. The participants in this research understood that monitoring and evaluation was important and a necessity, but they needed support to build capacity in this area.

\subsection{External Consultants and Reviewers}

Evaluations and reviews constitute a large share of participants' face-to-face interaction with donors. Consequently, a significant proportion of the conversation with participants around donors focused on external consultants and reviewers. Most participants discussed evaluations and reviews as something that was externally driven and conducted.

However, participants were very clear that the involvement of a local person was fundamental for a review or evaluation's success. Moreover, many participants considered it important to involve someone from the participating organisation or department in the running of the evaluation. One government employee even extended the necessary local involvement to a government and CSO employee. One participant explained how reviews or evaluations were carried out at their NGO, with the involvement of a staff member:

I think most of the reviews that come to [Name of NGO] have been, you know, working with [Name of NGO] and have a background of what [Name of NGO] is doing and kind of understand the situation in [location of NGO] and [Location of NGO] and then they walk around with some other good staff like [Staff member name] or [Staff member name] that helps take the information out from the staff that they inform. - NGO Employee E

It was acknowledged that involving someone from the organisation or department could lead to a conflict of interest, but involving staff was seen as necessary given their invaluable understanding of the organisation:

I think it's better and then it's better because then they'll know the situation and I dunno whether the information given it's you know, not conflict of 
interest and everything but it's honestly reporting on what's on the ground. NGO Employee E

Wallace et al. (2006: 113) describe donors' concern for objectivity in evaluations as leading to external evaluators who "often lack skills and understanding of local context". It was clear that a balance between objectivity and local ownership, between donor and recipients' needs must be found. Some areas of government are beginning to demand this ownership by requesting their own inclusion in evaluations; they are now being invited by donors to be part of evaluations. When their request for inclusion is declined, they assert ownership by going through subsequent reports and questioning any inconsistencies:

It's getting, I think in the past five years I think government has been emphasising has been telling donors that you guys if you want to evaluation you have to involve the local counterparts. But in some instances they don't involve us. I know for some projects, some programmes we are not part of, they just and then they present the findings to us. Say this is what we find out. And then we start asking questions! - Government Employee C

\subsubsection{Kastom}

Respecting kastom is important for effective communication and appropriate collection of information, hence, fundamental to a successful evaluation or review. Kastom stresses the need for locals to be significantly involved in evaluations, ideally leading them. Giving consideration to kastom in evaluation has the potential to increase ownership of the process. In turn, increasing ownership has the potential for even greater recognition of kastom in the monitoring and evaluation practice.

Kastom dictates the best methods to use in conducting an evaluation. These methods will vary between islands and villages. Sometimes simply involving a Ni-Vanuatu will not be enough, rather someone native to the area is needed, a man ples ${ }^{34}$. The role of kastom in dictating the best approaches and ways to communicate with communities was frequently pointed to. The participants stressed the importance of

\footnotetext{
${ }^{34}$ A local person
} 
the review/evaluation team's ability to understand the kastom of communities and the people they would be talking to:

Taem bifo yu ko yu mas save wanem nao culture blong olgeta, hao nao yu approachem ol man. Fasion blong toktok, sam taem yumi toktok strong. Yumi toktok strong se "Yu mas mekem!” Yu toktok strong hemia I no save mekem. Be sapos culture I se bae yu toktok slo I stap sakem sloslo I ko be hemia I stap harem ia, hem bae I mekem today. Be sapos yu luk hem yu toktok strong hem I no kat taem. ${ }^{35}$ - Government Employee A

Hence, foreigners conducting evaluations and reviews should familiarize themselves with the kastom of where they are carrying out their work to try and make the people they are interviewing more comfortable. Another participant gives a similar example:

Be ating sapos man we hemi kam blong review I mas save lelebit ol wei blong Melanesian people, hemi mas save gud olgeta lelebit before hemi kam blong review blong mekem se oli filim fri blong kivin ol gud information. Samtaem oli no kivim gud information nomo from maet oli fraed o no lisen o samting olsem. ${ }^{36}$ - NGO Employee $G$

However, there is no substitute for a local person. One participant explained that communities feel more comfortable when approached for an evaluation by someone who not only knows their kastom but also physically looks like them:

And then mekem se mifala I mekem review, culture blong yumi hemi very important so mi mas helpem donor blong save about sensitivity blong culture blong yumi. Mekem se taem we mifala I ko long wan community olsem sam

\footnotetext{
35 "Before you go you must know what their culture is, how to approach these people. Style of speaking, sometimes we speak strongly. We speak strongly saying "You must do it!" You talk strongly this person will not do it. But if the culture says you speak slowly, you deliver [the words] slowly, then this person will hear it and he will do it today. But if you look at him and speak strongly, he won't bother."

36 "But maybe if the man who comes to review he must know a little about the way of Melanesian people, he must know them well before he comes to make his review so they can feel free to give good information. Sometimes they don't give good information because they might be afraid or not listen or something like that."
} 
taem yu se people bambae save be open sapos oli luk appearance blong yu hemi klosap semak blong olgeta. ${ }^{37}$ - Government Employee A

\subsubsection{Language}

Language is another fundamental reason to involve local people. Language is strongly linked to kastom; it is one expression of kastom (Ligo, 1980). Language poses problems for external evaluators and communities alike. The participants highlighted the importance of carrying out any interviews in Bislama, or the language in which people interviewed feel comfortable to express themselves. Often people could not express themselves in English:

The time they come in every review and all this. It's good, it's good but they get the consultants all in English and sometimes they get someone to, you know, all the staff together, tok tok, might there's a chance later but the staff cannot really express themselves. - NGO Employee E

Communication in the community's tongue allows evaluators to present themselves and suitably explain their reason for conducting interviews. However when interviews are conducted in English, communities find it difficult to express themselves properly and do not fully understand where the evaluator is from and his or her reason for being there. Conducting interviews in English poses a barrier to community views being heard. This NGO employee explained how people often feel towards the evaluators:

Some but not all of them. There's always this. I don't know, it's like they all shut in their, all you know, mind and everything cannot really explain.

Unless they understand what's raised, where the reviewer is coming from.NGO Employee E

Another participant confirmed this:

\footnotetext{
37 “And then we review, culture is very important so I must help the donor know about the sensitivities of our culture. Therefore when we go to a community like sometimes people will be open if they see your appearance is quite similar to theirs."
} 
Hemia lo saed lo research olsem o hemia we oli kam review ia ol man blong review ia olsem se I gud blo wan we hemi review hemi toktok bislama hemi mas traem I understandam language blong ples long hia because samtimes sam information we I save gud be oli no save hao blong oli kivim stret tingting ia long wan man we I shud be. I mekem se sam taem oli fraed from oli no save toktok English, o oli fraed long man we I kam ia. ${ }^{38}-\mathrm{NGO}$ Employee $G$

\subsubsection{Ownership}

While an awareness of kastom and language, as well as involving a local person in evaluations and reviews is critical, it is also important for the NGO or government department to have a say on the person who is conducting the review. The ability to veto is an important step towards greater ownership. Government appeared to have a greater say on who is included in evaluations as well as the ability to demand the inclusion of Ni-Vanuatu. However one NGO participant indicated that saying 'no' to a donor would be an option. This participant explained:

I think depending on who is paying for it. Sometimes we have say who gets selected for some I think AusAID and NZAID funded reviews, we have the same who was selected so, other people who applied, we'd say no. And part of it is that we didn't really know somebody who had no idea, we actually had a bad experience with one of the consultants who came, who was recruited by a regional organisation and knew nothing about us and came and attended one play and wrote this really awful thing that took us a while to sift through and back and forth kind of thing, but yeah, we generally have, are able to say no. - NGO Employee B

\footnotetext{
38 "That's with regard to research, like, when they come and review here, all the people who do reviews, like it would be good if one who reviews speaks Bislama. He must try to understand the language of this place, because sometimes some information which can be good they don't know how to give their straight thoughts to this man. It makes it that sometimes they are afraid because they cannot speak English, or they are afraid of this man who comes."
} 


\subsubsection{Increases in Ownership of Evaluations and Reviews}

In order to summarise the thoughts and comments of participants with regard to evaluations and reviews, a figure has been drawn to illustrate the different degrees of ownership that their comments represent. Figure 1 maps the participants' suggestions about external evaluations and reviews and ranks them as to how much ownership they promote, their ability to incorporate kastom and their risk to objectivity. Different NGOs and government departments sit at different levels of the table, or may even sit at multiple levels. As discussed by one of the participants (and brought up as a donor concern by Wallace et al. (2006)), external evaluators may bring higher objectivity, so increased ownership by local NGOs and government of evaluations risks the loss of objectivity.

While ownership increases for the NGO or government department as they climb higher up the table, overall ownership of programmes and projects for recipients may not necessarily increase as there is a possibility for corruption to increase. In other words, ownership does not increase if only those in senior positions make decisions that do not represent others (Buiter, 2007). Movement up the table, however, can be seen as increase in ownership when viewing ownership as a relative term (EURODAD, 2001: 3) whereby ownership increases with movement away from the previous context and the application of processes by outsiders.

Finally, movement up the table increases the potential for kastom to be included in the evaluations or reviews. With greater involvement of Ni-Vanuatu, kastom and language can better direct the process. However whether they would be better incorporated in practice would fall to the implementers. 


\begin{tabular}{|c|c|c|c|}
\hline \multirow{6}{*}{ 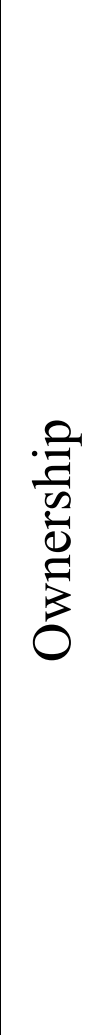 } & \multirow{6}{*}{ 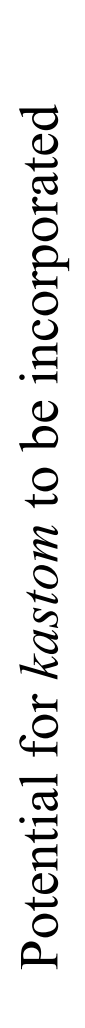 } & \multirow{6}{*}{ 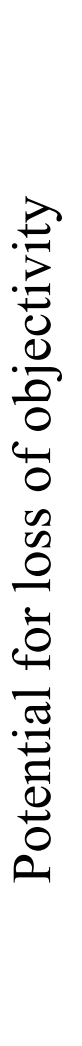 } & Ni-Vanuatu lead evaluations and reviews \\
\hline & & & $\begin{array}{l}\mathrm{Ni}-\text { Vanuatu included in evaluations and } \\
\text { reviews (higher ownership if selected by Ni- } \\
\text { Vanuatu) }\end{array}$ \\
\hline & & & $\begin{array}{l}\text { Government department or NGO can veto } \\
\text { reviewer/evaluator selected by donor }\end{array}$ \\
\hline & & & $\begin{array}{c}\text { Evaluator/reviewer has extensive knowledge } \\
\text { of Ni-Vanuatu kastom and Bislama }\end{array}$ \\
\hline & & & $\begin{array}{c}\text { Evaluator/reviewer has some knowledge of } \\
\text { Ni-Vanuatu kastom and Bislama }\end{array}$ \\
\hline & & & $\begin{array}{c}\text { Evaluator/reviewer has no knowledge of Ni- } \\
\text { Vanuatu kastom and Bislama }\end{array}$ \\
\hline
\end{tabular}

Fiqure 1: Increases in ownership of evaluations and reviews

\subsection{Harmonisation}

Harmonisation is central to the Paris Declaration (2005) and represents a major donor commitment within the agreement. Nevertheless, the participants found that donors were not harmonising and loaded participants with heavy monitoring and evaluation burdens. Consequently, the participants undertook a plethora of reporting for donors as donors regularly requested different information to be presented in unique formats. This situation even occurred when multiple donors were funding the same project. Understandably the participants found this difficult. If reported information was shared between donors the number of different processes undertaken for monitoring and evaluation could be reduced and subsequently relieve staff of unnecessary duplication.

The following government employee explains the current situation with multiple funders and multiple requirements: 
Oli kat difren kaen requirements but sem taem oli mas kam blong luk save se wanem nao hemi, wanem mifala, oli mas kam blong consideram that while we have multiple fund donors we have different requirements. We must be mindful se beneficiary blong yumi hemi kat limited resources. Filling different forms, adapting to different modalities, hemi no reli helpem mifala tumas. And you wantem usem se this $M \& E$ modality yu save then complitem lo other activities, other projects, lessons learnt from place ia yumi save expandem I ko long sam narafala. ${ }^{39}$ - Government Employee A

This same challenge was illustrated by Wallace et al. (2006: 113), where problems with multiple donors and multiple requirements could mean "major problems of multiple accounting and writing myriad reports". The difficulty and stress that a lack of harmonisation causes is highlighted in this participant's comment:

Hemi had. And especially lo mifala lo ples ia we mifala I lukaotem ol major infrastructure projects, samtaem bae I had if yumi kat wan $M \& E$ officer nomo. He mas mekem blong hemia blong mitim, after project ia I nidim se I mekem hemia, project ia hemi nidim hemia, and then inside lo project ia I kat multiple funders, multiple donors, head blong hemi fasfas bambae I ko kranke nao! ${ }^{40}$ - Government Employee A

The differences in reporting requirements for different donors were so significant that participants could compare the level of difficulty of reporting between donors. For example the following participants commented on the different levels of reporting requirements for different donors:

\footnotetext{
39 "They have different requirements but sometimes they must come to know that what it is, what we, they must come to consider that while we have multiple fund donors we have different requirements, we must be mindful that our beneficiary has limited resources. Filling different forms, adapting to different modalities is not really too helpful. And you want to use this M\&E modality, you can the complete for other activities, other projects, lessons learnt from this place we can expand to go to some other ones."

40 "It's hard. And especially for us here who look after all the major infrastructure projects. Sometimes it will be hard if we just have one M\&E officer. He has to do this for the meeting, and then this project here needs him to do this, this project needs him to do this, and then in this project there are multiple funders, multiple donors, his head will get confused then he will go crazy!"
} 
$O x \mathrm{Om}^{41}$ has a, some very specific question and their questions for $M \& E$ are always, you know, they always come back to us and really want us to prove that this has been the changes, and these are the changes. - NGO Employee E

Hemi isi lo sense that EU hemi talem wanem stret hemi requirem. Mi wok lo wan project bifo blong olgeta blong UN oli fundem, hemi no kam putum template so yu jas ko in write anything you want and hemi save kam out wan bifala. $^{42}-N G O$ Employee $A$

Globally, DAC donors are performing poorly in their attempt to harmonise (see performance in indicator 10a and 10b of the Paris Declaration (OECD, 2011a)). However, in Vanuatu donors were closer to their target in joint analytical work including evaluations (OECD, 2011c). In practice participants did not see donors prioritising harmonisation for reporting requirements:

Sector olsem M\&E yumi tokabaot donor, planti taem yumi tok abaot donor coordination but what hemi min? Sam taem I fasfas lelebit because sam taem samfala I no wantem to be coordinated too. ${ }^{43}$ - Government Employee A

In response, government departments are using ownership as a tool to harmonise donors on monitoring and evaluation. By compelling donors to align with local reporting they can stop the duplication of information:

They also have their different kind of, you know they have the expectations from the, different kind of reporting, format they want, but what we've been doing is that now, we've actually convinced them that we will only report to every one of you, we are going to produce only one report. So now everyone is accepting the report, the only report. - Government Employee C

\footnotetext{
${ }^{41}$ Oxfam here was funding a project, this is not the name of the participant's workplace.

42 "It's easy in the sense that the EU says exactly what it requires. I worked on one project before which the UN funded, they didn't give us a template so you just go and write anything you want and it can come out as a very big (report)."

43 "Sectors such as M\&E, we talk about donors, often we talk about donor coordination but what does it mean? Sometimes it's a bit confusing because sometimes some don't want to be coordinated too."
} 
This type of alignment was only evident in government, there was no such evidence from NGO participants. The preceding example showed government pushing alignment in reporting. Alignment in data collection for evaluations is also increasing. Despite the fact that evaluations are still largely conducted by donors, donors are beginning to accept government data:

Yeah, take the information we are actually providing them. And this happens, the same thing happens with AusAID now they actually came this morning, this afternoon they just came and they wanted to validate the data and the sources of information that I gave them last three days. So, basically they're actually using, they're actually trusting us with this information.Government Employee C

However the overall level of alignment was limited, confirming what is found in the global literature: donors have been slow to align with recipient countries' monitoring and evaluation systems (OECD/DAC as cited in Holvoet et al., 2012).

\section{$\underline{5.7 \text { Conclusion }}$}

The significant feedback from participants on donor behaviour and practice was overall consistent. The participants found the donor style of reporting difficult and inflexible to the local context, particularly kastom and language. This same critique applied to evaluators. The burden of the monitoring and evaluation processes, together with the lack of harmonisation from donors, undermines ownership. However, NGOs and government are slowly finding ways to assert more control over processes. This can be seen in small but significant ways such as government's influence on indicators, the NGO that can veto evaluators, the government's push for alignment and furthermore the ability of all the participants to reflect and critique the process.

While NGOs and government differed considerably in the levels of power they exercised in their relationships with donors, they each had similar concerns regarding donor practice. Namely, it is important that the local context is included, local participation increases and donors are receptive and encouraging of this. 


\section{Conclusions}

\section{$\underline{6.1 \text { Summary of Findings }}$}

This research sought to understand the place of ownership in monitoring and evaluation in Vanuatu. It explored and examined the monitoring and evaluation experience of NGO and government department employees involved in the practice. Subsequently an understanding of some of the factors affecting ownership of monitoring and evaluation has begun to be unravelled and recommendations for improving ownership can be made in this chapter.

The thesis began with a review of the literature that placed the research within a neostructural paradigm highly influenced by neoliberalism. Neostructuralism's push for ownership echoed in documents such as the Paris Declaration was explored and discussed. Ownership's increasing popularity, despite its vague definition, was highlighted. The literature also looked at neostructuralism's focus on accountability and results management that advocates for the increased application of monitoring and evaluation. However, research has shown that at present ownership is not strongly reflected in the practice. Looking closer into the geographical context of the research within Vanuatu and the Pacific, the literature showed that neoliberalism's presence is still evident through the reform packages accepted by many Pacific Island nations including Vanuatu. The neostructural agenda has also been adopted. Vanuatu has recognised the move to results management and has established a Monitoring and Evaluation Unit. However, the extent to which the neostructural focus on ownership is apparent within monitoring and evaluation in Vanuatu leaves a gap to which this research can contribute.

The research was influenced by social constructivism together with indigenous and feminist epistemologies. These epistemologies contributed to the use of semistructured interviews and the employment of constant reflexivity. In recognising the need to incorporate indigenous approaches, the research used a storian approach and interviews were conducted in Bislama where appropriate. Ethics remained a constant concern and all aspects of the methodology reflected on the need to operate ethically. 
The field research was conducted in Port Vila and Luganville, the two main urban centres of Vanuatu. Eighteen participants were recruited largely through email contact from personal connections or through the recommendations of others. Although set questions were written for the interviews the conversation often steered away from these and the most valuable insights came from asking " $y u$ kat eni narafala tingting blong yu?" or "do you have anything else you would like to say?" The data from the interviews was personally transcribed, analysed and coded allowing a closer relationship and understanding of the participants' comments.

The findings were presented over two chapters. The first chapter, "Looking In: Reflecting Internally" examined the participants' concerns and ideas regarding their own undertaking of monitoring and evaluation. They discussed general concerns centring on systems, staff capacity and communication and context-specific concerns addressing the discord between monitoring and evaluation and kastom, language and land. The second chapter, "Looking Out: Reflecting Externally" focused on the participants' thoughts about the donor behaviour and systems. These two findings chapters will be analysed, leading to the discussion of three themes: relationship, flexibility and ownership.

\subsubsection{Looking In: Reflecting Internally}

Monitoring and evaluation is a new practice to Vanuatu. Reporting was the main part of the monitoring and evaluation practice in which the participants were involved. Monitoring was occasionally discussed as a part of reporting and many participants noted that monitoring needed to be improved. Evaluation, on the other hand, was seen as a donor process. However, participants were concerned about the entire practice and subsequently results presented explore beyond reporting requirements.

Participants reflected on their own use of monitoring and evaluation and noted two main groups of tensions with the practice. Firstly, there were general barriers to monitoring and evaluation that are reflected widely in the development literature: weak systems and processes, limited staff capacity and poor coordination and communications both between and within government and NGOs. Limited staff capacity and weak systems and processes arise partly because of the novelty of the practice. The lack of harmonisation and coordination between and within 
government and NGOs meant that there was lost opportunity for sharing of data and skills, as well as for improving the processes between themselves. This is an area the participants had previously flagged as needing work. It is paramount that these general barriers are addressed as they are interconnected. Weakness in one area can affect another. Similarly, a strengthening of capacity, processes and skills in one area can have a flow-on effect in strengthening the whole group of factors.

Kastom, language and land constitute the second group of tensions identified by the participants. The participants noted the disharmony between these factors and monitoring and evaluation. Kastom, representing Ni-Vanuatu customs, culture and tradition, plays a very important part in the lives and identity of Ni-Vanuatu. It is ever present and dictates the Ni-Vanuatu way of life. Participants commented on the discord between the new practice of monitoring and evaluation and Ni-Vanuatu kastom. They furthermore noted the difficulty of a universal approach to monitoring and evaluation in Vanuatu when kastom differs considerably within the country. Vanuatu's unique linguistic situation, as one of the most linguistically diverse countries in the world, also poses difficulties for monitoring and evaluation. While many Ni-Vanuatu speak multiple languages, English may not be one of them. It can be challenging for Ni-Vanuatu to lead or participate in monitoring and evaluation, usually conducted in English, when the practice does not allow for their mother tongues. Finally, the Ni-Vanuatu geography influences the practice of monitoring and evaluation. An archipelago of diverse geography coupled with poor access means that processes have to be tailored to the difficulties inherent in the land. Many communities are excluded from the practice as they are difficult to reach, living in villages accessible via dirt roads difficult to use after the frequent, heavy rains.

While kastom, language and land are by no means an exhaustive list of Vanuatu's distinguishing features, they were those most discussed when considering monitoring and evaluation in Vanuatu. Kastom, language and land have earlier been described as fundamental to Ni-Vanuatu identity and therefore essential in defining $\mathrm{Ni}$-Vanuatu ownership. It is imperative that these factors are addressed not as barriers to overcome but as tools to shape monitoring and evaluation so the practice fits the Ni-Vanuatu context. These factors therefore are critical in supporting Ni- 
Vanuatu ownership of the monitoring and evaluation practice and any new process that is introduced to Vanuatu.

When 'looking in', the data resulting from interviews with NGOs and government departments was congruent. NGO and government participants reported similar concerns and thoughts regarding internal factors affecting monitoring and evaluation.

\subsubsection{Looking Out: Reflecting Externally}

The findings discussed in the "Looking Out: Reflecting Externally" chapter highlighted the challenges participants faced working with donors and using donor monitoring and evaluation systems. The necessity for donors and donor practices to better adapt to the local context, including respect for Vanuatu's kastom, language and land, underlay most of the concerns that participants raised. Similarly, these factors constituted a main critique of Vanuatu's CRP as illustrated in the literature (Gay, 2014). These context-specific concerns were evident in reporting formats, indicators, evaluations and donor harmonisation. The participants also pointed out that donors have a part to play in providing and funding training to improve capacity in Vanuatu.

The reporting that donors demand is often very rigid and requires a strong command of written English. Reporting is largely quantitative, but sometimes indicators provided by donors are not very representative of a situation on the ground. Only some participants felt they are in a position to contest indicators if they disagree with them. Frequency of reporting was also discussed. Participants often find reporting to be either too frequent in that it does not allow enough time for change to take place and the results reported on, or too infrequent so that challenges that arise cannot be reported in a timely enough manner to enable change. The reporting problems discussed indicated that monitoring and evaluation was not sufficiently tailored to the Ni-Vanuatu context to be used effectively.

Participants reported they are eager to use monitoring and evaluation as a longerterm tool for sustainability. However, at present they see it used primarily as a tool to meet donor accountability requirements and linked to past or future funding 
conditions. In essence monitoring and evaluation is approached narrowly in its place within the project cycle and is exercised in limited, project-bounded time frames. Unfortunately it is not exercised in the way in which participants saw its best value: as an overarching, holistic approach to inform development and improve overall sustainability.

Much discussion emerged about how evaluations could be improved. Evaluations are currently a donor-driven part of the monitoring and evaluation practice and local ownership is very low. Recommendations to improve the process varied, ranging from evaluators needing a better understanding of Melanesian culture, to the requirement of a local person being part of the evaluation, through to a local person leading it. The recommendations emphasised the need for evaluations to be conducted in a culturally appropriate manner. The boldness of the recommendations from the different participants reflected the varying degrees of ownership they exercised. Participants working for NGOs made suggestions indicating lower levels of ownership, such as the need for the evaluators to understand Melanesian culture. However, larger NGOs demonstrated the ability to make stronger recommendations. The government departments' push for greater involvement and leading of the process reflected their overall increased level of ownership and greater power in relationships with donors compared to NGOs.

While donors were close to their target in joint analytical work as measured against the Paris Declaration in Vanuatu (OECD, 2011c), in practice it did not appear that the principle of harmonisation is being played out in monitoring and evaluation. As a result, participants struggle with the heavy burden of fulfilling multiple requirements for donors. Some areas of government are using alignment as a tool to combat this. By pushing for donors to use their reporting, they force donors to harmonise by refusing to bow to multiple reporting requirements. Despite this example of alignment, overall alignment also appeared weak (confirmed by its poor performance in its Paris Declaration Assessment (OECD, 2011c)), despite this being a fundamental step in increasing local ownership.

Government and NGOs differed considerably in their relationships with donors and their ability to influence monitoring and evaluation processes. Government has gained stronger ownership and plays a much larger part in monitoring and 
evaluation. Its increased focus on the practice is seen in the literature through the creation of the Monitoring and Evaluation Unit and the Monitoring and Evaluation Policy (Prime Minister's Office, 2010a). Government departments also demonstrate greater power than NGOs in their relationship with donors. NGOs do not have such an influence on processes and are therefore more bound by donor demands. Their dependence on reporting to gain funding in the often-volatile funding situations of NGOs would undoubtedly be a factor contributing to this. This same behaviour by NGOs has been seen in the literature (e.g. Wallace et al., 2006). Larger, more established NGOs appeared to have more of a say, although not yet to the same extent as government. Interestingly, this finding illustrates the success of neostructuralism in building up the state. It furthermore marks the move away from neoliberalism's focus on NGOs as shown by the lower ownership demonstrated by NGO participants.

Despite the different types of relationships that government and NGOs have with donors, the two sectors offered the same overall critique of donors and their processes. Similar to the first findings chapter, the second findings chapter showed that government and NGOs were principally concerned with donors' inability to tailor their processes to the Ni-Vanuatu context. Government and NGOs advocated for increased involvement of local people in order to increase ownership and effectiveness of monitoring and evaluation.

\subsubsection{Looking In and Looking Out}

The two findings chapters highlighted concerns with monitoring and evaluation and ownership of the practice. These concerns are listed below in Figure 2. They illustrate that neostructuralism is struggling with enforcing multiple agendas. While results management is being pushed through monitoring and evaluation, the limited local participation in the practice, capacity issues, poor tailoring of the practice to the local context and the commonly held view that the practice is an extra burden for staff (Prime Minister's Office, 2010a: 5) do not illustrate a promotion of ownership. Moreover, the findings of this research could indicate that increased monitoring and evaluation requirements are creating an 'inverse sovereignty effect' (Murray \& Overton, 2011a) in Vanuatu whereby monitoring and evaluation is undermining sovereignty by increasing bureaucratic burdens. 
Internal concerns

- Staff capacity

- Communication and coordination

- Systems and processes

- Kastom

- Physical barriers

- Language

\section{Concerns regarding donors}

- Reporting style

- Frequency of reporting

- Funding of monitoring and evaluation training

- External evaluators/reviewers

- Harmonisation and alignment

\section{Figure 2: Participants' concerns}

The findings presented have uncovered the first part of the aim of the thesis: the place of ownership in monitoring and evaluation in Vanuatu. These findings will now be further explored in order to investigate the second part of the aim: how ownership in monitoring and evaluation can increase.

\subsection{Themes}

The need for kastom, language and land to inform monitoring and evaluation is highlighted in the first chapter of findings "Looking In: Reflecting Internally" and woven throughout the responses of the participants in the second chapter of findings "Looking Out: Reflecting Externally". The importance of these local factors, reflecting the identity of Ni-Vanuatu, highlights the critical importance of the local context in increasing ownership. The findings lead to recommendations for a focus on relationships and flexibility viewed through a local lens to bring about an increase in ownership of monitoring and evaluation. A local lens would ensure a tailored approach to monitoring and evaluation, allowing for higher ownership and sustainability (Lundgren \& Kennedy, 2009). Figure 3 conceptualises the main themes of this research to be further explored: relationships, flexibility and ownership. The local context, including kastom, language and land, informs the local 
lens through which these themes will be considered. The two themes of relationships and flexibility contribute to the increase of the third theme: ownership.

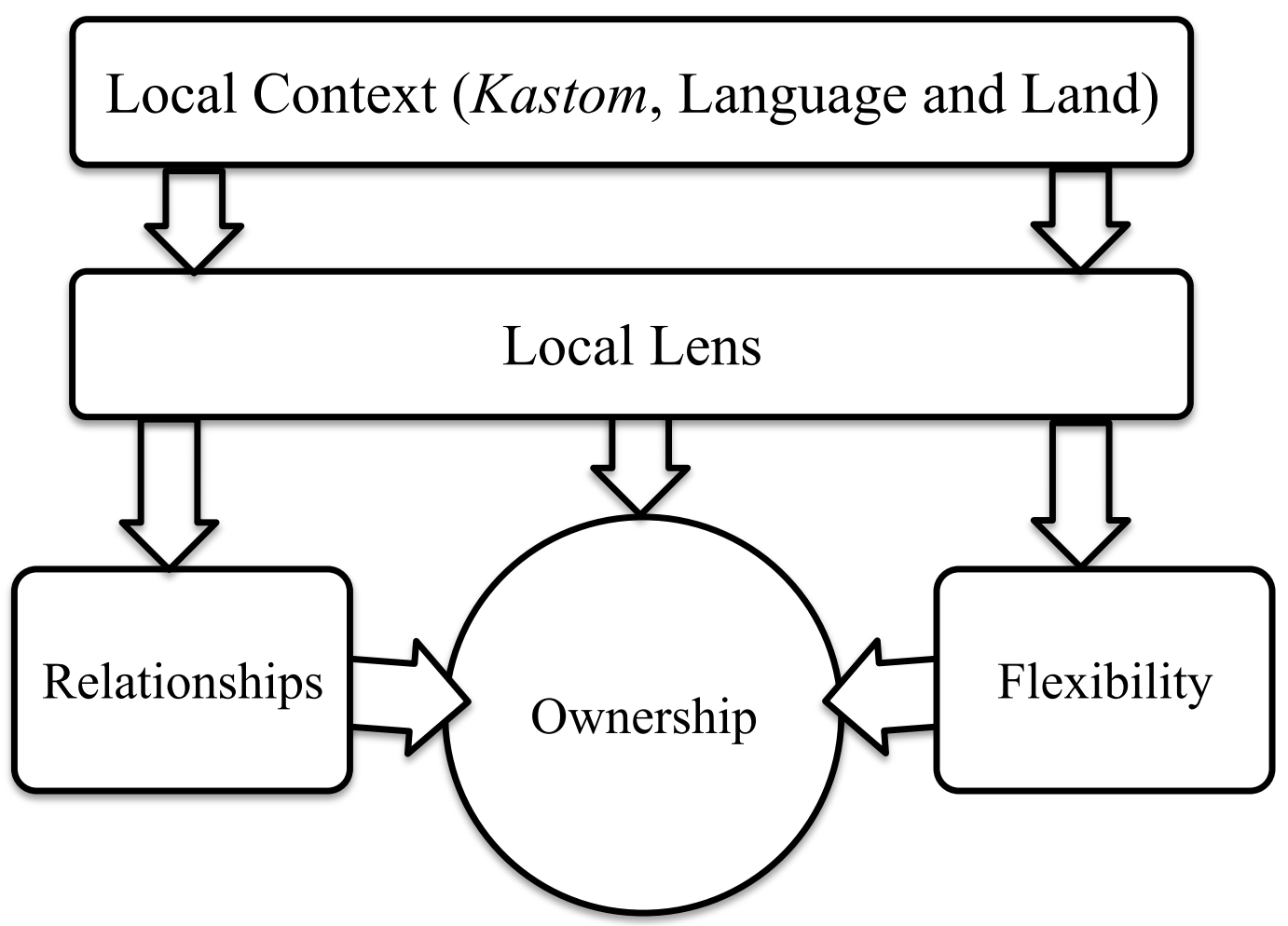

Figure 3: The role of local context and local lens in influencing themes of relationships, flexibility and ownership

Figure 4 further conceptualises the themes of this research. It shows how the themes are used to increase ownership of monitoring and evaluation. It identifies the local lens as the fundamental first step that is continuous and through which all stages of the process are viewed. As seen in Figure 3, the local lens reflects the local context. Following this, an emphasis on relationships and flexibility enables donors to be better aware of ownership issues, for balances of power to be examined and for NGOs and government to more effectively advocate their needs. Finally, once local approaches have begun to be developed and NGOs and government are able to claim their needs and direct processes with donors, capacity issues can be addressed. Capacity building is the final step as the capacity needs of Ni-Vanuatu need to be reassessed under a Ni-Vanuatu monitoring and evaluation framework. Training based around donor systems that disregard the local context could simply result in 
the promotion of donor-mirrored practices and systems. It would mean training in those same processes that have been critiqued in this thesis. Moreover, it would cause Ni-Vanuatu to change their behaviour for external systems, rather than the systems changing to fit $\mathrm{Ni}-$ Vanuatu.

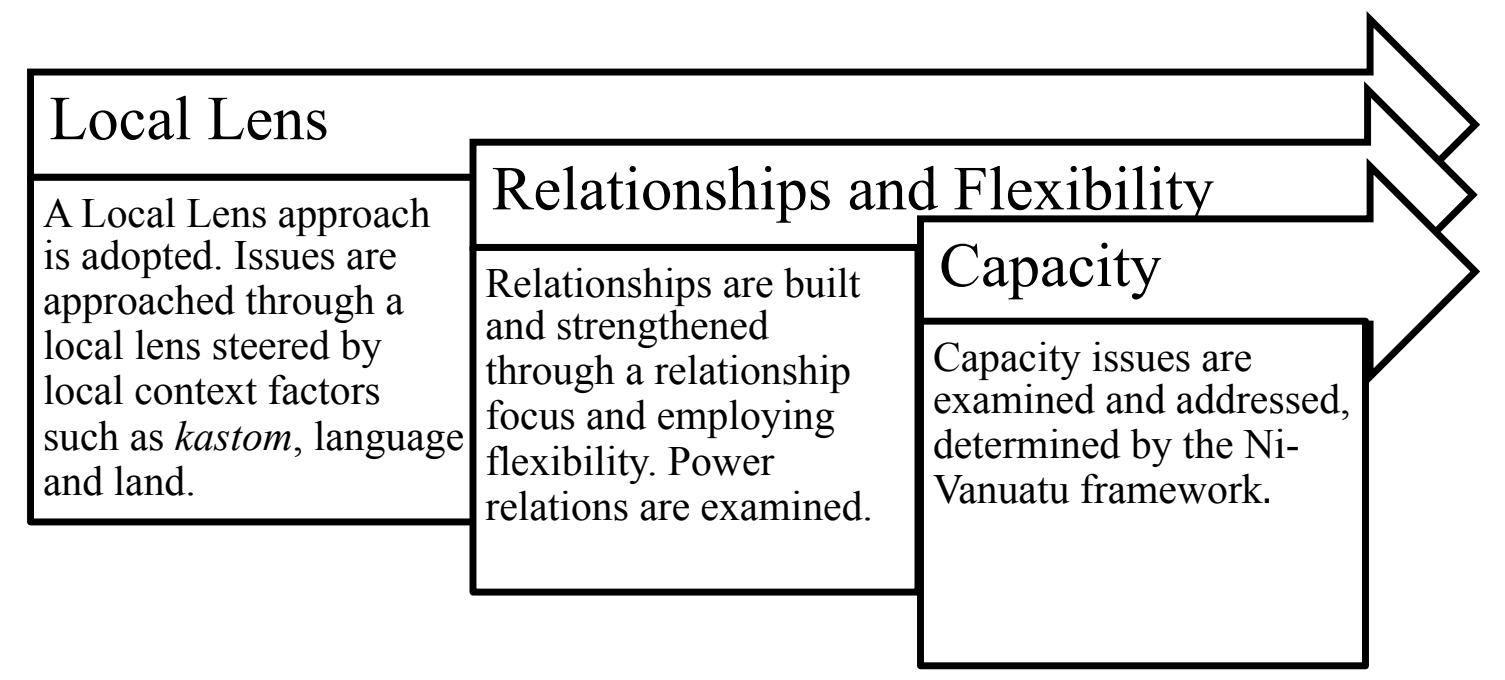

Figure 4: Increasing ownership of monitoring and evaluation

Unfortunately, aid practices and relationships are messy. The reality would not be as straightforward as Figure 4. Naturally, changes will not follow this exact path as the ideas involved are complicated and government and NGOs may be at different points on the figure. However, the figure does highlight the issues important to enabling ownership and how they might work together to improve ownership of aid practices such as monitoring and evaluation. The recommendations from Figure 4 are intended as a guide, based on the findings of the research. They need to be interpreted and moulded to the different contexts in which they apply. The underlying principles of the figure can be used to influence practice, using different elements to different degrees. The chapter will proceed with further discussion on the employment of this figure by examining the use of relationships and flexibility for ownership. 


\subsubsection{Relationships}

The need for relationships in addressing ownership was highlighted in the literature review. In order for ownership to develop partnerships need to evolve and power imbalances need to be addressed:

The form ownership takes and the problems of achieving it change over time. Whatever the form, ownership dynamics imply the renegotiation of partnerships to make them less unequal in bargaining power, more tolerant of differences in views, and based upon the recipient government and national stakeholders driving the development process (Cramer et al., 2006: 422).

For monitoring and evaluation to be better tailored to Vanuatu and for ownership to increase, changes need to be demanded by government and NGOs and equally encouraged by donors. For such demands to be made and for donors to understand how best to encourage changes, sound and respectful relationships need to be established. Such relationships would encourage NGOs and government to start asserting their views on monitoring and evaluation practices. Furthermore, through dialogue, relationships would allow NGOs and government to gain a better understanding of the needs of donors.

The importance of relationships was evident in this research. The advantages of stronger relationships with donors were seen in the different approaches to indicators and evaluations by government and NGOs. Government felt comfortable enough to refuse indicators and express their desire to be better represented in evaluations. NGOs were more limited in what they felt comfortable to convey to donors.

This need for an overall stronger focus on relationships has been seen elsewhere in the literature. An NGO participant in the Wallace et al. (2006) study into the aid chain commented, “...there needs to be a middle path between donors' interests and the NGOs' interests... Building relationships and not just systems is key" (2006: 116). Mancuso Brehm (2001) also stresses the need for this shift of focus to relationships, rather than projects. Eyben $(2004,2010)$ believes donors should focus more money on relationships. She found that while many aid practitioners are already focusing on relationships, it is in the guise of results management or other 
paradigms and so the importance of relationships is therefore not emphasised (Eyben, 2010).

The focus on relationships over projects challenges the idea that monitoring and evaluation is primarily a funding instrument. Presently a significant proportion of donors' communication with participants is through donor visits for evaluation and reporting, resulting in a relationship centring on funding. However, as one participant pointed out when commenting on the relationships between government and NGOs, a relationship should be built on the common interest of Vanuatu's development:

Whether you want to help improve the life blong man Vanuatu ${ }^{44}$, whether you want to help improve advancement of Vanuatu or olsem ia. ${ }^{45}$ - Government Employee A

Regardless of the differences between donors, NGOs and government, they (ideally) share this same objective even if it is not their sole ambition, and individual accountabilities, incentives, interests and approaches often cloud this objective.

In practice, building any relationship is difficult. However, strengthening the relationship between donors and NGOs or government, including negotiating intricate power relations, would not need to replicate a formal Western relationship, requiring an $\mathrm{MoU}$ and meetings at confirmed intervals of the year. Rather, the relationship should use the local lens and take the lead from the local context. Kastom has its own approaches to building and maintaining relationships incorporating different practices such as the sharing of food, the use of storian and the drinking of kava. It is logical that a relationship aiming to increase Ni-Vanuatu ownership is built through kastom approaches.

The storian approach, as employed in this research, emphasises relationship building (Warrick, 2009) through swapping stories and experiences with others. In my own experience of working in Vanuatu, I built relationships through getting to know my colleagues. I probably made a fool of myself in my use of Bislama, but it was

\footnotetext{
44، the life of Ni-Vanuatu"

45 "or [something] like this"
} 
through asking questions and relating personal experiences that strong ties were formed. In the preface to this thesis I talked about an evaluator who focused on relationships, on bonding with participants before asking his interview questions. $\mathrm{He}$ used storian techniques and was guided by kastom through the Ni-Vanuatu woman who accompanied and worked with him. It was furthermore seen in the data collection that often the richest material emerged from using interviewing techniques learnt from Ni-Vanuatu, employing a storian approach and remembering to be relaxed and build relationships with participants by sharing who I was and my connection with Vanuatu.

There are many opportunities for storian and shared experience between donors and participants in monitoring and evaluation. The act of teasing out processes together, for example, discussing language use or best practice in a certain community, could also be seen as a way of building a relationship. It is through this process, through communication that relationships start to be built. It is not one isolated event, or one signature by one person on a piece of paper. Discussions may not always go well or have the required outcome, but it is the process itself, taking part in the conversation, which can improve the relationship. Once relationships are more respectful and robust, communication can become even more effective and allow for honest monitoring and evaluation to occur, permitting better reflective data to emerge which in turn increases the effectiveness of monitoring and evaluation.

The processes and opportunities for working more closely will vary according to NGO or government department and depend on their current relationship with donors. A relationship will be slow to build and may be difficult for donors to justify if investment in relationship building doesn't produce immediate, quantifiable results. However, building the relationship slowly and allowing for both parties to feel comfortable with each other will benefit the work they are undertaking together in the longer term. Taking the processes slowly will require flexibility from donors who are bound to deadlines and accountability requirements. Finding a way to allow for flexibility within the constraints of accountability will be one of the main challenges for donors. 


\subsubsection{Flexibility}

The research highlighted the need for flexibility from donors. Processes need flexibility so that local approaches can be found. Donors need to be open to coaxing out difficulties in processes with NGOs and government so monitoring and evaluation can be used as a tool beyond donor reporting. For example, language barriers may be discussed and ideas might be trialled such as reporting in Bislama or the use of oral reporting, or another alternative completely may be suggested. Flexibility is imperative for the trialling of different approaches that are shaped by the context and better understood and adopted by all.

Flexibility requires donors to be willing to accept poor results, or a process being trialled and not succeeding at all. Failures must be viewed as learning. With the right channels of communication and strong relationships, lessons learnt can be built on to improve practice. The inflexibility of donor reporting often does not allow for mistakes to be made but there needs to be a channel for failure to be recognised and discussed if projects are to improve. It has been seen in the literature that increased donor demands have had a negative effect on accountability and transparency in reporting (Burger \& Owens, 2010). Increased flexibility to allow for conversations to be had about failure, together with better relationships, can be used to promote increased accountability and transparency.

It may, however, be difficult for donors to display flexibility when they are accountable to constituencies. It would furthermore be challenging for donors to exercise greater flexibility while also trying to increase harmonisation. Participants have already highlighted donors' poor harmonising in monitoring and evaluation. Relationships here have an important role to play. The different parties involved need to be aware of each other's responsibilities, and donors especially need to be clear where they can and cannot be flexible. Donors, NGOs and government need to understand the restraints each face in order to better understand each other's bounds of flexibility.

Flexibility is furthermore fundamental for relationships to be strengthened. Communication through strict templates, isolated visits and limited email contact will not promote the sharing of experiences and in turn, the strengthening of a 
relationship. Donors need to be flexible in how they relate to participants, allowing for communication to occur in different ways. Flexibility, in terms of data collection, can lead to the gathering of wider and deeper information. As a result, programmes and projects can be better informed by the reality on the ground.

For the most part, building relationships and being flexible is challenging. Relationships are difficult to measure and flexibility poses problems around issues such as harmonisation, deadlines and accountabilities. Building relationships takes time, but participants (and probably also donors) were already pressed for time to undertake the current monitoring and evaluation requirements. However, a relationship would not only benefit monitoring and evaluation. It would spread its benefits over into other aspects of donors, government and NGOs' work.

\subsubsection{Ownership}

This chapter has argued for the use of relationships and flexibility approached through a local lens in order to increase ownership. Many participants are already living out behaviour as described in this chapter. But a committed focus on these recommendations, especially from donors, could see a greater benefit to ownership and monitoring and evaluation.

Reflecting back to the literature review it was discussed that ownership is difficult to measure. However, a good working definition of ownership saw it as "a relative one. It really only makes sense when seen in the context of what happened before, and thus ownership can be seen as moving away from the imposition of the content and process... ${ }^{46}$ by outsiders" (EURODAD 2001:3). This research cannot comment on ownership as a relative term in Vanuatu given the novelty of monitoring and evaluation and the limited data available (e.g. OECD (2011c); Pacific Institute of Public Policy (2009)). However, future research could look at measuring ownership by looking at the change in a number of factors with regard to monitoring and evaluation. For example, it could reassess the issues government and NGOs have with monitoring and evaluation and how their relationship with donors has changed. Questions could be asked, such as whether participants can say 'no' to donors. Can

\footnotetext{
46 "of structural adjustment programmes" removed so that the definition could be applied to other situations.
} 
they influence processes or even lead processes? Are participants involved in a greater part of the practice, rather than solely reporting?

Moreover, changes in the use of the local context (kastom, language and land) could be examined to determine relative ownership. Language use is an easily identified and strong indicator of ownership. Therefore the extent of ownership can be analysed by looking at the degree of language use. For example, is Bislama being used? Are local languages being used? Can Bislama or local languages be used for reporting to donors or just internally? The presence of kastom could be seen in the methods used for data collection or evaluation. Are local techniques employed over popular Western participatory methods? Finally, land could be examined by asking whether Vanuatu's geography is taken into account as part of the practice. Are rural communities consistently participating in monitoring and evaluation? Have systems been set up to enable data from isolated areas to be included? The research argues that a focus on the recommendations of this thesis, the use of relationships, flexibility and the local lens would move toward more favourable answers to these questions, in other words, to increased ownership.

\subsection{Concluding Comments}

The current delivery of monitoring and evaluation as an aid practice does not promote Ni-Vanuatu ownership. The processes within the practice are discordant with the Ni-Vanuatu context, notably kastom, language and land. There is no single solution to improving a donor practice such as monitoring and evaluation so that $\mathrm{Ni}$ Vanuatu exercise greater ownership. The factors at play are dynamic and confusing. The relationships between donors, NGOs and government are affected by miscommunication, imbalances of power, accountabilities and cultural differences. However, approaching monitoring and evaluation through a local lens, focusing on relationships and adopting flexibility can lead to a new framework better fit for the $\mathrm{Ni}$-Vanuatu context. Capacity issues can be addressed following the establishment of this framework. This thesis demonstrates the need for monitoring and evaluation to be tailored by the local context. Monitoring and evaluation needs to be viewed through a local lens if ownership is to be increased. 


\section{Reference List}

ADB. (1999). Reforms in the Pacific: An Assessment of the Asian Development Bank's Assistance for Reform Programs in the Pacific. Manila: Asian Development Bank.

Adrien, M.-H., \& Jobin, D. (2009). Country-led impact evaluation. A survey of development practitioners. In M. Segone (Ed.), Country-Led Monitoring and Evaluation Systems (pp. 102-118). Geneva: UNICEF.

Alliance Development Works. (2012). WorldRiskReport 2012: Environmental Degradation Increases Disaster Risk Worldwide. WorldRiskReport Retrieved 21 February, 2014, from https://www.ehs.unu.edu/file/get/10487.pdf

Andreou, G., \& Galantomos, I. (2009). Conceptual competence as a component of second language fluency. Journal of Psycholinguistic Research, 38(6), 587591.

Berger, P. L., \& Luckmann, T. (1967). The Social Construction of Reality: A Treatise in the Sociology of Knowledge. Harmondsworth: Penguin.

Boardman, M. (2012). Seeking Proof. The (endangered) Art of Monitoring in Development Programmes Retrieved 11 November, 2013, from http://www.cid.org.nz/assets/Development/Development-Effectiveness/CIDSeminarUpdatedBoardman.pdf

Bolton, L. (2003). Unfolding the Moon: Enacting Women's Kastom in Vanuatu. Honolulu: University of Hawai i Press.

Bongmatur, W. (1994). National cultural policies. In L. Lindstrom \& G. M. White (Eds.), Culture, Kastom, Tradition: Developing Cultural Policy in Melanesia. Suva: Institute of Pacific Studies, University of the South Pacific.

Bornstein, L. (2006). Systems of accountability, webs of deceit? Monitoring and evaluation in South African NGOs. Development, 49(2), 52-61.

Brown, A., Foster, M., Norton, A., \& Naschold, F. (2001). The status of Sector Wide Approaches Working Paper 142. London: Overseas Development Institute.

Buiter, W. H. (2007). 'Country ownership': A term whose time has gone. Development in Practice, 17(4/5), 647-652.

Burger, R., \& Owens, T. (2010). Promoting transparency in the NGO Sector: Examining the availability and reliability of self-reported data. World Development, 38(9), 1263-1277.

Byrnes, H. (2012). Advanced language proficiency. In S. M. Gass \& A. Mackey (Eds.), The Routledge Handbook of Second Language Acquisition (pp. 506521). London: Routledge. 
Campbell, I. C. (1989). A History of the Pacific Islands. Berkeley: University of California Press.

Chacko, E. (2004). Positionality and praxis: Fieldwork experiences in rural India. Singapore Journal of Tropical Geography, 25(1), 51-63.

Charpentier, J.-M. (2006). The future of the languages of Vanuatu and New Caledonia. In D. Cunningham, D. E. Ingram \& K. Sumbuk (Eds.), Language Diversity in the Pacific: Endangerment and Survival (pp. 131-136). Clevedon: Multilingual Matters.

Chilisa, B. (2012). Indigenous Research Methodologies. Los Angeles: SAGE Publications.

Council for International Development. (2012). Civil society \& democratic ownership. Fact Sheet Retrieved 10 October, 2013, from http://www.cid.org.nz/assets/Key-issues/International-policy/New-FormatFact-Sheet-10-CSOs-Ownership.pdf

Craig, D., \& Porter, D. (2003). Poverty Reduction Strategy Papers: A new convergence. World Development, 31(1), 53-69.

Craig, D., \& Porter, D. (2006). Development Beyond Neoliberalism?: Governance, Poverty Reduction and Political Economy. Oxon: Taylor \& Francis.

Cram, F. (2009). Maintaining indigenous voices. In D. M. Mertens \& P. E. Ginsberg (Eds.), The Handbook of Social Research Ethics (pp. 308-322). Thousand Oaks: SAGE Publications.

Cram, F., \& Pipi, K. (2000). Māori/Iwi Provider Success: Report on the Pilot Project. Tamaki-Makaurau: International Research Institute for Māori and Indigenous Education.

Cramer, C., Stein, H., \& Weeks, J. (2006). Ownership and donorship: Analytical issues and a Tanzanian case study. Journal of Contemporary African Studies, 24(3), 415-436.

Creswell, J. W. (2007). Qualitative Inquiry and Research Design. Thousand Oaks: SAGE Publications.

Creswell, J. W. (2009). Research Design: Qualitative, Quantitative, and Mixed Methods Approaches. New Delhi: SAGE Publications.

Crowley, T. (1995). A New Bislama Dictionary. Suva: University of the South Pacific.

Crowley, T. (2000). The language situation in Vanuatu. Current Issues in Language Planning, 1(1), 47-132. 
Crowley, T. (2004). Bislama reference grammar. Oceanic Linguistics Special Publications, 31, 1-205.

Culliwick, J. (2007). Sessiva Vila burns, Vanuatu Daily Post, p. 1.

DAC/OECD. (2011). How DAC Members Work with Civil Society Organisations: An Overview. Paris: OECD.

Daley, L. (2010). Hijacking development futures: "Land development" and reform in Vanuatu. In T. Anderson \& G. Lee (Eds.), In Defence of Melanesian Customary Land (pp. 33-39). Sydney: AID/WATCH.

Davies, R., \& Dart, J. (2004). The 'Most Significant Change' (MSC) Technique- A Guide to Its Use. Retrieved from http://www.mande.co.uk/docs/MSCGuide.pdf

de Renzio, P., Whitfield, L., \& Bergamaschi, I. (2008). Reforming foreign aid practices: What country ownership is and what donors can do to support it. Global Economic Governance Briefing Paper. Retrieved from http://www.iese.ac.mz/lib/saber/fd_4002.pdf

Department of Foreign Affairs and Trade. (2013). Vanuatu. Retrieved 10 November, 2013, from http://aid.dfat.gov.au/countries/pacific/vanuatu/Pages/default.aspx

Devault, M. L. (1990). Talking and listening from women's standpoint: Feminist strategies for interviewing and analysis. Social Problems, 37(1), 96-116.

Dobell, G. (2007). The 'Arc of Instability': The history of an idea. In R. Huisken (Ed.), History as Policy: Framing the Debate on the Future of Australia's Defence Policy (pp. 85-104). Canberra: ANU E Press.

Dornan, M., \& Newton Cain, T. (2013). Pacific perspectives on infrastructure maintenance. Devpacific Dialogues Retrieved 2 November, 2013, from http://devpolicy.org/pacific-perspectives-on-infrastructure-maintenance20131029/

Dwivedi, O. P., Khator, R., \& Nef, J. (2007). Managing Development in a Global Context. New York: Palgrave Macmillan.

EURODAD. (2001). The changing nature of development co-operation: Building ownership. Many Dollars, Any Change? Brussels: European Network on Debt and Development.

EURODAD. (2008). Outcome-Based Conditionality: Too Good to Be True? Brussels: European Network on Debt and Development.

Eyben, R. (2004). Relationships matter for supporting change in favour of poor people (Vol. 8). Brighton: Institute of Development Studies. 
Eyben, R. (2010). Hiding relations: The irony of 'effective aid'. The European Journal of Development Research, 22(3), 382-397.

Farrelly, T., \& Nabobo-Baba, U. (2012, 3-5 December). Talanoa as empathic research. Paper presented at the International Development Conference: Integrating Research, Policy and Practice, Auckland, New Zealand.

Feinstein, O. (2009). Country-led evaluation. Learning from experience. In M. Segone (Ed.), Country-Led Monitoring and Evaluation Systems (pp. 96-101). Geneva: UNICEF.

Fischer, S. R. (2013). A History of the Pacific Islands (2 ed.). Hampshire and New York: Palgrave Macmillan.

Forsyth, M. (2009). A Bird That Flies With Two Wings: Kastom and State Justice Systems in Vanuatu. Canberra, Australia: ANU E Press.

Gay, D. (2004). The emperor's tailor: An assessment of Vanuatu's Comprehensive Reform Program. Pacific Economic Bulletin, 19(3), 22-39.

Gay, D. (2014). Development economics in the Vanuatu context: One size doesn't fit all Retrieved January 29, 2014, from http://emergenteconomics.com/2014/01/18/development-economics-in-thevanuatu-context-one-size-doesnt-fit-all/

Gegeo, D. W., \& Watson-Gegeo, K. A. (2002). Whose knowledge? Epistemological collisions in Solomon Islands community development. The Contemporary Pacific, 14(2), 377-409.

Gilbert, M. R. (1994). The politics of location: Doing feminist research at "home". The Professional Geographer, 46(1), 90-96.

Government of New Zealand, \& Government of the Republic of Vanuatu. (2011). New Zealand - Vanuatu Joint Commitment for Development. New Zealand Aid Programme Retrieved from https://www.aid.govt.nz/webfm send/108.

Government of the Republic of Vanuatu. (2006). Priorities and Action Agenda 2006 - 2015: “An Educated, Healthy and Wealthy Vanuatu”. Port Vila:

Department of Economic and Sector Planning, Ministry of Finance and Economic Management.

Government of the Republic of Vanuatu. (2011). Ministry of Agriculture. Retrieved 11 February, 2014, from http://www.governmentofvanuatu.gov.vu/index.php/government/agriculture

Government of the Republic of Vanuatu. (2013). Budget 2013 (Vol. 1 \& 2). Port Vila: Ministry of Finance and Economic Management. 
Halapua, S. (2000). Talanoa Process: The Case of Fiji. Retrieved 3 February, 2014, from

http:/unpan1.un.org/intradoc/groups/public/documents/un/unpan022610.pdf

Haraway, D. J. (1991). Simians, Cyborgs and Women: The Reinvention of Nature. New York and Abingdon: Routledge.

Hatton, M. J., \& Schroeder, K. (2007). Results-based management: Friend or foe? Development in Practice, 17(3), 426-432.

Hermes, N., \& Lensink, R. (2001). Changing the conditions for development aid: A new paradigm? The Journal of Development Studies, 37(6), 1-16.

Hesse-Biber, S. N., \& Leavy, P. (2010). The Practice of Qualitative Research. Thousand Oaks: SAGE Publications.

Holvoet, N., Gildemyn, M., \& Inberg, L. (2012). Taking stock of monitoring and evaluation arrangements in the context of Poverty Reduction Strategy Papers: Evidence from 20 aid-dependent countries in Sub-Saharan Africa. Development Policy Review, 30(6), 749-772.

Holvoet, N., \& Renard, R. (2007). Monitoring and evaluation under the PRSP: Solid rock or quicksand? Evaluation and Program Planning, 30(1), 66-81.

Holvoet, N., \& Rombouts, H. (2008). The challenge of monitoring and evaluation under the new aid modalities: Experiences from Rwanda. The Journal of Modern African Studies, 46(4), 577-602.

Hutchings, J. (2010). Guest lecture DEVE514: Development Research. Wellington, New Zealand: Victoria University.

IFRC. (2011). International Disaster Response Laws, Rules and Principles (IDRL) in Vanuatu. Geneva: International Federation of Red Cross and Red Crescent Societies.

IMF. (2001). Strengthening Country Ownership of Fund-Supported Programs. Washington: International Monetary Fund.

IMF. (2005). International Monetary Fund conditionality: A provisional update. In S. Koeberle, H. Bedoya, P. Silarszky \& G. Verheyen (Eds.), Conditionality Revisited: Concepts, Experiences, and Lessons (pp. 33-39). Washington, D.C.: The World Bank.

IMF. (2013). Vanuatu: 2013 Article IV Consultation IMF Country Report (Vol. 13). Washington, D.C.: International Monetary Fund.

International Labour Organization. (2009). Decent Work Country Programme Vanuatu (2009-2012), from http://www.ilo.org/wcmsp5/groups/public/--asia/---ro-bangkok/---ilo-suva/documents/publication/wcms_155723.pdf 
International Telecommunication Union. (2013). Mobile-cellular subscriptions Retrieved 25 November, 2013, from http://www.itu.int/en/ITUD/Statistics/Pages/stat/default/aspx

Jones, C. (2012). Weaving Niche Production into Pacific Economies: The Social, Economic and Environmental Impacts of FIJI Water on Local Communities. Master of Development Studies, Victoria University of Wellington, Wellington.

Jowitt, A. (2005). Vanuatu. In Transparency International (Ed.), Global Corruption Report 2005 (pp. 214-217). London and Ann Arbor: Transparency International.

Kay, C., \& Gwynne, R. N. (2000). Relevance of structuralist and dependency theories in the neoliberal period: A Latin American perspective. Journal of Developing Societies, 16(1), 49.

Kilby, C. (1999). Aid and sovereignty. Social Theory and Practice, 25(1), 79-92.

Killick, T. (1996). Principals, agents and the limitations of BWI conditionality. World Economy, 19(2), 211-229.

Killick, T. (1997). Principals, agents and the failings of conditionality. Journal of International Development, 9(4), 483-495.

Killick, T. (2003). Aid and the Political Economy of Policy Change. London: Taylor $\&$ Francis.

King, N., \& Horrocks, C. (2010). Interviews in Qualitative Research. London: SAGE Publications.

Knapman, B., \& Saldanha, C. (1999). Reforms in the Pacific: An Assessment of the Asian Development Bank's Assistance for Reform Programs in the Pacific. Manilla: Asian Development Bank.

Kobayashi, A. (1994). Coloring the field: Gender, "race," and the politics of fieldwork. The Professional Geographer, 46(1), 73-80.

Koeberle, S. (2005). Conditionality: Under what conditions? In S. Koeberle \& W. Bank (Eds.), Conditionality Revisited: Concepts, Experiences, and Lessons (pp. 57-84). Washington, DC: World Bank.

Kulwaum, G. (undated). Problems of devolution of PNG education Retrieved 20 November, 2013, from http://www.pngbuai.com/300socialsciences/education/policy/development/ku 1-devolution-chap5.html

Kusek, J. Z., \& Rist, R. C. (2004). Ten Steps to a Results-Based Monitoring and Evaluation System: A Handbook for Development Practitioners. Washington, DC: World Bank. 
Langdridge, D. (2004). Introduction to Research Methods and Data Analysis in Psychology. Harlow, Essex: Pearson Prentice Hall.

Larmour, P. (2005). Foreign Flowers: Institutional Transfer and Good Governance in the Pacific Islands. Honolulu: University of Hawaii Press.

Leach, M. (2013). Attitudes to National Identity in Melanesia and Timor-Leste: A Survey of Future Leaders in Papua New Guinea, Solomon Islands, Vanuatu and Timor-Leste. Oxford: Peter Lang AG.

Leandro, J. E., Schafer, H., \& Frontini, G. (1999). Towards a more effective conditionality: An operational framework. World Development, 27(2), 285300 .

Leslie, H., \& Storey, D. (2003). Entering the field. In R. Scheyvens \& D. Storey (Eds.), Development Fieldwork: A Practical Guide (pp. 119-138). London, Thousand Oaks and New Delhi: SAGE Publications.

Ligo, G. (1980). Kastom mo kalja. In B. Weightman \& H. Lini (Eds.), Vanuatu: Twenti Wan Tingting Long Team Blong Independens (pp. 54-65). Suva: Institute of Pacific Studies, University of the South Pacific and South Pacific Social Sciences Association.

Lincoln, Y. S., \& Guba, E. G. (1985). Naturalistic Inquiry. Newbury Park: SAGE Publications.

Lundgren, H., \& Kennedy, M. (2009). Supporting partner country ownership and capacity in development evaluation. The OECD DAC evaluation network. In M. Segone (Ed.), Country-Led Monitoring and Evaluation Systems (pp. 7795). Geneva: UNICEF.

Lynch, J., \& Crowley, T. (2001). Languages of Vanuatu: A New Survey and Bibliography. Canberra: ANU Press.

Mackay, K. (2009). Building monitoring and evaluation systems to improve government performance. In M. Segone (Ed.), Country-Led Monitoring and Evaluation Systems (pp. 169-187). Geneva: UNICEF.

Madge, C. (1993). Boundary disputes: Comments on Sidaway (1992). Area, 25(3), 294-299.

Mancuso Brehm, V. (2001). Promoting effective North-South NGO partnerships: A comparative study of 10 European NGOs. The International NGO Training and Research Centre Occasional Papers Series, 1-75. Retrieved from http://dspace.cigilibrary.org/jspui/bitstream/123456789/21784/1/Promoting\% 20Effective $\% 20$ North $\% 20$ South $\% 20$ NGO $\% 20$ Partnerships.pdf?1

McDowell, L. (1992a). Doing gender: Feminism, feminists and research methods in human geography. Transactions of the Institute of British Geographers, 17(4), 399-416. 
McDowell, L. (1992b). Valid games? A response to Erica Schoenberger. Professional Geographer, 44(2), 212-215.

McLafferty, S. L. (1995). Counting for women*. The Professional Geographer, 47(4), 436-442.

Mead, A. (2006, November). Kaupapa Māori ethics. Rangahau Retrieved 21 May, 2013, from http://www.rangahau.co.nz/ethics/111/\#

Miles, W. F. S. (1998). Bridging Mental Boundaries in a Postcolonial Microcosm: Identity and Development in Vanuatu. Honolulu: University of Hawai i Press.

Molisa, G., Vurobaravu, N., \& Van Trease, H. (1982). Vanuatu: Overcoming pandemonium. In R. Crocombe \& A. Ali (Eds.), Politics in Melanesia (pp. 84-115). Suva: Institute of Pacific Studies, University of the South Pacific.

Mooko, T. (2009). Language policy and practice in the multilingual Southern African development community. Current Issues in Language Planning, 10(2), 166-180.

Morra-Imas, L. G., \& Rist, R. C. (2009). The Road to Results: Designing and Conducting Effective Development Evaluations. Washington, DC: World Bank.

Mowforth, M., \& Munt, I. (1998). Tourism and Sustainability: New Tourism in the Third World. London: Routledge.

Murray, W. E. (2009). Neoliberalism and development. In N. Thrift \& R. Kitchen (Eds.), International Encyclopaedia of Human Geography (pp. 379-384). London, UK: Routledge.

Murray, W. E., \& Overton, J. D. (2003). Designing development fieldwork. In R. Scheyvens \& D. Storey (Eds.), Development Fieldwork (pp. 17-36). London: SAGE Publications.

Murray, W. E., \& Overton, J. D. (2011a). The inverse sovreignty effect: Aid, scale and neostructuralism in Oceania. Asia Pacific Viewpoint, 52(3), 272-284.

Murray, W. E., \& Overton, J. D. (2011b). Neoliberalism is dead, long live neoliberalism? Neostructuralism and the international aid regime of the 2000s. Progress in Development Studies, 11(4), 307-319.

OECD. (2005). Paris Declaration on Aid Effectiveness, Paris.

OECD. (2008). Accra Agenda for Action, Accra.

OECD. (2011a). Aid Effectiveness 2005-2010: Progress in Implementing the Paris Declaration Paris: Organisation for Economic Co-operation and Development. 
OECD. (2011b). Busan Partnership for Effective Development Co-operation, Busan.

OECD. (2011c). Vanuatu. Aid Effectiveness 2011: Progress in Implementing the Paris Declaration (Vol. 2). Paris: OECD.

OECD. (2012). The DAC list of ODA recipients Retrieved 21 February, 2014, from http://www.oecd.org/dac/aidstatistics/49483614.pdf

Overton, J., Prinsen, G., Murray, W. E., \& Wrighton, N. (2012). Reversing the tide of aid: Investigating development policy sovereignty in the Pacific. Journal de la Société des Océanistes, 2(135), 25-38.

Oxfam International. (2004). From "donorship" to ownership?: Moving towards PRSP round two. Oxfam Briefing Paper: Oxfam International.

Pacific Institute of Public Policy. (2009). Planning, Monitoring and Evaluation of Government Systems: A Women and Child Focussed Perspective Baseline Diagnosis. Kiribati, Solomon Islands and Vanuatu. Port Vila: Pacific Institute of Public Policy.

Pacific Islands Forum Secretariat. (2007). Pacific Aid Effectiveness Principles, Suva.

Pacific Islands Forum Secretariat. (2009). Cairns Compact on Strengthening Development Coordination in the Pacific, Cairns.

Poku, N., \& Whitman, J. (2011). The Millennium Development Goals: Challenges, prospects and opportunities. Third World Quarterly, 32(1), 3-8.

Pomerantz, P. R. (2011). Development theory. In M. Bevir (Ed.), The SAGE Handbook of Governance (pp. 160-178). London: SAGE Publications.

Prime Minister's Office. (2010a). Government Monitoring and Evaluation Policy. Port Vila: Government of Vanuatu.

Prime Minister's Office. (2010b). Millennium Development Goals 2010 Report for Vanuatu. Port Vila: Prime Minister's Office, Government of the Republic of Vanuatu.

Regenvanu, S. (1980). Kraon. In B. Weightman \& H. Lini (Eds.), Vanuatu: Twenti Wan Tingting Long Team Blong Independens (pp. 66-81). Suva: Institute of Pacific Studies, University of the South Pacific and South Pacific Social Sciences Association.

Reinharz, S. (1997). Who am I? The need for a variety of selves in the field. In R. Hertz (Ed.), Reflexivity and Voice. Thousand Oaks, CA: SAGE Publications.

Ritchie, J., \& Lewis, J. (2003). Qualitative Rsearch Practice: A Guide for Social Science Students and Researchers. London: SAGE Publications 
Robinson, D., \& Robinson, K. (2005). Pacific ways of talk: Hui and talanoa.

Retrieved 15 July, 2013, from http://www.scpi.org.nz/wpcontent/uploads/2013/02/Pacific Ways of Talk.pdf

Rodman, M. (2007). House-Girls Remember: Domestic Workers in Vanuatu. Honolulu: University of Hawai'i Press.

Rose, G. (1997). Situating knowledges: positionality, reflexivities and other tactics. Progress in Human Geography, 21(3), 305-320.

Rossman, G. B., \& Rallis, S. F. (2003). Learning in the Field: An Introduction to Qualitative Research. Thousand Oaks: Sage Publications.

Rousseau, B. (2011). Shifting others: Kastom and politics at the Vanuatu Cultural Centre. In J. Taylor \& N. Thieberger (Eds.), Working Together in Vanuatu: Research Histories, Collaborations, Projects and Reflections (pp. 23). Canberra: ANU E Press. Retrieved from http://press.anu.edu.au/apps/bookworm/view/Working+Together+in+Vanuat $\mathrm{u} \% 3 \mathrm{~A}+$ Research + Histories $\% 2 \mathrm{C}+$ Collaborations $\% 2 \mathrm{C}+$ Projects + and + Reflecti ons/7241/Text/ch23.html\#toc_marker-52.

Schoenberger, E. (1992). Self-criticism and self-awareness in research: A reply to Linda McDowell. Professional Geographer, 44(2), 215-218.

Secretariat of the Pacific Community. (2013). Pacific Island populations. Estimates and projections of demographic indicators for selected years Retrieved 3 February, 2013, from http://www.spc.int/sdd/index.php

Sidaway, J. D. (1992). In other worlds: On the politics of research by 'first world' geographers in the 'third world'. Area, 24(4), 403-408.

Sippel, M., \& Neuhoff, K. (2009). A history of conditionality: Lessons for international cooperation on climate policy. Climate Policy, 9(5), 481-494.

Smith, H. (2005). Ownership and capacity: Do current donor approaches help or hinder the achievement of international and national targets for education? International Journal of Educational Development, 25(4), 445-455.

Smith, L. (1999). Decolonizing Methodologies: Research and Indigenous Peoples. London: Zed Books.

Smith, L. (2006). Kaupapa Māori Ethics. Rangahau Retrieved 21 May, 2013, from http://www.rangahau.co.nz/ethics/109/\#

Temple, B., \& Young, A. (2004). Qualitative research and translation dilemmas. Qualitative Research, 4(2), 161-178.

Tonkinson, R. (1982). National identity and the problem of kastom in Vanuatu. Mankind, 13(4), 306-315. 
Transparency International. (2011). Corruption Perceptions Index 2011. Berlin, Germany: Transparency International Secretariat.

Ulu, A. J. (2013). Pule: Development Policy Sovereignty in Samoa. Master of Development Studies, Victoria University of Wellington, Wellington.

UN-OHRLLS. (2012). Least Developed Countries: About LDCs Retrieved 19 September, 2013, from http://www.unohrlls.org/en/ldc/25/

United Nations Conference on Trade and Development. (2012). Vulnerability Profile of Vanuatu Retrieved 3 December, 2013, from

http://www.un.org/en/development/desa/policy/cdp/ldc/profile/vulnerability profile_vanuatu_2012.pdf

United Nations Development Programme. (2009). Handbook on Planning, Monitoring and Evaluating for Development Results Retrieved from http://web.undp.org/evaluation/handbook/

Vaioleti, T. M. (2006). Talanoa research methodology: A developing position on Pacific research. Waikato Journal of Education, 12, 21-34.

Vanuatu Daily Post. (2012, 11 November). VANGO announces new Board of Directors, Vanuatu Daily Post. Retrieved from http://www.dailypost.vu/content/vango-announces-new-board-directors

Vanuatu Kaljoral Senta. (2013). The Vanuatu Cultural Centre Retrieved 20 November, 2013, from http://www.vanuatuculture.org/

Vanuatu National Cultural Council. (2009). Vanuatu Cultural Research Policy Vanuatu Foreign Policy and Government Guide (pp. 36-45). Washington: International Business Publications.

Vanuatu National Statistics Office. (2009a). 2009 National Census on Population and Housing. Port VIla: Vanuatu National Statistics Office.

Vanuatu National Statistics Office. (2009b). Census and surveys Retrieved 22 February, 2014, from http://www.vnso.gov.vu/index.php/census-a-surveys

Venter, E. (2008). Point of view: A work in progress. Finance and Development, 45(3), 20-22.

Wallace, T., Bornstein, L., \& Chapman, J. (2006). The Aid Chain: Coercion and Commitment in Development NGOs. London: Intermediate Technology Publications Ltd.

Warning, C., \& Post, U. (2007). Discomforting NGOs. D+C Magazine for Development and Cooperation Retrieved 27 February, 2013, from http://www3.giz.de/E+Z/content/archive-eng/02-2007/tribune art1.html 
Warrick, O. (2009). Ethics and methods in research for community based adaptation: Reflections from rural Vanuatu. In H. Reid (Ed.), Community-Based Adaptation to Climate Change (pp. 76-87). London: International Institute for Environment and Development.

Webber, M. (2006). Identity and whakapapa. A curriculum for the gifted Maori child Retrieved 4 June, 2013, from http://www.gifted.tki.org.nz/content/download/388/1712/file/Identity\%20and $\% 20$ whakapapa $\% 20$ $\% 20 \mathrm{~A} \% 20$ curriculum $\% 20$ for $\% 20$ the $\% 20$ gifted $\% 20 \mathrm{M} \% \mathrm{C} 4 \% 81$ ori $\% 20$ child. pdf

Weisbrot, D. (1989). Custom, pluralism, and realism in Vanuatu: Legal development and the role of customary law. Pacific Studies, 13, 65-97.

Wood, A., \& Lockwood, M. (1999). The "Perestroika of Aid"? New Perspectives on Conditionality Bretton Woods Project. Washington, DC: Bretton Woods Project.

World Bank. (1998). Assessing Aid: What Works, What Doesn't and Why. Oxford: Oxford University Press.

World Bank. (2006). Opportunities to Improve Social Services in Vanuatu. Washington: World Bank.

Wrighton, N. (2010). Participation, Power and Practice in Development: A Case Study of Theoretical Doctrines and International Agency Practice in Tuvalu. Master of Development Studies, Victoria University of Wellington, Wellington.

Wrighton, N., \& Overton, J. (2012). Coping with participation in small island states: The case of aid in Tuvalu. Development in Practice, 22(2), 244-255.

Zimmermann, F. (2008). Home-owned and home-grown: Development policies that can work. OECD Development Centre Policy Insights(71), 1-2. 


\section{Appendix I: Consent to Participation in Research Form}

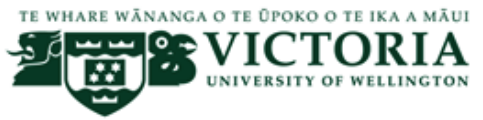

Project topic: Monitoring and Evaluation in Vanuatu

Researcher: Mattie Geary Nichol

You have been asked to participate in research looking at how monitoring and evaluation obligations that donors attach to aid impact upon Ni-Vanuatu development ownership. This research will form part of a thesis as part of the Master of Development Studies in the School of Geography, Environment and Earth Sciences, at Victoria University of Wellington. Please read the information sheet attached and ask any questions before deciding to take part in the research.

\section{Personal Declaration:}

I have been given an explanation and have understood this research project. I have had the opportunity to ask questions and have them answered to my satisfaction. I understand that I may withdraw myself (or any information I have provided) from this project (before data collection and analysis is completed by $10^{\text {th }}$ June 2013 without having to give any reason.

If I agree to be recorded, the recording will be held for a period of up to one year, after which it will be destroyed or electronically wiped unless I ask that it be returned to me. I understand that full interview transcripts will be kept confidential to the researcher and supervisor. I understand that I will have the opportunity to check the transcripts and any attributed quotes used before publication.

Please tick the appropriate boxes:

I agree to take part in this research

I give permission for the interview to be recorded

I give permission for my opinions to be recognised by the organisation I work for

(e.g.

"Government employee A, B or C" or "NGO employee A, B or C")

$\square$ I would like to receive a summary of the results of this research when it is completed.

Name of Participant:

Signature of Participant:

Date:

Email address of Participant (for return of transcripts or results as requested):

If you have any questions or require further information, please contact me (mattie.gearynichol@vuw.ac.nz or +64 276 326198) or my supervisor, Professor John Overton (School of School of Geography, Environment and Earth Sciences, Victoria University, PO Box 600, Wellington, email john.overton@vuw.ac.nz)

Thank you for your time. Tank yu tumas blong tekem pat blong risej ia. Sapos yu kat eni kwestion o mi save mekem eni samting I moa klia, plis no hesitate blong askem I kam long mi 


\title{
Appendix II: Participant Information Sheet
}

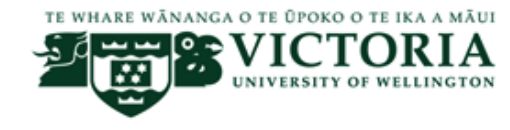 \\ Project topic: Monitoring and Evaluation in Vanuatu \\ Researcher: Mattie Geary Nichol \\ Tank yu tumas blong tekem intres long risej ia. I am a Master of Development Studies student in the \\ Department of Development Studies, School of Geography, Environment and Earth Sciences, at \\ Victoria University of Wellington. As part of the fulfilment of this degree, I am undertaking a \\ research thesis. The thesis will examine how monitoring and evaluation obligations that donors attach \\ to aid impact upon Ni-Vanuatu development ownership.
}

I am inviting non-governmental organization employees and government department employees to participate in this study. All participants will be interviewed through semi-structured interviews which should take about 20-30 minutes. Participants will have the opportunity to discuss the monitoring and/or evaluation that they carry out as part of their role and their opinions relating to the monitoring and evaluation process. Interviews will be conducted in either Bislama or English, depending on the preference of the participant. Interviews in Bislama will be translated into English for the thesis.

Your participation in the research is entirely voluntary. The responses collected will form the basis of my research project and will be put into a written report. I would like to record the interviews so that I can use the recordings to write my report. However, the interview will not be recorded without your permission. If you would like to withdraw from the project, you may do so at any time prior to the $10^{\text {th }}$ June 2013 when data collection and analysis is due to be completed. You can either let me know at the time or email or phone me if you would like any related material to be destroyed.

The interviews will form part of the final written thesis. You may choose to remain anonymous in your opinions and can do so by indicating in your consent form. The thesis will be submitted to the School of Earth Sciences for marking and deposited in the University Library. The collected, collated, and analysed data may be published in case studies, academic journals, and/or presented at conferences.

All material collected will be kept confidential, only my supervisor, Professor John Overton, and I will see this material. The material will be stored securely and destroyed after one year.

This project has ethics approval from the Victoria University Human Ethics Committee.

If you have any questions or require further information on the project, please contact me at mattie.gearynichol@vuw.ac.nz or +64 276326198 or my supervisor, Professor John Overton, at the School of Geography, Environment and Earth Sciences, Victoria University, PO Box 600, Wellington, or john.overton@vuw.ac.nz

Tank yu tumas blong tekem taem blong ridim infomeisin ia. Sapos yu kat eni kwestion o mi save mekem eni samting I moa klia, plis no hesitate blong askem I kam long mi. 


\title{
Appendix III: Sample Letter (Government Department)
}

\author{
TH:
}

Government Department Address

Martha (Mattie) Geary Nichol

Victoria University of Wellington

mattiegn@gmail.com

mattie.gearynichol@vuw.ac.nz

[Phone number]

24th of January 2013

Dear Participant

My name is Mattie Geary Nichol; I am representing the Victoria University of Wellington, New Zealand.

I am currently enrolled in a Master of Development Studies at Victoria University of Wellington. I am focussing my research on the monitoring and evaluation Ni-Vanuatu government and non-governmental organisations need to carry out, and are involved in, for donors and the effect on Ni-Vanuatu ownership of development. I was hoping to be able to interview [number] employees from your government department in Port Vila and Luganville who are involved with monitoring and/or evaluation.

The research would be through semi-structured interviews conducted in either English or Bislama (I learnt Bislama through volunteering in Vanuatu with VSA (Volunteer Service Abroad) in 2011.

Questions asked would be approved by the Victoria University Ethics Committee and would be emailed to your department in advance to give you the opportunity to review them. Government employees being interviewed would only answer questions they feel comfortable with. Furthermore, government department employees as well as the government department can remain anonymous if requested.

The aims of the research are as follows:

- To identify issues surrounding monitoring and evaluation for the benefit of government departments and non-governmental organisations

- To provide an opportunity for donors to gain a deeper understanding of the challenges monitoring and evaluation obligations place on government departments and non-governmental organisations

- To provide an opportunity for donors to gain an understanding of the impact of monitoring and evaluation on development ownership

- To contribute to Vanuatu and Pacific aid literature

At the conclusion of the research your department would receive a copy of the research.

I plan to conduct the research in Port Vila and Luganville throughout April and early May, 2013. The research will be funded by the New Zealand Aid Programme Field Research Award.

If your department is interested in taking part in the research, please contact me via my email address and I will be able to send you further information. The research has some flexibility and I would be happy to discuss ways to make the research as beneficial as possible for your department's use.

Please do not hesitate to contact me if you have any questions.

I look forward to hearing from you.

Kind regards,

Mattie Geary Nichol 


\section{Appendix IV: Participant Questions}

- What is your role?

- How long have you been working in this role?

- Have you worked anywhere else before? What were your other roles?

- Where did you go to school?

- Have you done any travel overseas?

- What monitoring and evaluation are you expected to conduct in your role?

- How is this carried out and how often? (e.g. report writing? If so, in what language?)

- Is monitoring and evaluation sometimes difficult to carry out?

- Do you have the time, resources, systems and support?

- Does anyone else in the organisation help you with monitoring and evaluation?

- Do you need any extra help with monitoring and evaluation?

- How can you tell if your job/programme is going successfully?

- How often do donors come in to assess progress?

- How do they carry this out?

- Do you think they ask the right questions to assess your work?

- What other questions could they ask?

- Can you give an example of a time when an evaluator have come in and done evaluation well?

- Can you give an example of a time when an evaluator has come in and not done evaluation well?

- How can you tell if your job/programme is going well?

- What kind of results do you think donors want to see?

- Do you keep in mind what kind of results donors want when designing programmes?

- How does this impact on the design?

- How do you think monitoring and evaluation could be better or easier for you? 